\title{
IV. Die deutsche Zentralbank und die Konstruktion eines neuen Europas 1955 bis 1958
}

Untersuchungen der deutschen Zentralbank im Zeitraum 1955 bis 1958 haben bisher vor allem die geldpolitischen Aktivitäten der Zentralbank analysiert und die Probleme einer Geldpolitik, die sich im „Spannungsfeld zwischen innerem und äußerem Gleichgewicht " befand, behandelt ${ }^{1}$. Dabei war die internationale Währungspolitik der Bank nicht oder nur am Rande Gegenstand. Für diese Vernachlässigung sind zwei Gründe verantwortlich.

Zum ersten war ab Mitte der fünfziger Jahre die Spannung zwischen binnen- und außenwirtschaftlichem Gleichgewicht für die Geldpolitik das beherrschende Problem. Im Rahmen der existierenden de-facto-konvertiblen Währungsordnung, die auf festen Wechselkursen beruhte, befand sich die deutsche Zentralbank vor einem Dilemma. Da sich seit Herbst 1954 das Preisklima merklich erwärmte, lag es nahe, eine restriktivere Kreditpolitik zu betreiben. Andererseits aber war abzusehen, daß kreditpolitische Restriktionen die schon existierenden Zahlungsbilanzüberschüsse weiter vergrößern würden. Das würde aber nicht nur das außenwirtschaftliche Gleichgewicht und das Funktionieren des europäischen Währungssystems beeinträchtigen. Vielmehr wären die Überschüsse auch mit inflationären Tendenzen verbunden, da sie in einem System von festen Wechselkursen zu einer Liquidisierung der Wirtschaft des Überschußlandes führen. Zu analysieren, wie die deutsche Zentralbank auf dieses Dilemma reagierte, war das vorherrschende Erkenntnisinteresse der Forschung, die sich mit der deutschen Zentralbank in der zweiten Hälfte der fünfziger Jahre befaßt hat.

Zum zweiten herrscht die Meinung vor, alle wichtigen Entscheidungen auf dem Gebiet der internationalen Währungspolitik seien schon im Sommer 1955 getroffen worden. Schließlich hätten die OEEC-Länder mit ihren Beschlüssen zur Härtung der EZU und mit der Unterzeichnung des EWA die Konvertibilität als künftiges internationales Währungssystem definitiv vereinbart. Nun sei nur noch abzuwarten gewesen, daß diese Vereinbarung bei der nächsten günstigen Gelegenheit umgesetzt werden würde. In dieser Perspektive war der weitere Weg der internationalen Währungspolitik klar vorgezeichnet: Die Jahre zwischen 1955 und 1958 waren demnach nur eine bloße Vorlaufphase des im Jahre 1958 dann tatsächlich realisierten Konvertibilitätsregimes. Sie werden deshalb

${ }^{1}$ Emminger, Geld- und Währungspolitik, S. 485. Vgl. auch Müller, Politik; Jenkis, Inflation; Dürr, Wirkungsanalyse. 
als ein „ruhigerer Zeitabschnitt" verstanden². Diese Interpretation ist aber nicht angemessen.

Festzuhalten ist nämlich, daß mit den währungspolitischen Beschlüssen der OEEC vom Sommer 1955 nur wenig entschieden war. Zwar hatten die OEEC-Länder mit dem EWA einen Kredit- und Kooperationsmechanismus vereinbart, der nach einer Auflösung der EZU greifen sollte. Auch hatte sich die EZU mit ihrer Härtung auf 75 Prozent einem konvertiblen Währungssystem angenähert, und die OEEC-Mitglieder mußten seit Mitte 1955 unter den Bedingungen der de-facto-Konvertibilität operieren. Andererseits aber war keineswegs ausgemacht, inwieweit diese Entscheidungen irreversibel waren. $\mathrm{Da}$ die OEEC-Länder die EZU beibehalten hatten, gab es durchaus die Möglichkeit, das Kreditsystem wieder aufzuweichen und so einen Schritt auf dem Weg zur Konvertibilität zurückzugehen ${ }^{3}$. Wichtiger aber noch war, daß die OEECLänder nicht verbindlich vereinbart hatten, ob und wann sie die EZU auflösen und die Konvertibilität erklären würden. Da die Auflösung der EZU und die Anwendung des EWA nur auf Antrag von Mitgliedern, die 50 Prozent der EWA-Quoten stellten, erfolgen konnte, war es durchaus möglich, eine Konvertibilitätserklärung zu behindern oder zu verzögern. Deshalb darf die Periode von 1955 bis 1958 nicht als eine Wartezeit auf die Konvertibilität verstanden werden. Vielmehr war sie eine Probezeit für die gehärtete, de-facto-konvertible EZU und damit für die Konvertibilität selbst. Die deutsche Zentralbank mußte auch in dieser Zeit entscheiden, wie sie sich zu der Frage eines globalen Währungssystems und zur europäischen Kooperation im Rahmen der EZU verhalten sollte.

Aber auch in einer zweiten Hinsicht war die Situation offen, denn in der zweiten Hälfte der fünfziger Jahre wurden auch andere Kooperationsprojekte diskutiert. Im Mai 1955 hatten Belgien, Luxemburg und die Niederlande ihren EGKS-Partnern Frankreich, Italien und der Bundesrepublik die Errichtung eines Gemeinsamen Marktes und einer Atomgemeinschaft vorgeschlagen. Diese Initiative mündete nach fast zweijährigen, intensiven, problematischen und mehrmals vom Abbruch bedrohten Verhandlungen in der Unterzeichnung der Römischen Verträge, die zur Schaffung neuer Institutionen und Kooperationsforen führten und damit das Gesicht Europas nachhaltig veränderten. Nach der erfolgreichen Ratifizierung der Verträge nahm die Europäische Wirtschaftsgemeinschaft (EWG) am 1.Januar 1958 ihre Arbeit auf. Da die EWG-Staaten zum 1.Januar 1959 planmäßig die erste Binnenzollsenkung durchführten und da zeitgleich die im Rahmen der OEEC geführten Verhandlungen über eine OEECweite Freihandelszone scheiterten, zerfiel Anfang 1959 der bisher einheitliche westeuropäische Wirtschaftsraum in zwei Handelsblöcke.

${ }^{2} \mathrm{Kaplan} / \mathrm{Schleiminger,} \mathrm{EPU,} \mathrm{S.} 231 \mathrm{ff}$.

${ }^{3}$ Im Sommer 1956 schlossen weder das Auswärtige Amt noch die BdL eine Aufweichung der EZU aus. Vgl. hierzu S. $208 \mathrm{f}$. 
Der Prozeß der Europäischen Integration und die Verhandlungen zur Gründung der EWG haben in der Forschung große Aufmerksamkeit gefunden ${ }^{4} . \mathrm{Da}$ aber in den Verhandlungen unbestreitbar die hohe Politik eine herausragende Rolle spielte, wurden die währungspolitischen Aspekte weitgehend ausgespart, zumal die Währungspolitik im Vertragswerk letztlich auch nur „eine klägliche Nebenrolle" einnahm". Gleichwohl sollte die Europäische Integration der Sechs hier nicht ausgeklammert werden. Zum einen ist jede Analyse der internationalen Währungspolitik der deutschen Zentralbank ohne eine Behandlung dieses Prozesses unvollständig. Hinzu kommt, daß die historische Forschung der letzten Jahre die Bedeutung der hohen Politik relativiert hat. So hat Wilfried Loth Anfang der neunziger Jahre betont, daß die Sechserlösung zumindest teilweise wirtschaftlich bedingt war, und Alan Milward hat in bezug auf die europäischen Integrationsbemühungen formuliert: „Foreign policy bowed to those economic imperatives. "6 Darüber hinaus ist festzuhalten, daß die "klägliche Nebenrolle“ der Währungspolitik nicht von Anfang an gegeben war, sondern auch als ein Verhandlungsergebnis angesehen werden muß. Schließlich ist zu beachten, daß es zwischen den Optionen: Europäische Integration zu Sechst, Konvertibilität und EZU/OEEC-Kooperation zahlreiche wechselseitige Beziehungen gab. Anläßlich der Konvertibilitätserklärung bezeichnete zum Beispiel Erhard dieses weltweite Währungsregime als eine notwendige Ergänzung zur Europäischen Integration ${ }^{7}$. Ein politikwissenschaftliches Handbuch aus den achtziger Jahren stellt die EWG als Verdrängerin der OEEC bzw. die EZU und das EWA als „Opfer“ der Spaltung Europas in EWG und EFTA dar ${ }^{8}$. In ihrer Darstellung der EZU sehen Kaplan und Schleiminger in der EWG die logische Konsequenz der währungspolitischen Beschlüsse der OEEC des Jahres 1955, da mit dieser Zustimmung zur späteren Auflösung der EZU die Etablierung neuer Integrations- und Kooperationsformen unabweisbar geworden sei9.

Sofern das neue Integrationsprojekt in den Blick genommen wird und die Jahre von 1955 bis 1958 als eine Probezeit für eine europäische Zusammenarbeit im Rahmen der de-facto-konvertiblen EZU verstanden werden, lag also ein „ruhigerer Zeitabschnitt ${ }^{\alpha}$ nicht vor. Vielmehr galt es Entscheidungen zu treffen, die grundlegend für die wirtschaftliche Organisation Europas sein würden. Da die deutsche Zentralbank sich schon vor 1955 in der internationalen Währungspolitik als bedeutender Faktor etabliert hatte, konnte ihr auch zwischen 1955 und 1958 eine wichtige Rolle zukommen. Die Tatsache, daß die BdL in dieser Zeit

\footnotetext{
${ }^{4}$ Aus der zahlreichen Literatur vgl. Morgan, Politics; Schwarz, Adenauer und Europa; Küsters, Gründung; Gerbet, Construction; Guillen, L'Europe.

5 Andersen, Währungspolitik, S.297. Vgl. auch den Vertrag zur Gründung der EWG, abgedruckt in: BGBL 1957 II, S.766ff.

6 Vgl. Loth, Weg, S.136; Milward, Conclusions, S. 189.

${ }^{7}$ Bulletin des Presse- und Informationsamtes, Nr. 238, 30.12. 1958.

${ }^{8}$ Andersen, Währungspolitik, S. 297.

9 Vgl. Kaplan/Schleiminger, EPU, S.227.
} 
in die Deutsche Bundesbank überführt und damit ein neuer institutioneller Rahmen für die deutsche Währungspolitik errichtet wurde, beeinflußte die Bedeutung und Rolle der deutschen Zentralbank, ihre Politik und Funktion nicht wesentlich ${ }^{10}$. Abgesehen davon, daß sich die deutsche Zentralbank in der zweiten Jahreshälfte 1957 in einem Interregnum befand, erwies sich die Überführung der BdL in die Deutsche Bundesbank bei weitgehender personeller Kontinuität als folgenlos für die internationale Währungspolitik der Bank ${ }^{11}$.

\section{Die deutsche Zentralbank und das de-facto-konvertible EZU-System}

\section{Das außenwirtschaftliche Dilemma}

Im Jahre 1955 existierte für die OEEC-Länder ein de-facto-konvertibles EZUSystem: Die mengenmäßigen Beschränkungen und die Devisenrestriktionen waren weitgehend abgebaut; das transferierbare Pfund Sterling war mit einem geringen Diskont in Dollar umtauschbar; die EZU war auf 75 Prozent gehärtet worden. Dieses Währungssystem hatte in den Jahren 1955 bis 1958 einige Schwierigkeiten zu meistern.

Vor dem Hintergrund weiteren Wachstums, zunehmenden innereuropäischen Handels, größerer Wettbewerbsfähigkeit auf außereuropäischen Märkten, anfangs noch ansteigender Liberalisierung und aggregiert noch immer anwachsender Reserven manifestierten sich in dieser Zeit in Europa Preissteigerungen und ein vergrößertes Zahlungsbilanzdefizit zum Dollarraum ${ }^{12}$. Das brachte mit sich,

${ }^{10}$ Mit dem Gesetz vom 26.7.1957 wurde die BdL zum 1.8.1957 in die Deutsche Bundesbank überführt. Dabei wurde viel vom alten Zentralbanksystem - seine Unabhängigkeit und seine geldpolitischen Instrumente - übernommen. Es gab aber auch einige Neuerungen. So wurde nun auch de jure das zentrale Element verstärkt: Das zweistufige Zentralbanksystem wurde durch das Filialsystem der Bundesbank ersetzt; der Präsidentendualismus wurde abgeschafft; die Direktoriumsmitglieder erhielten Sitz und Stimme im Zentralbankrat. Für weitere Einzelheiten vgl. BGBL 1957 I, S. 745 ff.; Hentschel, Bundesbankgesetz, S. 3 ff.; Deutsche Bundesbank, 30 Jahre.

11 Am 1.1.1958 übernahmen Karl Blessing als Präsident und Heinrich Troeger als Vizepräsident die Leitung der Bundesbank. Blessing ( $(1900)$ war in den zwanziger Jahren in die Reichsbank eingetreten. Im Jahre 1939 wurde er trotz NSDAP-Mitgliedschaft entlassen. Während und nach dem Krieg leitete er die Margarine-Union AG. In den fünfziger Jahren trat er v. a. als wirtschaftspolitischer Berater Adenauers auf. Die Briten sahen Blessing als flexibler und orgineller als Vocke an. Vgl. BoE, OV 34/96, British Embassy an Bank of England, 9.8.1957. Heinrich Troeger (*1901) war bis 1933 als SPD-Mitglied Bürgermeister in Salzach/Oder. Nach dem Krieg war er bis 1946 Oberbürgermeister in Jena. In den Jahren 1947 bis 1951 war er Ministerialdirektor erst im hessischen, dann im nordrhein-westfälischen Finanzministerium. Im Zeitraum von 1951 bis 1956 bekleidete er die Stelle des hessischen Finanzministers. Im Jahre 1956 wurde er zum Präsident der Landeszentralbank Hessen bestellt. Vgl. BBK, BSG.

12 Vgl. OEEC, 9 th Annual Report (1958). Die Liberalisierung stieg bis 1956 auf durchschnittlich $89 \%$ an. Danach sank sie auf 83\% (1957) ab. Für diesen Rückgang waren die französischen Entliberalisierungsmaßnahmen verantwortlich. Der größte Teil der aggregiert angestiegenen Währungsreserven entfiel auf die Bundesrepublik. 
Abbildung S: Kumulative Positionen einiger EZU-Mitglieder 1955-1959

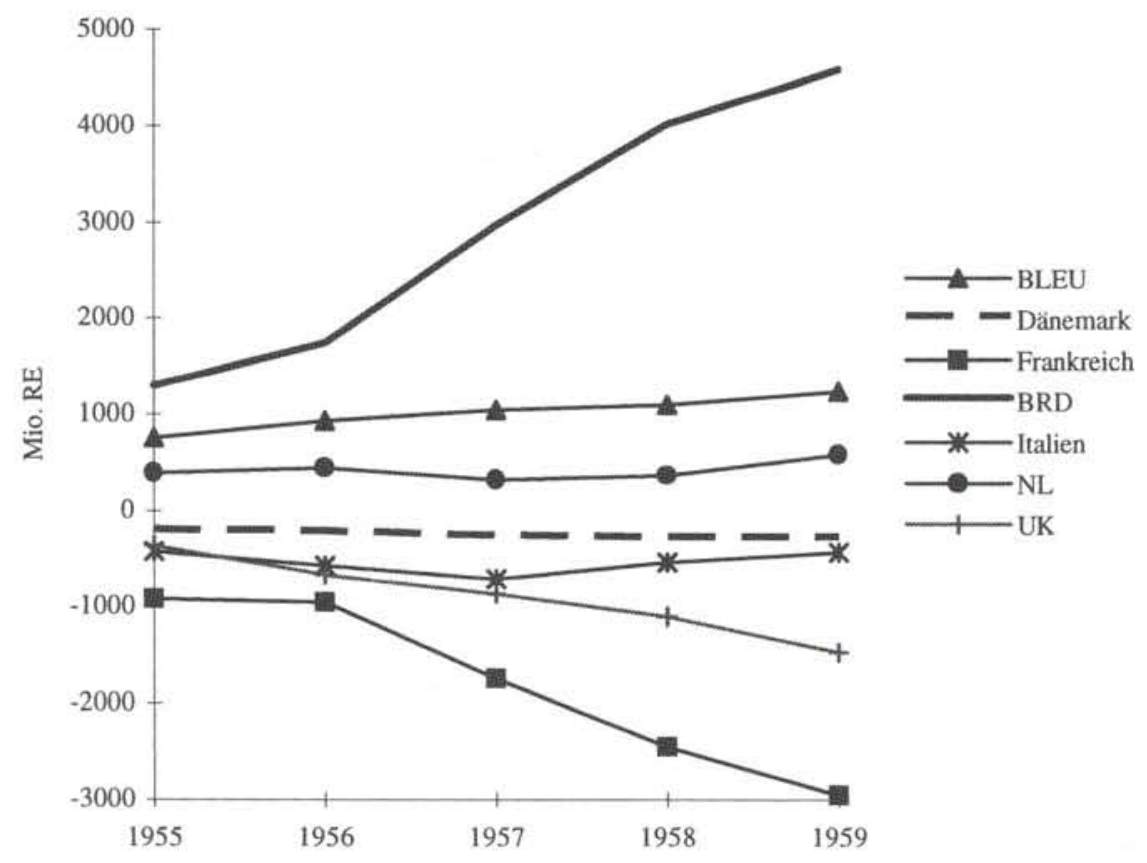

Quelle: BIS, Annual Reports, versch. Ausgaben.

daß einige Länder seit 1955 wieder mit erheblichen Zahlungsbilanzdefiziten zu kämpfen hatten. Wichtiger aber war, daß sich die Ungleichgewichte innerhalb der EZU, wie Abbildung 5 illustriert, verstärkten. Während Frankreich und das Vereinigte Königreich erhebliche EZU-Defizite zu verzeichnen hatten, erwirtschaftete die Bundesrepublik weiterhin Überschüsse zum EZU-Raum. Sie akkumulierte trotz Härtung der EZU bis Ende 1958 Guthaben in Höhe von 4,5 Mrd. DM und wurde so zur herausragenden und letztlich fast alleinigen Kreditgeberin Europas ${ }^{13}$. Für diese Überschüsse war das Wachstum der deutschen Exporte, das nicht durch den Anstieg der Importe aufgewogen wurde, verantwortlich. Aber auch die Tatsache, daß in einem Währungssystem mit festen Wechselkursen gefahrlos auf Wechselkursanpassungen spekuliert werden konnte, war von Bedeutung. Tatsächlich war in der zweiten Hälfte der fünfziger Jahre ein Großteil der Überschüsse auf Wechselkursspekulation zurückzuführen.

${ }^{13}$ Die deutschen Kredite an die EZU wuchsen von 2054 Mio. DM im Jahre 1954 auf 4597 Mio. DM zum Jahresende 1958 an. Demgegenüber hatten die anderen EZU-Gläubiger zusammen insgesamt nur Kredite in Höhe von 1213,8 Mio. DM gewährt. Davon entfielen auf die Belgisch-Luxemburgische-Wirtschaftsunion 646,8 Mio. DM, auf Italien 29,4 Mio. DM, auf die Niederlande 508,2 Mio. DM, auf Österreich 25,2 Mio. DM und auf Schweden 4,2 Mio. DM. Vgl. Deutsches Geld- und Bankwesen, S. 349; Monetäre Statistiken, S. 347. 
Tabelle 11: Wirtschaftliche Entwicklung der BRD 1954-1958

\begin{tabular}{lrrrr} 
Inflation & $\begin{array}{c}\text { Wachstum } \\
\text { in \% }\end{array}$ & $\begin{array}{c}\text { Arbeitslose } \\
\text { in \% }\end{array}$ & $\begin{array}{c}\text { Leistungsbilanzsaldo } \\
\text { in Mrd.DM }\end{array}$ \\
\hline 1953 & & & 8,4 & 4,1 \\
1954 & $-1,7$ & 7,1 & 7,6 & 4,0 \\
1955 & 2,2 & 11,8 & 5,6 & 2,7 \\
1956 & 1,2 & 7,5 & 4,4 & 5,0 \\
1957 & 2,1 & 5,9 & 3,7 & 6,5 \\
1958 & $-0,7$ & 4,1 & 3,7 & 6,6 \\
\hline
\end{tabular}

Anmerkung: Sp. 1 berechnet anhand der Erzeugerpreise gewerblicher Produkte. Sp. 2 berechnet als Wachstum des Bruttosozialprodukts in Preisen von 1980. Quelle: Monetäre Statistiken 1988, $2 \mathrm{ff}$.

Die Aufgabe, die sich Europa und somit auch der Bundesrepublik in dieser Zeit stellte, bestand darin, die Ungleichgewichte innerhalb der EZU einzudämmen. Für die Bundesrepublik war das ein schwieriges Unterfangen, da die Überschüsse durch eine Erhöhung der deutschen Liberalisierung schwerlich ausgeglichen werden konnten. Gleichwohl waren Maßnahmen notwendig, denn das europäische Währungssystem drohte zusammenzubrechen, und die Partner sprachen gelegentlich die Möglichkeit diskriminatorischer Maßnahmen gegen deutsche Exporte an. Darüber hinaus war für die deutsche Zentralbank, beauftragt mit der Wahrung der Preisstabilität, in den Jahren 1955 bis 1958 auch der Erhalt des inneren Gleichgewichtes ein akutes Thema. Bei beachtlichen Wachstumsraten näherte sich die deutsche Volkswirtschaft, wie Tabelle 11 zeigt, der Vollbeschäftigung, und zum Jahresende 1954 zeigten sich inflationäre Tendenzen.

$\mathrm{Da}$ zu befürchten war, daß diese inflationären Tendenzen durch eine Auflösung der vom Finanzminister für die Aufrüstung angesammelten Guthaben akzentuiert werden würden ${ }^{14}$, verlangte die binnenwirtschaftliche Situation eine restriktive Geldpolitik. Da aber andererseits die Zahlungsbilanzüberschüsse eine expansive Politik erforderten, befand sich die deutsche Geldpolitik in einer schwierigen Lage. Mehr noch: Sofern sie nicht das de-facto-konvertible EZU-System mit festen Wechselkursen aufgeben wollte, stand sie vor einem Dilemma, denn ein solches Währungssystem verlangt von seinen Teilnehmern nicht nur die Beachtung der außenwirtschaftlichen Entwicklung, sondern es erzwingt sie letztendlich durch den Mechanismus der importierten Inflation. Tatsächlich schien die deutsche Zentralbank in der zweiten Hälfte der fünfziger Jahre zeitweise vor der Wahl einer freiwilligen Expansion oder einer zwangsweisen Inflation zu stehen.

${ }^{14}$ Der Finanzminister hatte Vorsorge für die Aufrüstung getroffen: Die Zentralbankeinlagen der öffentlichen Stellen beliefen sich im Dezember 1953 auf 3181,4 Mio. DM, im Dezember 1954 auf 4684,7 Mio. DM, im Dezember 1955 auf 5949,7 Mio. DM, und erreichten im Dezember 1956 den Stand von 6711,8 Mio. DM. Im Jahre 1957 wurden sie auf 4017,1 Mio. DM abgebaut. Vgl. Deutsche Bundesbank, Monatsbericht Dezember 1958, S.36. 
Schon oft ist die Politik der deutschen Zentralbank im „Spannungsfeld zwischen innerem und äußerem Gleichgewicht" zur Zeit dieses „außenwirtschaftlichen Dilemmas" untersucht worden ${ }^{15}$. Dabei wurde der Schwerpunkt meist auf die Analyse der Geldpolitik gelegt. Es wurde gefragt, ob und inwieweit die deutsche Zentralbank die Bewahrung des inneren Gleichgewichtes verfolgte. Auch ohne Quellenanalyse war es ein leichtes festzustellen, daß die Bank eindeutig eine restriktive Politik einschlug, denn selbst bei dramatischen Überschüssen, Gefahr von importierter Inflation und verstärkten Ungleichgewichten innerhalb der EZU lockerte sie nur zögerlich ihre Mitte 1955 eingeläutete restriktive Politik seit Sommer 1956. Entsprechend kamen diese Untersuchungen zu dem Ergebnis, daß die Zentralbank trotz aller Bemühungen, die außenwirtschaftliche Entwicklung zu beachten und die Überschüsse zu mildern, in diesem Zielkonflikt die Priorität auf die Erhaltung des inneren Gleichgewichts gelegt hat ${ }^{16}$.

Eine solche Aussage ist aber problematisch. Wenngleich nicht bezweifelt werden kann, daß für die Zentralbank die Bewahrung der Preisstabilität ein wichtiges Ziel war, ist festzuhalten, daß in einem de-facto-konvertiblen Währungssystem mit festen Wechselkursen der Preisstabilität nicht ohne weiteres die Priorität eingeräumt werden kann. Sobald die deutsche Zentralbank in dieses existierende oder in irgendein anderes de-facto-konvertibles Währungssystems eingebunden war, konnte sie nicht das außenwirtschaftliche Gleichgewicht vernachlässigen. $\mathrm{Da}$ zwischen 1955 und 1958 die Option eines Ausstieges geradezu undenkbar war, muß die Periode in erster Linie als eine Zeit der Auseinandersetzung mit anderen Ländern über die in dem existierenden Währungssystem zu verfolgende Geldpolitik verstanden werden. Aus diesem Grund ist eine weitergehende Analyse notwendig. Nicht nur die Endergebnisse der Geldpolitik, sondern auch die Entscheidungsprozesse innerhalb der Bank, die Reaktionen der Partner und die biund multilateralen Diskussionen sind einzubeziehen. Darüber hinaus ist nicht nur die Geldpolitik, sondern die gesamte Außenwirtschaftspolitik der deutschen Zentralbank von Interesse. Eine Analyse der deutschen Zentralbankpolitik muß auch herausarbeiten, wie die Zentralbank ihre Situation sah und welche flankierenden Maßnahmen sie auf dem Gebiet der Außenwirtschaftspolitik befürwortete. Ferner ist zu fragen, ob und inwieweit die seit Anfang der sechziger Jahre auch von Mitgliedern des Zentralbankrates öffentlich formulierte Kritik an dem System der Konvertibilität, einschließlich seiner unliebsamen Nebenerscheinungen wie Spekulation und importierte Inflation, schon zur Zeit der Bewährungsprobe des de-facto-konvertiblen Währungssystems virulent war $^{17}$.

${ }^{15}$ Emminger, Geld- und Währungspolitik, S.485ff. Vgl. auch Müller, Politik; Jenkis, Inflation; Dürr, Wirkungsanalyse.

${ }^{16}$ Vgl. Hein, Mainsprings, S. $317 \mathrm{ff}$.; Jenkis, Inflation, S. $72 \mathrm{ff}$.; Müller, Politik, S. $46 \mathrm{ff}$; Emminger, Geld- und Währungspolitik, S. $485 \mathrm{ff}$.

17 Carl Wagenhöfer, Präsident der Landeszentralbank Bayern, formulierte Anfang 1961 in aller Öffentlichkeit Zweifel an der Konvertibilität. Er sprach von einer eventuellen „Zurückschraubung" der Konvertibilität. Vgl. Wagenhöfer, Währungspolitik, S.19. 


\section{Die Geldpolitik der deutschen Zentralbank}

\section{Restriktionen}

Da sich das deutsche Kreditsystem schon seit 1953 durch eine hohe Liquidität auszeichnete, hatte es auch in der Vergangenheit Plädoyers für neutralisierende Geldmarktoperationen gegeben. Von diesen hatte aber der Zentralbankrat in der ersten Hälfte der fünfziger Jahre Abstand genommen. Da die Preisentwicklung stabil war, sollte sich die vor allem aus den Überschüssen resultierende Liquidität entsprechend den Regeln des klassischen Goldstandards auswirken. Die Geldpolitik sollte höchstens glättend eingreifen. Wie der Zentralbankrat festhielt, war „die Verflüssigung des Marktes [...] der organische Niederschlag der Zahlungsbilanzentwicklung, und es bestehe kein Anlaß, den Verflüssigungseffekt der natürlichen Kräfte durch Gegenoperationen der Notenbank zu unterdrücken"18.

Anfang 1955 änderte sich diese Haltung angesichts der Konjunkturentwicklung, der Kreditausweitung und des Wachstums des Geldvolumens. Vereinzelte Preissteigerungen waren zu verzeichnen. $\mathrm{Um}$ in dieser Situation für restriktive Geldmarktoperationen gewappnet zu sein, vereinbarte die BdL mit dem Finanzminister die Umwandlung eines Teils der Ausgleichsforderungen (vorerst $2 \mathrm{Mrd} . \mathrm{DM})$ in Geldmarktpapiere und verabschiedete eine neue, interventionistische Linie für die Offenmarktpolitik ${ }^{19}$. Dieser Maßnahme folgten am 3. August 1955 - sobald das EWA unter Dach und Fach war - weitere Restriktionen, namentlich eine Diskonterhöhung von 3 auf 3,5 Prozent, eine Mindestreserveerhöhung um 1 Prozent und eine Erhöhung der Abgabesätze um 0,25 Prozent ${ }^{20}$.

Bei den ausländischen Zentralbanken stießen diese Maßnahmen auf Wohlwollen und Verständnis ${ }^{21}$. Innerhalb der Bundesrepublik führten sie zu erheblichen Unstimmigkeiten über die Geldpolitik: Während die BdL die vom Finanzminister und seiner „Hortung" ausgehenden Gefahren betonte und dabei herausstellte, daß sie sich nicht scheuen würde durchzugreifen, kritisierte Adenauer die Geldpolitik der BdL und monierte die mangelnde Zusammenarbeit zwischen Bonn und Frankfurt ${ }^{22}$. Diese Kontroverse spitzte sich im Frühjahr 1956 zu, als

${ }^{18}$ BBK, B 330/71, ZBR, Protokoll, 19.8.1953. Vgl. auch Kapitel III, Fußnote 190.

19 Vgl. die Diskussionen im Zentralbankrat von März bis Juli 1955, insbesondere die Zentralbankratsitzung am 7.6.1955, in: BBK, B 330/86. Die Vereinbarung mit dem Finanzminister über die Mobilisierung von Ausgleichsforderungen wurde mehrmals aufgestockt, Anfang 1957 auf $3 \mathrm{Mrd}$. DM, im April 1957 auf 4 Mrd. DM, im September 1957 auf 7 Mrd. DM. Im Juli 1958 wurden alle im Portefeuille der Bundesbank vorhandenen Ausgleichsforderungen - 8,1 Mrd. DM - mobilisiert. Die Ergebnisse dieser Politik sind Tabelle 12 zu entnehmen.

20 Vgl. BBK, B 330/87, ZBR, Protokoll, 3.8.1955.

${ }^{21}$ Vgl. FedNY, C 26, Germany, BdL 1952-1957, Dernburg an Exter, 5.4.1955 und 4.8.1955; BoE, OV 34/40, Bolton, Basle Notes, The German Monetary Situation, 16.11.1955.

${ }^{22}$ Vgl. BAK, B 136/652, o.V., Notizen zum Gespräch Erhard, Vocke, Bernard, Schäffer u.a., 8.9.1955; Haenlein, Entwicklung der Preise und Löhne, 21.9.1955; Schäffer, Denkschrift, 
mit Blick auf die Bundestagswahl im September 1957 und auf die vollen Kassen des Finanzministers der „Kuchen-Ausschuß“, der die Aufteilung der gehorteten Gelder in Angriff nehmen wollte, ins Leben gerufen wurde. Im März 1956 erhöhte der Zentralbankrat - mit der Unterstützung des Wirtschaftsministers, aber gegen eine Stellungnahme des Kabinetts - den Diskontsatz auf 4,5 Prozent $^{23}$. Wenngleich das zu kritischen, aber immer noch verständnisvollen Fragen des Auslandes führte und sich diese Politik auch wegen der durch diese Geldknappheit induzierten erstaunlich hohen Überschüsse weitgehend als kontraproduktiv erwies, wurde im Mai - mit ausdrücklicher Billigung Erhards und Schäffers - eine nochmalige Heraufsetzung des Diskontsatzes auf 5,5 Prozent beschlossen ${ }^{24}$.

Die entscheidenden Beweggründe für die Diskonterhöhungen und die restriktive Politik waren die binnenwirtschaftliche Entwicklung und das Verhalten der Regierung. Wie das BdL-Direktorium anläßlich der Diskonterhöhung vom Mai 1956 feststellte, hoffte es, daß diese Maßnahmen „ihren Eindruck auf Regierung und Parlament nicht verfehlen" und zu einem Überdenken der Finanzpolitik führen werden ${ }^{25}$. Hingegen standen die außenwirtschaftlichen Zusammenhänge und Probleme bei diesen geldpolitischen Entscheidungen im Hintergrund. Obwohl im Frühjahr 1956 wieder eine Verlängerung der EZU anstand, blieben die europäischen Ungleichgewichte unbeachtet. Der Zentralbankrat sah keinen Anlaß zur Besorgnis für die EZU. Zum ersten - so stellte er fest - war das Kreditobligo der BdL bei der EZU noch nicht ausgeschöpft. Überschüsse konnten somit ohne verrechnungstechnische Schwierigkeiten abgedeckt werden. Zum zweiten würden die deutschen Überschüsse weder die EZU noch einzelne Mitgliedsländer in Verlegenheit bringen ${ }^{26}$. Zu Hilfe kam aber auch, daß die restriktive deutsche Geldpolitik die Zustimmung der ausländischen Währungsexperten fand. Mitarbeiter der Bank von England bemerkten zu den Diskonterhöhungen: „Our conclusion was that it was necessary for something to be done at the time

26. 9. 1955; Haenlein, Vermerk, 28.9.1955; BAK, B 136/4800, o.V., Protokoll der Besprechung des "Kleines Kreises“, 16.12.1955.

${ }^{23}$ Vgl. BBK, B 330/92, ZBR, Protokoll und Stenogramm, 7./8.3.1956. Laut Gesetz konnte die Bundesregierung die Beschlüsse des Zentralbankrates für acht Tage aufschieben. Als Erhard dieses Recht im Auftrag des Kabinetts in Anspruch nehmen wollte, stellte Bernard fest, daß der Zentralbankrat schon in der vorangegangenen Sitzung aus Rücksicht auf die Regierung auf einen Beschluß verzichtet habe. Das Veto-Recht der Regierung sei somit „konsumiert“. Zur Kabinettssitzung vgl. BAK, NL Schäffer 168, Hartmann, Notizen zur Kabinettssitzung am 8.3.1956.

24 Vgl. BBK, B 330/94, ZBR, Protokoll und Stenogramm, 18.5.1956. Zur Reaktion des Auslandes vgl. BAK, B 102/55333, von Mangoldt, Bericht über die 70. Sitzungsperiode des EZU-Direktoriums, 20.4.1956.

25 BBK, B 330/2057, Direktorium, Protokoll, 17.5.1956. Vgl. auch BBK, B 330/94, ZBR, Protokoll und Stenogramm, 18.5.1956. Diese Diskonterhöhung veranlaßte Adenauer, sich auf der Mitgliederversammlung des BDI harsch gegen die BdL, den Finanz- und den Wirtschaftsminister auszusprechen. Zum Verhältnis Erhard - Adenauer zu dieser Zeit vgl. LESt, I 4), Erhard an Adenauer, 16.3.1956; Adenauer an Erhard, 21.3.1956; Erhard an Adenauer, 11.4.1956; Adenauer an Erhard, 13.4.1956; Erhard an Adenauer, 27.4.1956.

${ }^{26}$ Vgl. BBK, B 330/95, ZBR, Protokoll, 11.7.1956. 
Tabelle 12: Entwicklung der Bankenliquidität 1955-1957

\begin{tabular}{|c|c|c|c|c|c|c|c|c|c|}
\hline & \multicolumn{4}{|c|}{ aufgrund von Veränderungen bei: } & & \multicolumn{3}{|c|}{ aufgrund der Kreditpolitik: } \\
\hline & $\begin{array}{l}\text { Bargeld- } \\
\text { umlauf }\end{array}$ & $\begin{array}{l}\text { Zentral- } \\
\text { bank- } \\
\text { kredi- } \\
\text { ten }\end{array}$ & $\begin{array}{l}\text { Einlagen } \\
\text { v. Nicht- } \\
\text { banken } \\
\text { beim } \\
\text { ZBS }\end{array}$ & $\begin{array}{l}\text { Devi- } \\
\text { senan- } \\
\text { käufen }\end{array}$ & Sonst. & $\begin{array}{l}\text { Gesamt- } \\
\text { summe } \\
\text { Spalten } \\
\text { I-V }\end{array}$ & $\begin{array}{l}\text { Offen- } \\
\text { markt- } \\
\text { politik }\end{array}$ & $\begin{array}{l}\text { Gutha- } \\
\text { ben d. } \\
\text { Banken } \\
\text { beim } \\
\text { ZBS }\end{array}$ & $\begin{array}{l}\text { Kredite } \\
\text { d. ZBS } \\
\text { an } \\
\text { Banken }\end{array}$ \\
\hline 119 & -122 & 50 & -374 & 289 & 169 & 12 & -142 & -1056 & -926 \\
\hline II 1 & -376 & -118 & & 590 & 2 & 715 & -494 & 179 & -42 \\
\hline III 1955 & -526 & -58 & -998 & 609 & 119 & -854 & 92 & 147 & 909 \\
\hline IV 1955 & -322 & 218 & -989 & 583 & -156 & -666 & 528 & 1228 & 1366 \\
\hline I 1956 & -462 & -292 & -917 & 592 & 197 & -882 & -589 & -976 & 495 \\
\hline II 1956 & -88 & -19 & -555 & 1625 & -15 & 948 & 163 & 176 & -935 \\
\hline III 1956 & -232 & 18 & -454 & 1919 & 120 & 1371 & -132 & 217 & -1022 \\
\hline IV 1956 & -166 & 89 & 131 & 1490 & -242 & 1302 & 32 & 1289 & -45 \\
\hline I 1957 & -145 & -138 & -670 & 1634 & 434 & 1115 & -1300 & -1037 & -852 \\
\hline II 1957 & -792 & 5 & -306 & 2221 & -135 & 993 & -769 & 1080 & 856 \\
\hline III 1957 & -509 & -53 & 139 & 3942 & 217 & 3736 & -1925 & 352 & -1459 \\
\hline IV 1957 & -237 & 11 & 367 & 108 & -182 & 67 & 1388 & 1486 & 31 \\
\hline
\end{tabular}

Anmerkungen: + = Mittelzuflüsse; - = Mittelabflüsse; alle Angaben in Mio. DM.

Sp. 2: ohne An-/Verkauf von Geldmarkttiteln.

Quelle: Monatsbericht, Dezember 1958, $32 \mathrm{f}$.

that the Central Bank acted and they used the weapon most clearly understood by the public, namely the Bank Rate. " 27

\section{Lockerungen}

Bis zum Ende des ersten Quartals 1956 bewirkten verschiedene Faktoren, daß sich die Bankenliquidität nicht ausweitete. Wie Tabelle 12 zeigt, waren vor allem aufgrund der Entwicklungen beim Bargeldumlauf, bei den Einlagen von Nichtbanken, die vor allem Einlagen des Bundes und der Länder umfaßten, und wegen der Offenmarktpolitik Mittelabflüsse zu verzeichnen. Zwar standen diesen Bewegungen Mittelzuflüsse aus den Devisenankäufen gegenüber, doch insgesamt konnten diese Zuflüsse vorerst noch durch die Abflüsse kompensiert werden. Das änderte sich aber im zweiten Quartal 1956. Während die Entwicklungen beim Bargeldumlauf und bei den Einlagen von Nichtbanken nur noch für mäßige Mittelabflüsse sorgten, führten die Devisenankäufe nun zu einer beachtlichen Liquidisierung. Zwar wurde diese zum Teil durch die restriktive Politik

${ }^{27}$ BoE, OV 34/243, Rootham/Bridge, Note on a visit to Düsseldorf and Frankfurt, 21.6.1956. Vgl. auch BBK, B 330/3381, von der Lippe, Vermerk, 14.6.1956. Natürlich gab es auch kritische Stimmen wie z. B. Sir Otto Niemeyer. Vgl. BoE, OV 34/41, Niemeyer, Note, 8.7.1956; BoE, OV 46/ 75, Bolton, Conversations at Basle, 9.7.1956. 
kompensiert. Andererseits aber führten auch die Restriktionen zu verstärkten Devisenankäufen und schufen damit weitere Liquidität. So mußte der Zentralbankrat im April 1956 die „erstaunlich hohen“ deutschen Überschüsse feststellen, die er korrekterweise auf die herrschende "Geldknappheit" und auf das Ausweichen auf ausländische Kreditmöglichkeiten zurückführte ${ }^{28}$. Trotz dieser Diagnose verfügte er aber keine Lockerungen.

Sein Festhalten an der restriktiven Politik begründete der Zentralbankrat damit, daß die Überschüsse nur temporär seien. Sie seien nicht in erster Linie auf das erhöhte deutsche Zinsniveau und die Zinsdifferenzen zwischen europäischen Ländern zurückzuführen. Da auf Anlagen von Ausländern keine Zinsen gezahlt werden durften ${ }^{29}$, seien vielmehr die veränderten terms of payments sowie die Spekulation, die durch Erhards Wechselkursvorstöße $\mathrm{e}^{30}$ verursacht worden war, maßgeblich. Er argumentierte, die Überschüsse würden sich in Kürze wieder zurückbilden. Eine Herabsetzung der Zinssätze, so stellte der Zentralbankrat im Juli 1956 fest, sei sinnlos ${ }^{31}$.

Erst im September 1956 wurde eine geringfügige Diskontsenkung verfügt. Dabei waren binnenwirtschaftliche Motive, vor allem die inzwischen gedämpfte „Konjunkturauffassung“, ausschlaggebend. Außenwirtschaftliche Motive trugen zu dieser Entscheidung nicht wesentlich bei, selbst wenn die Mitglieder des Zentralbankrates in der Erleichterung der "taktischen" Situation in Paris ein positives Nebenergebnis sahen ${ }^{32}$. Auch als sich im Sommer/Herbst 1956 mit der Suez-Krise die Ungleichgewichte im europäischen Währungssystem erneut verstärkten, fühlte sich der Zentralbankrat nicht zu geldpolitischen Lockerungen veranlaßt. Zwar drängte Vocke die Regierung zu Maßnahmen, die die britische Position entlasten würden ${ }^{33}$. Gleichzeitig aber war die BdL der Überzeugung, daß in bezug auf die Diskontpolitik „das Primat der internen konjunkturellen Bedürfnisse $^{a}$ gelten solle ${ }^{34}$. Der leisen Kritik des Auslandes hielt sie entgegen, für die Ab-

${ }^{28}$ BBK, B 330/93, ZBR, Stenogramm, 11.4. 1956.

${ }^{29}$ Dieses Verzinsungsverbot wurde aber keineswegs immer beachtet. Vgl. BoE, OV 34/42, Bridge, Activities of German Banks, 14.10.1957.

${ }^{30}$ Im Sommer 1956 hatte Erhard die europäischen Wechselkursrelationen in Frage gestellt. Das führte zum Zufluß von Spekulationsgeldern in die Bundesrepublik. Vgl. hierzu S. $211 \mathrm{ff}$.

${ }^{31}$ Vgl. BBK, B 330/95, ZBR, Protokoll und Stenogramm, 11.7. 1956. Die deutschen Überschüsse im EZU-Raum stiegen im März 1956 auf 51,1 Mio. RE, im April auf 60,5 Mio. RE, im Mai 1956 auf 86,2 Mio. RE an. Im Juni 1956, nach der zweiten Diskonterhöhung, beliefen sie sich auf 114,2 Mio. RE, sanken im Juli und August auf noch immer beträchtliche 106,6 Mio. RE bzw. 66,7 Mio. RE ab. Im September, Oktober und November stiegen sie aber, trotz Diskontsenkung, wieder auf 91,9 Mio. RE bzw. 101,4 Mio. RE bzw. 133,5 Mio. RE an. 1957 erreichten die Überschüsse im Juli 180,3 Mio. RE, im August sogar 280,8 Mio. RE. Vgl. BdL, Monatsberichte, versch. Ausgaben.

${ }^{32}$ BBK, B 330/96, ZBR, Stenogramm, 5./6.9.1956.

${ }^{33}$ Vgl. BAK, B 136/2595, o. V., Vermerk zur Ressortbesprechung am 24.10. 1956, 24.10. 1956. Die Beziehung zwischen der BdL und der Bank von England war zu dieser Zeit durch die gemeinsame Opposition gegen Erhard und seine Wechselkursvorstöße geprägt und demnach z. T. geradezu herzlich. Vgl. BoE, OV 45/75, Governor, Conversation in Basle, 9.7.1956. Vgl. hierzu auch S. $211 \mathrm{ff}$.

${ }^{34}$ BAK, B 102/11579, I A 1, Ergebnisprotokoll über die Ressortbesprechung am 5.10.1956, 8.10.1956; BAK, B 136/2595, Gerbaulet, Vermerk, 24.10.1956. 
schwächung der EZU-Ungleichgewichte seien vor allem binnenwirtschaftliche Maßnahmen der Defizitländer notwendig. Das „Kernproblem“ liege in der „ständigen schleichenden Inflation einiger Schuldnerländer“" ${ }^{35}$. Darüber hinaus hoben Vertreter der BdL bei Gesprächen mit ausländischen Zentralbankkollegen stets den begrenzten Handlungsspielraum der Bank hervor: „Dr. Guth from the BdL said that a reduction in bank rate sufficient to reverse the foreign capital flow would be wildly inflationary. " ${ }^{\text {36 }}$ "Herr Könneker left us with the impression that he regarded the situation as very unsatisfactory but could not see what to do about it [...] Herr Tüngeler believes that a great part of Germany's balance of payments surplus is due to a combination of pure speculation in the mark and its concomitant. " ${ }^{\text {37 }}$

Im Ausland wurde die Argumentation, daß in erster Linie restriktive Maßnahmen der Schuldnerländer notwendig seien, vorerst akzeptiert, und im Winter 1956/57 ergriffen einige Länder entsprechende geldpolitische Maßnahmen ${ }^{38}$. Vor diesem Hintergrund beschloß der Zentralbankrat im Januar 1957 gegen die Opposition des Wirtschaftsministers eine weitere leichte Diskontsenkung ${ }^{39}$.

Im Frühjahr 1957 veränderte sich die Situation. Während bis zum Winter 1956/57 die restriktive Politik der BdL trotz einiger kritischer Anmerkungen auf die Zustimmung des Auslandes traf, verschärfte sich im Frühjahr bei anhaltenden deutschen Überschüssen das Diskussionsklima. Die Bank von England meinte nun, von der deutschen Regierung und der BdL entschiedenere Maßnahmen fordern zu müssen ${ }^{40}$. Auch in der EZU herrschte - unter der Führung des britischen Vertreters - offene Kritik vor, und der Ton war zeitweise ausgesprochen ,unerfreulich“41. So war die Bundesrepublik im Frühjahr 1957 mit ihrer Meinung, $\mathrm{da} ß$ in erster Linie die Schuldnerländer ihre Politik korrigieren müßten, isoliert ${ }^{42}$. Trotz des erheblichen ausländischen Druckes beschloß der Zentralbankrat aber keine weitere Diskontsenkung. Selbst als Wolf, der für eine Diskontsenkung eintrat, in Bonn Verbündete fand, lehnte eine knappe Mehrheit des Zentral-

${ }^{35}$ BBK, B 330/2020, Emminger an Vocke, 28.9.1956; BBK, NL Emminger, Deutschland als EZUGläubiger, Abt. IV, Stichworte, 12.7.1956.

${ }^{36} \mathrm{BoE}$, OV 34/41, Tomkins, Report on a visit to Germany, 19.10.1956.

${ }^{37}$ BoE, OV 45/75, Parsons/Rootham, Note on a visit to Frankfurt, 7./9.11.1956.

${ }^{38}$ Vgl. BAK, B 102/11579, Emminger, Kurzbericht über die Sitzung der volkswirtschaftlichen Experten der OEEC, 22./23.10.1956; BAK, B 102/12598, Guth, Vermerk, 14.1.1957. Zur Geldpolitik anderer europäischer Länder vgl. BIS, 26 th Annual Report (1955/56), S. $35 \mathrm{ff}$.

39 Vgl. BBK, B 330/2057, Direktorium, Protokoll, 28.12.1956; BBK, B 330/99, ZBR, Protokoll und Stenogramm, 10./11.1.1957. Zur Auseinandersetzung Wirtschaftsministerium - BdL vgl. BAK, B 102/12598, I A 1, Entwurf eines Ergebnisprotokolls über die Sitzung des Abteilungsleiterausschusses für Konjunkturpolitik am 8.1.1957, 22.1.1957.

${ }^{40} \mathrm{Vgl}$. BoE, OV 34/42, Tomkins, Germany, 14.5.1957.

41 BAK, B 102/25 878, Steffe, Ergebnisbericht über die Sitzung der Ministerstellvertreter, 24.6.1957. Ähnlich auch BBK, B 330/103, Emminger, Bericht über die Sitzung des Ministerstellvertreterausschusses am 17./18.6.1957.

42 Vgl. BBK, B 330/103, Bericht über die Sitzung des Ministerstellvertreterausschusses am 17./ 18.6.1957 in Paris, Anlage zum ZBR-Protokoll vom 26.6.1957; BBK, B 330/3314, BdL an BMZ, 17.5.1957. 
bankrates eine solche Maßnahme $\mathrm{ab}^{43}$. Zwar sah der Zentralbankrat das Zahlungsbilanzproblem als „Problem Nr. ${ }^{\text {“ }}$ an und wäre auch fast zu einer Diskontsenkung bereit gewesen ${ }^{44}$. Ausschlaggebend war aber, daß er dies wegen der Spekulation als unwirksam einschätzte: „Zugegeben, daß es (eine Diskontsenkung um ein halbes Prozent, M.D.) sich optisch nicht schlecht ausmachen würde, doch würde die Abwehr des Zustroms ausländischer Gelder mit einer 0,5 prozentigen Zinssenkung als solche bestimmt nicht zu erreichen sein. Warum das Geld einströmt, wissen wir alle: aus Gründen der Werterhaltung und nicht der Zinsen wegen, die es sowieso nicht gibt. “45

Erst kurz vor der Jahresversammlung des IWF, als sich eine Änderung der britischen Haltung andeutete und die Bank von England wieder der Meinung zuneigte, daß die Defizitländer - das Vereinigte Königreich eingeschlossen - zur Inflationsbekämpfung übergehen sollten ${ }^{46}$, konnte sich der Zentralbankrat, gefördert durch eine Intervention des stets für eine "gesunde" Währungspolitik eintretenden IWF-Direktors Per Jacobsson, zu einer Diskontsenkung von einen halben Prozentpunkt durchringen ${ }^{47}$. Da zeitgleich, wenn auch vermutlich nicht abgesprochen, eine zweiprozentige britische Diskonterhöhung beschlossen wurde, war dem Bedürfnis der deutschen Zentralbank, möglichst wenig Inflation zu importieren und möglichst viel Stabilität zu exportieren, Rechnung getragen ${ }^{48}$.

\section{Die internationale Währungspolitik der deutschen Zentralbank}

Ein konvertibles Währungssystem sieht vor, daß Überschüssen und Defiziten mit der entsprechenden expansiven bzw. restriktiven Geldpolitik begegnet wird. In einem de-facto-konvertiblen Währungssystem wie dem der EZU gab es aber auch noch andere Möglichkeiten, auf Überschüsse zu reagieren. Zum ersten konnte das System modifiziert oder gar abgeschafft werden. Zum zweiten konnte versucht werden, den Handel selbst zu beeinflussen und die Zahlungsbilanz durch Importförderung bzw. Exportbeschneidung auszugleichen. Zum dritten gab es die Möglichkeit, die Ungleichgewichte mit einer Wechselkursanpassung zu entschärfen. Schließlich konnten Linderungsmaßnahmen wie die vorzeitige Abtragung der Auslandsverschuldung, Rüstungszahlungen und das Einzahlen

\footnotetext{
43 Vgl. BAK, B 102/12598, I A 1, Ergebnisbericht über die Sitzung des Abteilungsleiterausschusses am 12.7.1957, 25.8.1957.

${ }^{44}$ BBK, B 330/104, ZBR, Stenogramm, 10.7.1957.

${ }^{45}$ Ebenda. Vgl. auch BBK, B 330/133, ZBR, Stenogramm, 8./9.8.1957.

${ }^{46}$ BoE, OV 46/75, o.V., Germany, 5.9.1957.

47 Vgl. BBK, B 330/134, ZBR, Protokoll und Stenogramm, 18.9.1957; BoE, G 1/99, Cobbold an Jacobsson, 18.9.1957.

${ }^{48}$ Die Quellen legen die Schlußfolgerung nahe, daß die deutsch-britischen Maßnahmen nicht abgesprochen waren. Vgl. BoE, G 1/99, Cobbold an Vocke, 18.9.1957. Demnach war die deutsche Diskontsenkung kein quid pro quo für die britische Diskonterhöhung. Zur englischen Entscheidung vgl. Chapman, Decision Making, S. $353 \mathrm{ff}$.
} 
der Weltbankquote eine Abschwächung der Ungleichgewichte herbeiführen. Welche dieser Maßnahmen befürwortete die deutsche Zentralbank?

\section{EZU-Reform oder Konvertibilität}

Als die EZU gegründet wurde, war nicht nur die Erhöhung der internationalen Liquidität, sondern auch die Schaffung von Anreizen zur Korrektur von Zahlungsbilanzstörungen das Ziel. Im Verlauf der Konvertibilitätsverhandlungen aber hatten die OEEC-Länder diese Anreize vermindert oder ganz abgebaut. Wenn auch die Konvertibilität nicht verwirklicht worden war, hatten sich die europäischen Länder - gestützt auf angestiegene Devisenreserven, interessiert an weiteren Krediten und an dem Abbau von Handelsrestriktionen - geeinigt, die Anreize des EZU-Systems weitgehend durch die Vorteile eines konvertiblen Währungssystems zu ersetzen. Als sich aber in der zweiten Hälfte der fünfziger Jahre die europäischen Ungleichgewichte verstärkten, lag es nahe, das nunmehr de-facto-konvertible EZU-System zu überdenken. Durch eine Erhöhung des Kreditanteils konnte unter Umständen eine zahlungsbilanzkonforme Politik der Gläubiger, durch eine weitere Härtung oder einen Übergang zur Konvertibilität unter Umständen eine zahlungsbilanzkonforme Politik der Schuldner befördert werden. Die jährlich anstehenden Diskussionen über die Verlängerung der EZU boten Gelegenheit zu solchen Modifikationen.

Im Sommer 1956 schlug der britische Schatzkanzler Harold Macmillan eine Aufweichung der EZU für extreme Gläubiger vor. Die Kreditverpflichtung der Bundesrepublik sollte von 25 Prozent auf 50 Prozent erhöht, der Goldanteil entsprechend von 75 auf 50 Prozent gesenkt werden. Dies wurde zwar von deutscher Seite einmütig als Diskriminierung der Bundesrepublik und als Rückschritt vom Weg der Konvertibilität abgelehnt ${ }^{49}$. Allerdings war die Ablehnung vorerst erstaunlich moderat. Erhard versprach Macmillan, diesen Vorschlag ernsthaft zu erwägen ${ }^{50}$. Das Auswärtige Amt sah eine solche Modifikation als unabweisbar $\mathrm{an}^{51}$. Obgleich die BdL im Gefolge der Dollarliberalisierung seit Sommer 1955 einen jährlichen Dollarzufluß über die EZU in Höhe von 150 Mio. Dollar für notwendig erachtete ${ }^{52}$, stellte sie zu dem Vorschlag Macmillans lediglich fest, eine solche Modifikation sei „zur Zeit nicht [...] sinnvoll“53. Erst im weiteren Verlauf wurde die ablehnende Haltung pointierter formuliert. Als sich zeigte, daß auch die anderen Gläubigerländer den britischen Vorschlag ablehn-

${ }^{49} \mathrm{Vgl}$. BoE, OV 46/75, Rowan, Note of a talk with von Mangoldt, 1.7.1956.

50 Vgl. BoE, OV 46/75, HMT, Note of a talk between the Chancellor of the Exchequer and Dr. Erhard, 17.7.1956. Erhards Reaktion war vermutlich auch davon bestimmt, daß er kurz zuvor mit seinen Äußerungen über die europäischen Wechselkurse einen faux pas begangen hatte.

51 Vgl. PA AA, Abt. 4/Ref. 401/22, Hardenberg, Aufzeichnung zum Gespräch Erhard - Macmillan, 15.8.1956.

52 Vgl. BBK, B 330/86, ZBR, Stenogramm, 7.6. 1955. Dieser Dollarzufluß wäre aber schon bei einem durchschnittlichen Überschuß von 25 Mio. RE im Monat auch bei 50\%iger Kreditgewährung erreicht worden. Die deutschen Überschüsse lagen meist deutlich über 25 Mio. RE. Vgl. Fußnote 31.

${ }^{53}$ BBK, B 330/95, ZBR, Protokoll, 11.7.1956. 
ten, die Schuldner desinteressiert und das Vereinigte Königreich keineswegs von einer solchen Maßnahme überzeugt war, vertraten die Bundesregierung und die BdL vehement eine definitiv ablehnende Haltung ${ }^{54}$. Man setzte nun sogar das Vereinigte Königreich, das anläßlich der Suez-Krise mit einer Flucht aus dem Pfund Sterling zu kämpfen hatte, unter Druck. Als quid pro quo für Entlastungsmaßnahmen verlangten die Bundesregierung und die BdL vom Vereinigten Königreich, „daß es mit uns und den übrigen Gläubigerländern dafür stimme, die EZU nicht durch eine Verminderung des Goldanteils von 75 Prozent aufzuwei-

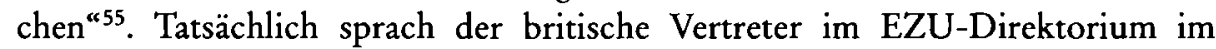
Frühjahr 1957 eine Aufweichung der EZU nicht an, und das Direktorium schlug eine Verlängerung ohne Veränderung des Gold-Kredit-Verhältnisses vor. Wenngleich diese Empfehlung im OEEC-Rat auf den Einspruch Norwegens traf, konnte die EZU letztlich unverändert verlängert werden. Ohne auf seinem Veto-Recht zu beharren, zog Norwegen den Einspruch zurück ${ }^{56}$. Kaplan und Schleiminger führen den norwegischen Rückzug auf mangelnde Unterstützung zurück ${ }^{57}$. So richtig das ist, so sehr sind die dahinterliegenden Motive festzuhalten: Während die Gläubiger eine Aufweichung der EZU aus prinzipiellen Gründen ablehnten, fürchteten die EZU-Schuldner, die Bundesrepublik würde bei einer Aufweichung der EZU ihre Mitgliedschaft kündigen ${ }^{58}$.

Natürlich war auch die Idee einer Weiterentwicklung des de-facto-konvertiblen EZU-Systems - eine weitere Härtung der EZU oder die Ersetzung dieses Systems durch die Konvertibilität - virulent. Dies würde den Druck auf die Schuldnerländer vergrößern, die Kreditierungsverpflichtungen der Gläubiger vermindern oder gar die Überschüsse zu vollwertigen Währungsreserven machen. Doch obgleich solche Maßnahmen im Interesse der Gläubiger lagen und das Vereinigte Königreich sogar befürchtete, es könnte von der Bundesrepublik in die Konvertibilität gezwungen werden, erwies sich eine solche Angst als unbegründet $^{59}$. Zwar hatte die Bundesrepublik Anfang 1956 für eine weitere Härtung der EZU plädiert ${ }^{60}$, aber schon wenig später setzte sich in Deutschland die Mei-

\footnotetext{
${ }^{54} \mathrm{Vgl}$. BBK, B 330/95, Emminger, Bericht von der Ministerratssitzung, 25.7.1956.

${ }^{55}$ BAK, B 136/2595, Gerbaulet, Vermerk Überschußposition der Bundesrepublik in der EZU, Ressortbesprechung am 24.10.1956, 24.10.1956.

56 Vgl. HAEC, OEEC-TRA 358, Joint Trade and Intra-European Payments Committee, TP/M(57)3, Summary Record of the 275 th Session, 8.4.1957; MBC(57)40, EPU, Renewal of the Union, 13.5.1957. Vgl. auch BBK, B 330/1310, IV, Französische Zahlungsbilanzkrise und Verlängerung der EZU, 12.4.1957; BBK, B 330/101, ZBR, Protokoll, 6.3.1957; BBK, B 330/102, ZBR, Protokoll, 3.5.1957.

57 Vgl. Kaplan/Schleiminger, EPU, S. 239.

${ }^{58}$ Von den Briten sind derartige Befürchtungen überliefert. Vgl. BoE, OV 46/76, Fenton, European Economic Situation, 27.9.1957; BoE, OV 34/43, Kommentar Roothams zu Portsmore, Tomkin's Note, 7.2.1958.

59 Vgl. BoE, OV 46/75, Rootham, Germany, 14.6.1957; Rootham, Policy and Tactics on Germany and EMA at the IMF, 4.9.1957. Vgl. auch BoE, OV 46/75, Hubback, Brief on EMA and EPU, 4.9.1957.

${ }^{60}$ Vgl. PRO, T 236/4114, Brief for Sir Edward Bridges' Visit to Germany, Januar 1956.
} 
nung durch, daß nicht auf eine Änderung der EZU-Regeln gedrängt werden sollte. Hierfür war unter anderem die politische Situation maßgebend: Adenauer bestand auf einem gemeinsamen Vorgehen mit dem Vereinigten Königreich. Gleichzeitig verpflichtete er die deutsche Politik unter Hinweis auf seine Richtlinienkompetenz auf die Beschlüsse der Messina-Konferenz und machte damit einen Konvertibilitätsschritt von Frankreich abhängig ${ }^{61}$. Aber auch Erhard wollte Anfang 1956 eine Auseinandersetzung in der OEEC über die Härtung der EZU vermeiden. Angesichts der neuen europäischen Integrationsprojekte sollte dem Ansehen der OEEC nicht geschadet werden. Bei einem Gespräch mit dem britischen Schatzkanzler betonte er: "He would like to see some further action by OEEC as evidence of its progressive liberal policy. This would help to keep down less promising forms of integration. One thing must not be allowed to happen: that was to have discussions in OEEC of proposals for hardening EPU and increasing liberalisation to which the UK objected. That would drive European countries into other forms of integration. ${ }^{\text {62 }}$ Außerdem bestand auch die BdL nicht auf einer Änderung des EZU-Systems. Wie schon in den Jahren zuvor, scheute Vocke auch jetzt jede Veränderung der EZU ${ }^{63}$.

Die Motive für die Haltung der BdL sind darin zu suchen, daß sie nicht mehr auf eine Akkumulierung vollwertiger Währungsreserven angewiesen war. Auch hatte sie Bedenken, schon zu diesem Zeitpunkt den EZU-Raum als Sonderraum aufzugeben. Dem Vorschlag, Frankreich die Begleichung seiner EZU-Defizite durch vom IWF gezogene DM zu ermöglichen, stand sie im Winter 1956/57 vor allem aus diesem Grund skeptisch gegenüber ${ }^{64}$. Darüber hinaus, so stellte Emminger fest, lag es durchaus im Interesse der Bank, das EZU-System beizubehalten. Die Vorteile des Konvertibilitäts-Regimes - wie zum Beispiel geringere Kreditverpflichtungen - wurden seines Erachtens durch Nachteile eindeutig aufgewogen, weil „sich dann noch sichtbarer als bisher die europäischen Gold- und Dollarreserven in Richtung auf die Bundesrepublik in Bewegung setzen würden. Dies würde uns einem noch stärkeren Druck als bisher aussetzen, Kredit zu gewähren, und uns vor allem handelspolitisch natürlich in weit größere Gefahr als bisher bringen, durch Mitgliedsländer mit Zahlungsbilanzdefiziten auf die gleiche Linie mit den USA gestellt und diskriminiert zu werden. Unter dem EWA würde eine längere Fortdauer der gegenwärtigen deutschen Überschüsse wahrscheinlich von den anderen noch weniger ertragen werden, als unter der EZU“65.

${ }^{61} \mathrm{Vgl.} \mathrm{PA} \mathrm{AA,} \mathrm{Abt.} \mathrm{4/Ref.} \mathrm{401/22,} \mathrm{Hardenberg,} \mathrm{Vermerk,} \mathrm{8.5.1956} \mathrm{und} \mathrm{Adenauer,} \mathrm{Erinnerungen,}$ S. $253 \mathrm{ff}$.

${ }^{62} \mathrm{PRO}, \mathrm{T}$ 236/4274, HMT, Note of a meeting at the Treasury, 21.2.1956.

${ }^{63} \mathrm{Vgl}$. BBK, B 330/1306, Tüngeler, Memo der Banque Nationale de Belgique, 28.3.1956.

${ }^{64}$ Vgl. BBK, B 330/1310, J 201, Vermerk 2.1.1957; IV, Französische DM-Ziehung im IWF, 11.1.1957. Letztendlich entschied sich der Zentralbankrat aber dafür, einen entsprechenden Antrag nicht zu opponieren. Vgl. BBK, B 330/99, ZBR, Protokoll, 9./10.1.1957.

${ }^{65}$ BBK, B 330/1314, IV, Vermerk, 31.5.1957. 
Als das Wirtschaftsministerium angesichts der EZU-Verlängerung und der deutschen Überschüsse im Frühjahr und Sommer 1957 bei Ressortbesprechungen die Möglichkeit ansprach, zum EWA überzugehen, fand die BdL eine Konvertibilitätserklärung „nicht angängig“. Sie wies darauf hin, daß zuerst die europäischen Probleme gelöst werden müßten. Auch erfordere der Gemeinsame Markt einen gemeinsamen Zahlungsmechanismus ${ }^{66}$. Da auch andere Ressorts die Meinung der Zentralbank teilten ${ }^{67}$, willigte die Bundesrepublik in die Verlängerung der EZU ohne weitere Härtung ein. Festzuhalten ist allerdings, daß mit dieser Einwilligung weder eine prinzipielle Ablehnung der Konvertibilität einherging noch für die anderen EZU-Teilnehmer eine verläßlichere Situation geschaffen wurde. Weiterhin stand die Möglichkeit einer deutschen Konvertibilitätserklärung im Raum und fungierte, selbst unausgesprochen, als Drohmittel.

\section{Aufwertung}

Die Unterzeichner des Bretton-Woods-Abkommens hatten sich nach dem Zweiten Weltkrieg auf ein System fester Wechselkurse geeinigt. In diesem System war aber die Möglichkeit von Wechselkursänderungen gegeben. Das Abkommen formulierte ausdrücklich, daß bei grundlegenden Gleichgewichtsstörungen die Paritäten verändert werden können ${ }^{68}$. Bei den nunmehr schon seit geraumer Zeit anhaltenden deutschen Überschüssen zu fast allen Währungsräumen war demnach zu prüfen, ob die DM aufgewertet werden sollte ${ }^{69}$.

Schon in der ersten Hälfte der fünfziger Jahre hatte Erhard verschiedentlich die Wechselkurse als starr und verzerrt angegriffen und den französischen Franken als überbewertet bezeichnet. Im Frühsommer 1956 griff er das Thema der Wechselkurse wieder auf. In einem Artikel in der Hamburger Wochenzeitung „Die Zeit" stellte er fest, daß sich die Preisniveaus der europäischen Länder in den letzten Jahren unterschiedlich entwickelt hätten, daß aber die Wechselkurse nicht angepaßt worden seien. Deshalb sei es „hohe, nein höchste Zeit“, die europäischen Wechselkursrelationen auf einer internationalen Konferenz zu diskutieren $^{70}$. Wenig später wandte sich Erhard an den britischen Schatzkanzler Macmillan und an die ausländische Presse. Er führte aus, daß es Grenzen für eine GuteGläubiger-Politik Deutschlands gäbe. Veränderungen der europäischen Paritäten seien notwendig. Wenngleich Erhard dabei aus Gründen der „Billigkeit“ vor al-

${ }^{66}$ BBK, B 330/1314, J 2, Zur Frage des Übergangs von der EZU zum EWA, 31.5.1957.

67 Vgl. BAK, B 136/2595, o. V., Ressortbesprechung am 3.6.1957 zur Vorbereitung der Arbeitsgruppe 19 der OEEC, o.D.; BAK, B 102/12598, I A 1, Vermerk für die Sitzung des Abteilungsleiterausschusses für Konjunkturpolitik, 12.7.1957.

${ }^{68} \mathrm{Vgl}$. IWF-Abkommen, Art. IV, Abschnitt 5, abgedruckt in: BGBL $1952 \mathrm{II}, \mathrm{S} .638 \mathrm{ff}$.

${ }^{69}$ Zwar war die deutsche Handelsbilanz zum Dollarraum noch immer negativ, doch in einem de-facto-konvertiblen System sollte nicht das, sondern vielmehr die Gesamtbilanz und die Währungsreserven den Ausschlag geben. Die konvertiblen Währungsreserven der Bundesrepublik beliefen sich Ende 1955 auf 9618 Mio. DM, die Nettoauslandsposition gar auf 13141 Mio. DM. Das entsprach fast fünf bzw. fast sieben Monatseinfuhren. Vgl. Monetäre Statistiken, S.5 und S. 346.

${ }^{70}$ Erhard, "Konjunktur und Außenwirtschaft", in: Die Zeit, Nr.24, 14.6.1956, S. 1 f. 
lem an Abwertungen der anderen Währungen dachte, so lehnte er eine Aufwertung der DM nicht prinzipiell $\mathrm{ab}^{71}$.

Mit seiner Initiative stach Erhard in ein Wespennest. Aufgrund seiner Äußerungen setzte eine massive Spekulation auf eine Aufwertung der DM ein. Die deutschen EZU-Überschüsse stiegen von schon beachtlichen 86,2 Mio. RE im Mai auf 114,2 Mio. RE im Juni an ${ }^{72}$. Darüber hinaus hatte Erhard mit seinen ÄuBerungen für erhebliche Verstimmung im In- und Ausland gesorgt. Die Bank von England bezeichnete Erhards Vorstoß als "wholly deplorable, whether viewed as a means of achieving his object or from the point of view of international courtesy ${ }^{473}$. Macmillan fand Erhards Vorschlag und vor allem das sich daran anschließende Interview mit der Financial Times höchst unglücklich und stellte fest, es vertrüge sich nicht mit den gemeinsamen Zielen und Interessen. Er lehnte jedwede britische Teilnahme in einer Diskussion über die Wechselkurse kategorisch $\mathrm{ab}^{74}$. Im Inland reagierte vor allem die BdL, unterstützt von der deutschen OEEC-Delegation, heftig. Sie mißbilligte jegliche Veränderung der DM-Parität. Ein Grund für diese Haltung lag darin, daß sie die Entwicklung der Preisniveaus anders als Erhard einschätzte. Emminger stellte fest, daß sich zwar die deutschen und britischen Einzelhandelspreise erheblich auseinander entwickelt hätten. $\mathrm{Er}$ hob aber hervor, daß die Entwicklung der britischen und deutschen Ausfuhrpreise parallel verlaufen $\operatorname{sei}^{75}$. Hinzu kam, daß die Bank erhebliche formalrechtliche und prinzipielle Bedenken hatte. Emminger wies auf die Statuten des IWF hin, und Vocke betonte, daß Wechselkursänderungen prinzipiell nicht wünschenswert seien. Das war seines Erachtens „die falsche Einstellung“: „Wenn man immer wieder die Wechselkurse als Gegenstand von Revisionen und Korrekturen nach unten oder oben ansieht, so wird man denjenigen Vorschub leisten, die die Währungsparität und ihre Veränderungen als ein Instrument des Handelskrieges und des Wettbewerbs betrachten, wie das ja in den letzten 20 Jahren leider Gottes nur zu oft geschehen ist, allerdings, ohne daß die, die die Abwertung vorgenommen haben, davon einen nachhaltigen Nutzen gehabt hätten. ${ }^{76}$ So waren für die Ablehnung einer Aufwertung weitgehend Prinzipien entscheidend. Die Exportinteressen hingegen spielten keine Rolle für die Haltung der Bank. Em-

${ }^{71}$ BBK, B 330/3172, Erhard an Macmillan, 3.7.1956; Erhard, Exposé zur intervalutaren Lage, 3.7.1956.

72 Vgl. BdL, Monatsberichte, diverse Ausgaben. Schon vor Erhards Artikel in „Die Zeit“ wurde auf eine Aufwertung der DM spekuliert. Der Zentralbankrat hatte sich deshalb am 13.6.1956 veranlaßt gesehen, eine Presseverlautbarung herauszugeben. Darin wurde betont, daß Bundesregierung und BdL eine Aufwertung nicht in Erwägung ziehen. Vgl. BBK, B 330/94, ZBR, Protokoll, 13.6.1956.

${ }^{73}$ BoE, OV 46/75, Bolton, Anglo-German Exchange Relations, 12.7.1956.

${ }^{74}$ Am 11.7.1956 schrieb Macmillan zwei Briefe an Erhard, vor und nach der Lektüre der Financial Times. Vgl. PRO, PREM 11/1321.

$75 \mathrm{Vgl.} \mathrm{BBK}, \mathrm{B}$ 330/95, ZBR, Stenogramm, 11.7.1956.

${ }^{76}$ BBK, NL Emminger, Wechselkursfrage, Vocke an Erhard, 19.6.1956; Emminger an Erhard, 18.6.1956, von Mangoldt an Erhard, 25.6.1956. Vgl. auch BoE, OV 46/75, Vocke an Cobbold, 17.7.1956. 
minger war sogar der Meinung, die deutsche Exportindustrie könne eine „mäßige Aufwertung" durchaus verkraften ${ }^{77}$.

$\mathrm{Da}$ die Idee einer europäischen Wechselkursanpassung offensichtlich wenig Gegenliebe fand, aber auch weil weder das Wirtschaftsministerium noch Erhard entschlossen waren ${ }^{78}$, wurde eine Aufwertung der DM nicht weiter verfolgt. Um weiterer Spekulation vorzubeugen, nahm die Bundesregierung im Juni mit einer offiziellen Stellungnahme von einer DM-Aufwertung Abstand ${ }^{79}$. Doch wenn nach diesem Dementi auch die spekulativen Devisenzuflüsse leicht zurückgingen, war das Thema einer Aufwertung nicht erledigt. Bei weiteren deutschen Handelsbilanzüberschüssen kam es schon im Herbst 1956 aus Anlaß der Suez-Krise zu erneuten spekulativen Devisenzuflüssen. Die Diskussion um eine Aufwertung der DM lebte wieder auf. Inzwischen hatte sich das Meinungsbild innerhalb der $\mathrm{BdL}$ verändert. Nun befürwortete Emminger eine Aufwertung. Da weder die spekulativen Zuflüsse noch die „echten “ Handelsbilanzüberschüsse in der nächsten Zeit nachlassen würden, müsse wegen der inneren Stabilität, und um eine Entlastung der Geldpolitik zu erreichen, aufgewertet werden. Falls die DM nicht aufgewertet würde, würden die europäischen Diskrepanzen festgeschrieben. Dadurch entzöge man dem deutschen Wirtschaftskreislauf Güter und behindere nützliche inländische Investitionen, nur „um die (viel weniger wichtige) Investition in Devisenreserven “ fortsetzen zu können ${ }^{80}$.

Obgleich nun einige Mitglieder des Zentralbankrates Emmingers Analyse zustimmten ${ }^{81}$, laut der Bank von England im Herbst 1956 sogar innerhalb der BdL eine beträchtliche Unterstützung für eine DM-Aufwertung zu finden war ${ }^{82}$, der Wissenschaftliche Beirat beim Wirtschaftsministerium für eine Aufwertung eintrat $^{83}$ und auch das EZU-Direktorium die Notwendigkeit fundamentaler Maßnahmen ansprach ${ }^{84}$, blieb Vocke bei seiner strikten Ablehnung einer Aufwertung. In autokratischer Weise, ohne das Thema im Zentralbankrat zur Diskussion zu stellen und ohne durch einen Beschluß des Zentralbankrates gedeckt zu

77 BBK, B 330/95, ZBR, Stenogramm, 11.7.1956.

${ }^{78}$ Vgl. BBK, B 330/2030, Könneker an Vocke, 14.7.1956. Zu Erhard stellte Könneker fest: „Wie Erhard denkt, weiß man in Wirklichkeit nicht."

${ }^{79}$ Vgl. Bulletin des Presse- und Informationsamtes, Nr. 128, 13.6.1956.

${ }^{80}$ BBK, NL Emminger, Wechselkursfrage, IV, Vermerk, 10.11.1956.

81 York Hoose, Präsident der Landeszentralbank Niedersachsen, befürwortete beispielsweise eine Aufwertung. Vgl. BBK, B 330/103, ZBR, Stenogramm, 12.6.1957; Hoose, Aufwertung, S. $461 \mathrm{ff}$.

${ }^{82} \mathrm{Vgl}$. BoE, OV 46/75, Fenton, Germany, 29.10.1956.

${ }^{83}$ Vgl. Wissenschaftlicher Beirat beim Bundeswirtschaftsministerium, Gutachten vom 30.4.1957, S. $333 \mathrm{ff}$.

${ }^{84}$ Vgl. BBK, B 330/103, ZBR, Protokoll, 26. 6. 1957; Bericht über die Sitzung des Ministerstellvertreterausschusses am 17./18.6.1957. Die Meinung in Paris war keineswegs einheitlich. Es gab Befürworter und Gegner einer DM-Aufwertung. Vgl. HAEC, OEEC-TRA 358, Kirschen, Les theories économiques et politiques de Mr. Cahan, 4.1.1957. Die Bank von England befürchtete, eine Aufwertung der DM würde den europäischen Dollaranfall insgesamt verkleinern. Vgl. BoE, OV 34/96, Gunn an Tomkin, 4.10.1957. 
sein, bezog er wiederholt gegen eine Aufwertung Stellung ${ }^{85}$. Dies sorgte zwar für einigen Unmut. Hermann Tepe, Präsident der Landeszentralbank Bremen, monierte Vockes Vorgehen und vor allem die Tatsache, daß er „dem Zentralbankrat bisher [...] die Tatsache offenbar sehr eingehender Diskussionen des Themas zwischen Ihnen und den Bundesministern und Ihre vorliegende Stellungnahme offenbar bewußt vorenthalten [hat]". In diesem Zusammenhang bezweifelte er, „ob es zweckmäßig ist, die Minister in einer so grundlegenden Frage der Währungspolitik nur mit Ihrer persönlichen Ansicht zu versehen, so wertvoll sie zweifellos immer ist ${ }^{\text {"86 }}$. Trotzdem konnte sich Vockes Ansicht letztendlich durchsetzen. Während seine Meinung die Unterstützung von Adenauer und dem Auswärtigen Amt, von Blücher, der deutschen OEEC-Delegation und dem Ministerium für wirtschaftliche Zusammenarbeit, von IWF-Direktor Per Jacobsson, dem Kanzlerberater und Bankier Hermann J. Abs sowie der deutschen Exportindustrie fand ${ }^{87}$, diskutierte der Zentralbankrat die Aufwertungsfrage nicht und blieb konsequenterweise in seinem Urteil unsicher. Im Sommer 1957 hatte Bernard, trotz inzwischen einjähriger öffentlicher Diskussion über eine Anpassung der Wechselkurse, noch immer keine Meinung ${ }^{88}$. Erst in der Zentralbankratsitzung am 21./22. August 1957, nachdem der Bundeskanzler angesichts der inzwischen bedrohlichen Spekulation eine gemeinsame Verlautbarung von Bundesregierung und Bundesbank gefordert und erhalten hatte ${ }^{89}$, wurde in Aussicht genommen, über dieses Thema „demnächst“ eine „längere Diskussion“ zu führen ${ }^{90}$. Bevor es jedoch zu dieser ausführlicheren Diskussion kommen konnte, schwächte sich die Währungsspekulation im September 1957 im Anschluß an eine deutsche Diskontsenkung um ein halbes Prozent und vor allem nach einer britischen Diskonterhöhung um zwei Prozent ab. Sie kehrte sich sogar zum Teil um ${ }^{91}$. Das Thema der Aufwertung verlor dadurch an Brisanz.

Die Haltung des Zentralbankrates zur Aufwertung der DM erklärt sich zu großen Teilen also aus den innerhalb des Zentralbanksystems herrschenden Machtpositionen und dem Führungsstil Vockes. Das hat auch schon Emminger

${ }^{85}$ BBK, B 330/2021, Vocke an Erhard, 2.5.1957. Keineswegs stand Vocke damit in der BdL alleine. Der gleichen Meinung war Tüngeler. Vgl. BBK, B 330/2047, Tüngeler an Vocke, 24. 4.1957.

${ }^{86}$ BBK, B 330/2047, Tepe an Vocke, 21.5.1957.

${ }^{87}$ Vgl. BAK, B 136/7864, Haenlein, Probleme der deutschen Devisenüberschüsse, 13. 9.1957; BAK, B 136/2595, Blücher, Überlegungen an Müller-Armack, 6.9.1957; BBK, B 330/2028, Jacobsson an Vocke, 24.4.1957. Für Abs vgl. Abs, Aufwertung. Für die Exportindustrie vgl. BAK, B 136/7864, Praß an Bundeskanzler, 13.9.1957; BBK, B 330/2015, Brinckmann an Vocke, 22.7.1957.

${ }^{88}$ Vgl. BBK, B 330/133, ZBR, Stenogramm, 21./22. 8.1957.

${ }^{89}$ Vgl. BAK, NL Schäffer 34, Hartmann, Vermerk zur Kabinettssitzung vom 20.8.1957; Bulletin des Presse- und Informationsamtes, Nr.153, 21.8.1957.

${ }^{90}$ BBK, B 330/133, ZBR, Stenogramm, 21./22.8.1957.

91 Damit liegt die Vermutung nahe, diese Diskontsenkung sei der Preis gewesen, den der Zentralbankrat für die Ablehnung einer Aufwertung zahlte. Für eine solche Annahme spricht, daß sie erfolgte, obwohl Geldvolumen und Kreditgewährung weiterhin anstiegen. Vgl. Deutsche Bundesbank, Monatsbericht Dezember 1958, S. 30 und S.34. Dagegen spricht, daß der Zentralbankrat in der entsprechenden Sitzung festhielt, die Kreditexpansion sei in der ersten Monatshälfte rückläufig gewesen. Vgl. BBK, B 330/134, ZBR, Stenogramm, 18.9.1957. 
in seinen Memoiren herausgestellt ${ }^{92}$. Hinzu kam aber auch, daß in der deutschen Zentralbank in bezug auf die internationale Währungspolitik Beharrungstendenzen existierten und es somit zu einer beachtenswerten Zeitverzögerung zwischen der außenwirtschaftlichen Entwicklung und dem Niederschlag dieser Entwicklung in Diskussionen bzw. Beschlußfassungen kam. Wie Bernard im August 1957 freimütig einräumte, war für ihn das Verhältnis der DM zum Dollar bisher eben einfach ein „Datum“ gewesen ${ }^{93}$. Da solche Beharrungstendenzen in der Bank vorherrschten und die deutsche Zentralbank die Möglichkeit einer Aufwertung nicht nachhaltig prüfte, kann man ihr eine fehlerhafte Politik vorwer$\mathrm{fen}^{94}$. Gleichwohl ist festzuhalten, daß sich ihr Standpunkt nicht vollständig mit Beharrungstendenzen erklären läßt. Vielmehr war der Zentralbankrat auch der Meinung, ein gewisser Druck auf die anderen europäischen Währungen solle aufrechterhalten werden, denn dadurch sollten die anderen Länder zur "Gesundung" gezwungen werden. Im August 1957 faßte Bernard den Standpunkt des Zentralbankrates zusammen: „Ferner bleibt zu bedenken, inwieweit man bei denjenigen Volkswirtschaften, bei denen wir alle meinen, daß ihre Währungen falsch liegen, eine Adjustierung verhindert, wenn wir u.U. vorzeitig etwas derartiges (abwerten, M.D.) tun. Muß man nicht solange Geduld haben und darf man nicht vorzeitig schwach werden? Jetzt hat bereits Frankreich angefangen; es wird ihm zugeredet, noch etwas mehr zu tun. England steht unter diesem Druck; Holland auch. Ist es zu verantworten, daß wir die möglicherweise heilsame Entwicklung, die wir für die Gesamtgesundung eigentlich benötigen, im ungünstigen Sinne dadurch beeinflussen, daß wir von uns aus etwas Bestimmtes tun? ${ }^{\text {“95 }}$

\section{Importförderung und Abbau der Exportförderung}

Im November 1956 stellte A.M. Stamp von der Bank von England in einem Vermerk kategorisch fest: "The fundamental trouble is that Germany is exporting too much and importing too little. ${ }^{\text {"96 }}$ Sofern man dieser Meinung beipflichtete, mußten Maßnahmen zur Importsteigerung und Exportbegrenzung ergriffen werden. In bezug auf die Importe konnte die deutsche Wirtschaftspolitik nur durch Zollermäßigungen oder anderweitige Importförderungsmaßnahmen eingreifen. Zum einen konnten die Importe angesichts des hohen Liberalisierungssatzes nicht mehr wesentlich durch einen Abbau der mengenmäßigen Beschränkungen erhöht werden"; zum anderen lehnte die Zentralbank eine Stimulierung der Importe durch Ausweitung der internen Nachfrage mittels geldpolitischer Maßnahmen ab, so daß es neben Zollabbau und speziellen Importförderungsmaßnahmen

92 Vgl. Emminger, D-Mark, S. $78 \mathrm{ff}$

${ }^{93}$ BBK, B 330/133, ZBR, Stenogramm, 21./22. 8.1957.

${ }_{94}$ Grosser/Müller-Armack, Marktwirtschaft, S.87f. werfen der Bank einen Analysefehler vor.

${ }^{95}$ BBK, B 330/133, ZBR, Stenogramm, 21./22. 8.1957.

$96 \mathrm{BoE}, \mathrm{OV} 46 / 75$, Stamp, German surplus and the future of Sterling, 1.11.1956.

${ }^{7}$ Im Jahre 1955 betrug der Liberalisierungssatz bereits $91,5 \%$. Bis Juli 1958 wurde er in kleinen Schritten auf $94 \%$ erhöht. 
andere Optionen nicht gab. In bezug auf die Exporte bot sich neben dirigistischen, exportbeschränkenden Maßnahmen vor allem der Abbau der während der Koreakrise eingeführten Exportförderungsmaßnahmen an ${ }^{98}$.

Seit Anfang 1955 befürworteten Erhard und Schäffer Zollsenkungen. Dadurch wollten sie sowohl den Preissteigerungen als auch den Überschüssen entgegenwirken ${ }^{99}$. Doch wenn sie auch mehrere entsprechende Vorstöße unternahmen, konnten sie sich letztendlich nicht durchsetzen, denn Zollsenkungen begegneten erheblicher Opposition. Das Ministerium für Landwirtschaft lehnte Zollsenkungen für Agrarprodukte ab. Der Bundestag war nicht bereit, auf seine zollpolitischen Kompetenzen zu verzichten. Ferner hielt es Adenauer zusammen mit seinem Berater Fritz Berg für „ganz unmöglich“, daß sein Wirtschaftsminister die Zollsätze bestimmt ${ }^{100}$. So konnten im Verlauf der Jahre nur mehrere sogenannte konjunkturpolitische Zollsenkungen verfügt werden, die für einzelne Produkte für eine bestimmte Zeit galten ${ }^{101}$. Doch schon zeitgenössische Beobachter bemängelten, daß diese Maßnahmen zu begrenzt und insgesamt wirkungslos wa$\operatorname{ren}^{102}$. Trotzdem konnte eine lineare Zollsenkung, die der Wirtschaftsminister befürwortete und die er im Sommer 1957 schon lautstark der OEEC angekündigt hatte, nicht beschlossen werden. Von Bedeutung war dabei, daß der Zentralbankrat zwar Erhards Ansinnen befürwortete, jedoch in seiner Befürwortung blaß blieb $^{103}$. Zwar hatte er schon im Jahre 1956 Zollsenkungen begrüßt und dabei sogar den Einschluß von landwirtschaftlichen Produkten gefordert. Davon versprach er sich einen Abbau der Überschüsse und eine Stabilisierung der Preise ${ }^{104}$. Da sich aber im weiteren Verlauf das Konjunkturbild wieder ausgeglichener zeigte und mit dem Ansteigen der ausländischen Preisniveaus eine wichtige Funktion der Zollsenkungen, die Stabilisierung der Preise, nicht mehr gegeben war, ließ das Interesse der Zentralbank schnell wieder nach ${ }^{105}$.

Der Abbau von Exportförderungsmaßnahmen war schon im Jahre 1953/54 Thema internationaler Diskussionen gewesen. Obwohl Erhard einen solchen Ab-

${ }^{98}$ Neben einer steuerlichen Förderung wurden die deutschen Exporte durch besonders günstige Finanzierungsmöglichkeiten gefördert. Für die Exportkredite der Kreditanstalt für Wiederaufbau oder der AKA Ausfuhrkredit-Gesellschaft galten spezielle Refinanzierungsbestimmungen. Darüber hinaus war im Jahre 1950 das Exporttrattenverfahren als eine billige Finanzierungsmöglichkeit eingerichtet worden. Hier zog der Exporteur auf seinen ausländischen Abnehmer eine Tratte, die zu besonderen Diskontsätzen rediskontiert werden konnte.

${ }^{99}$ Vgl. BAK, B 136/378, Erhard/Schäffer an Bundeskanzleramt, Februar 1955. Vgl. hierzu auch Asbeek Brusse, Tariff Plans, S. $290 \mathrm{ff}$.

100 BAK, B 136/378, Auszug aus dem Kabinettsprotokoll, 3.3.1955; BAK, B 136/652, Adenauer an Erhard, 6.9.1955.

101 Im Herbst 1955 wurden 120 Zollsenkungen für die Zeit vom 1.12.1955 bis 30.6.1956 beschlossen. Anfang 1956 folgten - befristet auf die Zeit 15.1.1956 bis 30.6.1956 - weitere Zollsenkungen. Im Juli 1956 wurde diese Zollsenkung verlängert und nochmals erweitert.

102 Vgl. Gr, „Konjunkturpolitische Zollsenkung“, in: Der Volkswirt Nr. 47/1955, S. 5.

${ }^{103}$ Vgl. BAK, B 136/2595, Ressortbesprechung zur Vorbereitung der Arbeitsgruppe 19 der OEEC, 3.6.1957.

104 Vgl. BBK, B 330/94, ZBR, Stenogramm, 18.5.1956.

105 Vgl. BBK, B 330/103, ZBR, Stenogramm, 12.6.1957 
bau öfters lauthals forderte, hatte die Bundesrepublik letztlich Zurückhaltung geübt. Erst solle es - so beharrten deutsche Vertreter im Jahre 1954 bei den entsprechenden Diskussionen mit dem Vereinigten Königreich - vollkommen eindeutig sein, daß die deutschen Überschüsse strukturell seien ${ }^{106}$. In der zweiten Hälfte der fünfziger Jahre ließ die Klarheit nicht mehr zu wünschen übrig. Innerhalb der Zentralbankrates bestanden trotzdem Zweifel. So fragte Bernard in einer Zentralbankratsitzung: „Gibt es denn heute Tatbestände, die es völlig eindeutig ausschließen, daß unsere starke Überschußposition nur ephemer sein könnte? Läßt sich heute bereits apodiktisch sagen: Das kann nicht ephemer sein, sondern es zeichnet sich heute bereits ab: Das ist unter allen Umständen etwas Strukturelles. " ${ }^{107}$

Bei solchen Zweifeln ging ein Abbau der Förderungsmaßnahmen nur langsam voran. Zwar erklärte Vocke schon 1955 dem BDI-Vorsitzenden Fritz Berg unumwunden, daß eine Förderung des Exportes nicht mehr nötig sei ${ }^{108}$. Auch plädierte Vocke seit November 1956 für eine Einstellung des Exporttrattenverfahrens ${ }^{109}$. Dieser Vorschlag fand aber im Zentralbankrat nur mäßige Zustimmung. Wenn auch der Zentralbankrat behauptete, den Export in den EZU-Raum nicht mehr subventionieren zu wollen, wurden in der Diskussion über die Abschaffung des Exporttrattenverfahrens die möglichen Schwierigkeiten für die Exportindustrie herausgestellt. Das Protokoll der Zentralbankratsitzung hielt fest: „Bei aller grundsätzlichen Würdigung dieser Argumentation tragen einige Mitglieder Bedenken [...], weil namentlich kleine und auch mittlere Exportfirmen darin eine erhebliche Erschwerung ihres Exportes sehen würden. " 110

Aus diesem Grund wollte der Zentralbankrat das Exporttrattenverfahren nur mit „angemessenen Übergangsregelungen“ zum 30. November 1957 auslaufen lassen ${ }^{111}$. Den endgültigen Ausschlag für diese Entscheidung gab dabei das Kursrisiko, das die Bank bei auf französischen Franken lautenden Tratten übernahm ${ }^{112}$. Insgesamt muß festgehalten werden, daß zwar Exportförderungsmaßnahmen abgebaut wurden. Das geschah aber nur allmählich und hatte deutliche Grenzen. Keinesfalls wurden dabei alle Maßnahmen aufgehoben ${ }^{113}$. Weiterhin war die Rede davon, „daß die Pflege des deutschen Exports notwendig ist“"114.

106 Vgl. PRO, FO 371/109620, Beckett, Minutes, 30.4.1954.

107 BBK, B 330/135/I, ZBR, Stenogramm, 16.10.1957.

${ }^{108}$ Vgl. BBK, B 330/2015, Vocke an Berg, 18.10.1955.

${ }^{109}$ Vgl. BBK, B 330/98, Vocke, Einstellung des Ankaufs von Exporttratten, 9.11.1956.

110 BBK, B 330/98, ZBR, Protokoll, 28.11.1956.

111 BBK, B 330/133, ZBR, Protokoll, 21./22. 8.1957. Allerdings hatte der Zentralbankrat schon Anfang 1957 eine Beschränkung dieses Verfahrens beschlossen. Vgl. BBK, B 330/99, ZBR, Protokoll, 9./10.1.1957.

112 Vgl. BBK, B 330/2057, Direktorium, Protokoll, 22.7.1957.

113 Auslandswechsel wurden seit Mai 1956 nicht mehr zu Vorzugssätzen hereingenommen. Auch wurden sie auf das Rediskontkontingent angerechnet. Vgl. BBK, B 330/94, ZBR, Protokoll, 18.5.1956. Der AKA Plafonds B blieb bestehen, wurde aber reduziert. Vgl. BBK, B 330/99, ZBR, Stenogramm, 6.2.1957. Über die Ausmaße der noch 1958 existierenden kreditpolitischen Exportförderung unterrichtet: BoE, OV 34/43, o. V., Germany - Official Export Credit, 3.7.1958.

114 BAK, B 136/2595, Turowsky, Vermerk, 4.6.1957. 
Während gewisse Exportförderungsmaßnahmen trotz aller Überschüsse in Kraft blieben, beschloß der Zentralbankrat aber vergleichbare kreditpolitische Maßnahmen zur Förderung des Importes nicht. Die Gründe dafür waren vielfältig. Zum einen sollten laut dem Zentralbankrat Notenbankinstrumente prinzipiell nicht zur Importförderung eingesetzt werden. Er berief sich auf die Prinzipien der Marktwirtschaft und lehnte solche dirigistischen Maßnahmen ab - zumal sie die Restriktionspolitik unterlaufen würden: „Beispielsweise würde die Nichtanrechnung oder die teilweise Nichtanrechnung eines auf Importgeschäften beruhenden privilegierten Wechseltyps auf die Rediskontkontingente auf eine bedenkliche Aufweichung der kreditpolitischen Grundhaltung hinauslaufen [...]. Eine so einschneidende und den Prinzipien der Marktwirtschaft zutiefst widersprechende Maßnahme, wie sie in einer Politik des gespaltenen Diskontsatzes zu erblicken wäre, erscheint um so weniger vertretbar, als der Erfolg einer kreditpolitischen Verbilligungsaktion durchaus ungewiß wäre. "115 Zum zweiten war die Einsicht, daß der Import gesteigert werden mußte, im Zentralbankrat keineswegs fest verwurzelt. Der Präsident der Landeszentralbank Niedersachsen, York Hoose, formulierte zum Beispiel noch im Sommer 1956: „Es ist heute eigentlich nicht so ganz klar zu erkennen, warum à tout prix der Import gefördert werden sollte." ${ }^{116}$ Auch als im Sommer 1956 die Regierung und der Großund Außenhandelsverband vehement für eine kreditpolitische Erleichterung der Importe plädierten, konnte sich der Zentralbankrat nicht zu einer Förderung der Importe durch notenbankpolitische Mittel durchringen ${ }^{117}$.

Als Ergebnis dieser Politik stiegen zwar, wie Tabelle 13 zeigt, die Importe zeitweise erheblich an, die Steigerungsraten blieben aber noch immer hinter den Exporten zurück. Während die Exporte im Zeitraum von 1955 bis 1958 um fast 30 Prozent stiegen, betrug das Wachstum der Importe nur 20 Prozent.

\section{Linderungsmaßnahmen}

Im Sommer 1956 schlug der deutsche Vertreter im EZU-Direktorium Hans Karl von Mangoldt vor, die Bundesrepublik könne der EZU zwecks Erleichterung der europäischen Zahlungsbilanzspannungen weitere Rallongen oder gar Sonderkredite gewähren. Wenngleich solche und andere Maßnahmen von den Briten nur als „sinnvolle Linderungsmaßnahmen“ angesehen wurden ${ }^{118}$, erfreuten sie sich einiger Beliebtheit. Im Juli 1956 schlugen die Briten einen vorzeitigen Abbau der deutschen Auslandsverschuldung und Vorauszahlungen auf ein Rüstungskonto vor. Die Weltbank regte die Einzahlung der deutschen Subskription an.

115 BBK, B 330/95, ZBR, Protokoll, 25.7.1956. Diese Meinung vertrug sich schlecht mit den kreditpolitischen Exportförderungsmaßnahmen. Dessen war sich der Zentralbankrat bewußt. Er stellte hierzu fest, er wolle den damals gemachten Fehler nicht wiederholen.

116 BBK, B 330/95, ZBR, Stenogramm, 27.6.1956.

117 Vgl. BBK, B 330/95, ZBR, Protokoll, 27.6.1956; ZBR, Protokoll, 25.7.1956; BMWi an Bernard, 11.7.1956.

118 Vgl. BoE, OV 46/75, Rowan, Note on a talk with von Mangoldt, 17.7.1956. 
Tabelle 13: Deutsche EZU-Im- und-Exporte 1956-1958

\begin{tabular}{lcc} 
& $\begin{array}{c}\text { Importe } \\
\text { Steigerung in \% } \\
\text { zum Vorjahresquartal }\end{array}$ & $\begin{array}{c}\text { Exporte } \\
\text { Steigerung in \% } \\
\text { zum Vorjahresquartal }\end{array}$ \\
\hline I 1956 & 3,0 & 10,8 \\
II 1956 & 9,1 & 24,7 \\
III 1956 & 5,8 & 21,7 \\
IV 1956 & 6,0 & 18,7 \\
I 1957 & 14,0 & 27,9 \\
II 1957 & 3,8 & 11,2 \\
III 1957 & 8,4 & 14,4 \\
IV 1957 & 10,6 & 8,1 \\
I 1958 & 6,3 & 1,5 \\
II 1958 & 2,9 & $-0,8$ \\
III 1958 & 3,6 & 0,7 \\
IV 1958 & 2,1 & $-0,2$ \\
\hline
\end{tabular}

Anmerkungen: berechnet nach Einkaufs- und Käuferländern.

Quelle: Außenhandel der BRD, Januar 1956, 23; Januar 1958, 23; Dezember 1958, 23.

Innerhalb der Bundesrepublik trafen derartige Vorschläge keineswegs nur auf Gegenliebe. Aus Haushaltsgründen lehnte der Finanzminister eine vorzeitige Schuldenrückzahlung ab. Auch eine Einzahlung der deutschen Subskriptionsquote für die Weltbank mißbilligte er ${ }^{119}$. Allerdings trafen diese Vorschläge auf das Wohlwollen der BdL. Selbst auf die Gefahr hin, daß ihr bei einem vorzeitigen Schuldenabbau der Gegenposten zu dem deutsch-britischen Konsolidierungsabkommen von 1954 fehlen würde, setzte sie sich für eine vorzeitige Rückzahlung der Schulden ein ${ }^{120}$. Letztendlich ermöglichte sie dies dadurch, daß sie dem Finanzminister einen Kredit zum Kauf der erforderlichen Devisen einräum$t^{121}$. Ähnlich verhielt sich die deutsche Zentralbank bei der Einzahlung der deutschen Subskriptionsquote für die Weltbank. Auch hier sagte sie dem Finanzminister eine Vorfinanzierung $\mathrm{zu}^{122}$. Auch der Einrichtung eines Rüstungskontos stand sie positiv gegenüber. Allerdings drängte sie hier auf Sicherstellung gegen mögliche Wechselkursänderungen ${ }^{123}$.

119 Vgl. BBK, NL Emminger, Wechselkursfrage, Emminger, Englische Vorschläge zur Milderung der Zahlungsbilanzspannungen, 17.8.1956; BBK, B 330/2057, Direktorium, 22.11.1956.

${ }^{120} \mathrm{Vgl}$. BBK, B 330/1310, Emminger an von Mangoldt, 23.8.1956. Im Rahmen der EZU-Konsolidierungsaktion hatten das Vereinigte Königreich und die Bundesrepublik im Sommer 1954 ein Abkommen abgeschlossen. Dieses sah vor, daß die jährliche Rate, die das Vereinigte Königreich an die Bundesrepublik zahlen sollte, gegen die jährliche Rate aus den deutschen Nachkriegsschulden verrechnet würde. $\mathrm{Zu}$ den entsprechenden Verhandlungen vgl. S. $172 \mathrm{ff}$.

121 Vgl. BBK, B 330/2057, Direktorium, Protokoll, 25.10.1956 und 7.1.1957.

122 Vgl. BBK, B 330/99, ZBR, Protokoll, 23.1.1957.

123 Vgl. BBK, NL Emminger, Wechselkursfrage, o.V., Germany's EPU surplus and possible German Arms Purchases in UK, o.D. Der Finanzminister übernahm letztendlich eine Kursgarantie für 
Insgesamt erwies sich die deutsche Zentralbank, insoweit „sinnvolle Linderungsmaßnahmen" betroffen waren, als ausgesprochen kooperationsbereit. Das Vereinigte Königreich hob das in mehreren Gelegenheiten hervor und würdigte die Bemühungen der Bank: „It is relevant to note, the German Government have been spared putting up 90 million (Pound Sterling, M.D.) which will have been done exclusively by the BdL from its foreign exchange reserves. To put it bluntly: it seems to us that the German Government have been lucky in having the BdL to dig them out of a nasty hole." ${ }^{124}$

Die Erklärung dafür, daß die Bank nur derartige Linderungsmaßnahmen befürwortete, liegt darin, daß sie zwar an einer Entschärfung der Ungleichgewichte und an einer Entlastung der britischen Situation interessiert war, gleichzeitig aber grundlegende Maßnahmen für unnötig hielt. Wie im folgenden gezeigt wird, waren damit erhebliche Vorteile, vor allem ein Anwachsen ihrer Machtposition und eine Stärkung ihrer Führungsrolle in Europa, verbunden.

\section{Die dentsche Zentralbank im de-facto-konvertiblen EZU-System}

Die Jahre 1955 bis 1958 waren eine Probezeit des de-facto-konvertiblen EZUSystems. In diesem Zeitraum war dieses Währungssystem mit einigen Problemen - Ungleichgewichten, deutschen Überschüssen, Spekulation - konfrontiert. Mit diesen mußte sich die deutsche Zentralbank beschäftigen. Gleichzeitig mußte sie ihrer zentralen Aufgabe, der Bewahrung der Preisstabilität, nachkommen.

In den Jahren 1955 bis 1958 verfolgte die Bank eine Politik der Restriktion und Passivität. Um die Geldwertstabilität zu bewahren, ergriff die Zentralbank restriktive Maßnahmen und kümmerte sich nicht um die außenwirtschaftlichen Folgen dieser Politik. Für das Festhalten an dieser restriktiven Linie war die Preisstabilität keineswegs das einzige Motiv. Wichtig war auch, daß die Bank ihren Handlungsspielraum als begrenzt einschätzte. Tatsächlich war ein Großteil der Überschüsse auf die Spekulation in Auf- oder Abwertung zurückzuführen, und deshalb lag eine Zinsreagibilität nicht vor. Zinssenkungen waren sinnlos und konsequenterweise abzulehnen. Selbst wenn Erhard es nicht beabsichtigte, so hat er mit seinen Aufwertungsvorstößen der deutschen Geldpolitik einen guten Dienst erwiesen, denn damit hat er ihr eine kreditpolitische Abstinenz ermöglicht. Aber auch in bezug auf die Außenwirtschaftspolitik sah sich die Bank nicht zu durchgreifenden Maßnahmen veranlaßt. Vielmehr war es nur ihr Ziel, die Überschüsse zu lindern, und dementsprechend machte sie sich nur für begrenzte Maßnahmen

eine Devisenanlage der Deutschen Bundesbank bei der Bank von England in Höhe von 75 Mio. $£$. Vgl. BGBL 1957 I, S.1745. Vgl. hierzu auch BBK, B 330/98, ZBR, Protokoll, 28.11.1956 und 19.12.1956; BBK, B 330/99, ZBR, Protokoll, 9./10.1.1957 und 6.2.1957; BBK, B 330/101, ZBR, Protokoll, 6.3.1957.

${ }^{124}$ BoE, OV 34/42, Rootham an Rickett, 17.1.1957. Vgl. auch BoE, OV 46/62, Fenton, EPU UKGerman Amortisation Agreement, 26.7.1957: „The fact that the operation has nevertheless taken place is, I gather, entirely due to the pressure exerted by the BdL.“ 
stark. Fundamentale Mittel wie eine Aufwertung lehnte sie ab. Wenngleich sie sich in vielen Gelegenheiten für eine Importsteigerung und für den Abbau der Exportförderung aussprach, verfolgte sie diese nicht mit dem entsprechenden Nachdruck. Modifikationen des internationalen oder europäischen Währungssystems hielt sie für unangebracht. Ohne offiziell von dem Konzept der Konvertibilität Abstand zu nehmen, votierte sie weiterhin für die EZU.

Eine derartige Politik der Restriktion und Passivität brachte Probleme mit sich. Während die Bank einen "geradezu verzweifelten Kampf" gegen die aus den Überschüssen resultierende Liquidisierung führen mußte ${ }^{125}$, bestanden die deutschen Überschüsse fort. Die deutschen Reserven, inzwischen als sinnlose Investition angesehen, wuchsen, und die deutschen Kredite an die EZU stiegen an. Die Ungleichgewichte in der EZU verstärkten sich und konnten, je länger, je mehr, den Fortbestand der EZU gefährden. Auch konnten sie dazu führen, daß sich die europäischen Partner auf eine Diskriminierung der Bundesrepublik einigen würden. Trotzdem hielt die deutsche Zentralbank an dieser Politik fest.

Um die Politik der Zentralbank zu erklären, ist angeführt worden, daß sie in diesem Interessenkonflikt ihre Priorität auf die Bewahrung der Preisstabilität legen mußte ${ }^{126}$. Diese Erklärung hat zu Widerspruch angeregt. So stellt Heinz-Peter Spahn fest, daß der Grund für diese Politik darin liege, daß die deutsche Zentralbank „merkantilistisch“ gesinnt gewesen sei ${ }^{127}$. Als weitere Erklärung ist angeführt worden, die Bundesregierung und die Zentralbank hätten die Probleme nicht ernst genommen und sie hätten nur konzeptionslos auf sie reagiert. Schon Zeitgenossen hatten hervorgehoben, „the Germans have not (at least as yet) any real plan for coping with present difficulties and are unlikely to have much to contribute in any talks next week ${ }^{\text {“128, }}$, und entsprechend ist die internationale Währungspolitik der deutschen Zentralbank als eine Politik des "muddling through", als „unbewußt" oder als ad-hoc-Politik angesehen worden ${ }^{129}$.

Diese Erklärungen stellen nicht zufrieden. Zwar war die Bewahrung der Preisstabilität eine wichtige und entscheidende Kategorie für die Bank, doch war sie sich auch bewußt, daß sie, eingebunden in ein internationales Währungssystem, ihre Priorität nicht einfach auf die binnenwirtschaftliche Entwicklung legen konnte. Eine merkantilistische Grundhaltung, die nur an Devisenanhäufung interessiert war, lag in der zweiten Hälfte der fünfziger Jahre nicht mehr vor. Vielmehr sah die Bank zu dieser Zeit eine weitere Stärkung der Devisenreserven als

125 BBK, B 330/134, ZBR, Stenogramm, 2. 10.1957.

${ }^{126}$ Das ist die Begründung, die die Bank selbst, z. B. in ihren Geschäftsberichten, anführt. Vgl. BdL, Geschäftsbericht 1956, S. $19 \mathrm{ff}$. Ähnlich Emminger, Geld- und Währungspolitik, S. $487 \mathrm{ff}$.

127 Spahn, Wirtschaftswunder, S.75.

$128 \mathrm{BoE}$, OV 46/77, Jenkis an Rootham, 9.10.1957.

129 So beurteilten Vertreter der britischen OEEC-Delegation - vgl. PRO, PREM 11/1807, UK-Delegation an FO, 20.5.1957 - bzw. Angehörige der Federal Reserve Bank von New York - vgl. FedNY, C 261A, de Vries, German Balance of payments surplus, 20.9.1960 - die Politik der deutschen Zentralbank. Zum Begriff und zur Politik des „muddling through“ vgl. Lindblom, Muddling Through, S.79ff. 
sinnlose Investition an. Die Politik der deutschen Zentralbank als "muddling through" zu bezeichnen, ist zwar zutreffend. Doch verhüllt diese Kennzeichnung, daß eine solche Politik als angemessen angesehen und zum Teil sogar bewußt verfolgt wurde. Sie wurde als adäquat angesehen, da man zum Teil noch immer unsicher war, ob die Überschüsse wirklich strukturell seien. Sie wurde mit Absicht verfolgt, da sich die Bank in einer Auseinandersetzung mit anderen europäischen Staaten befand. In dieser Auseinandersetzung ging es darum, einen Standard zur "gesunden Währungspolitik" und Geldwertstabilität zu definieren, diesem Standard vor allem im EZU-Raum Geltung zu verschaffen und dadurch das de-facto-konvertible EZU-System zu prägen. Wenn auch richtig ist, daß ein internationales Währungssystem die Bereitschaft zur „Bescheidenheit" und zur „Durchschnittlichkeit der Geldpolitik“ verlangt ${ }^{130}$, so muß festgehalten werden, $\mathrm{da} ß$ in einem System von managed money der geldpolitische Standard nicht von Anfang an definiert ist. Vielmehr muß betont werden, daß der Durchschnitt der Addition und anschließenden Division entspricht, also das Ergebnis von Spannungen und Auseinandersetzungen ist. Im Rahmen dieser Auseinandersetzung setzte die deutsche Zentralbank Geld und gute Worte ein, bot Kooperation an, hielt Druck aufrecht und stellte der EZU Kredite zur Verfügung. Dadurch ermöglichte sie das Funktionieren der EZU. Sie verlangte aber auch Maßnahmen von den Schuldnerländern. Daß diese Forderungen einerseits einige Aussichten auf Erfolg hatten, andererseits aber an Grenzen stießen, kann am Fall der französischen Wirtschaftskrise verdeutlicht werden.

Seit spätestens Frühjahr 1956 war offensichtlich, daß sich die IV. Republik in wirtschaftlichen Schwierigkeiten befand ${ }^{131}$. Französische Defizite zum Dollarund zum EZU-Raum waren mit Reserveverlusten und einem Anwachsen der kumulativen Schuldnerposition Frankreichs in der EZU verbunden. Nach Meinung der deutschen Zentralbank war das vor allem auf die inflationäre französische Politik zurückzuführen. Nachdem Frankreich im Herbst 1956 einen IWF-Standby Kredit in Höhe von 262,5 Mio. Dollar erhalten hatte, wandte es sich im Dezember 1956 mit der Bitte um weitere Kredithilfe informell an die EZU. Wenngleich der Zentralbankrat im Sommer 1956 explizit festgehalten hatte, daß er "mit EZU-Sonderkrediten, nach Wunsch der anderen Partnerländer auch mit [...] bilateralen Devisenkrediten (bzw. Swaps), [...] außerhalb der EZU“ helfen wollte, zeigte er sich nun zögerlich und ablehnend ${ }^{132}$. Zwar prüfte die BdL im Dezember

${ }^{130}$ John Maynard Keynes stellte 1930 fest: „For it is, as we have seen, the essence of membership of an international system that international equilibrium (i.e. $G=0$ ) [ . . ] requires that the main criterion of the banking policy of each member should be the average behaviour of all other members, its own voluntary and independent contribution to the final result being a modest one." Keynes, Treatise, S. 271.

${ }^{131}$ Für einen Überblick über die französische Wirtschaftsentwicklung vgl. Bonin, France depuis 1880, S. 151 ff.; Pitman, Crisis.

132 BBK, B 330/95, ZBR, Protokoll, 11.7.1956; ZBR, Protokoll, 25.7.1956. Als Cahan vom OEECSekretariat im Frühjahr 1957 einen deutschen Sonderkredit an Frankreich vorschlug, verhielt sich der Zentralbankrat abwartend. Vgl. BBK, B 330/103, ZBR, Protokoll und Stenogramm, 28.5.1957. 
1956 die Möglichkeit einer Kreditvergabe an Frankreich ${ }^{133}$, doch als im Jahre 1957 ein solches Projekt mit den Ressorts vorbereitend diskutiert wurde, knüpfte der Zentralbankrat einen Kredit an die Bedingung eines französischen Sanierungsprogramms ${ }^{134}$. Bei jeder Gelegenheit wies Vocke auf die Folgen eines Sonderkredites ohne Sanierungsprogramm hin. Wiederholt warnte er davor, „Frankreich zu bald mit einem Kredit zu winken, da alles geschehen müsse, um Frankreich zu veranlassen, energische Sanierungsmaßnahmen zu ergreifen. Ein zu leichter Kredit veranlasse die französische Regierung, die Zügel schleifen zu lassen “135.

Das Insistieren Vockes fiel bei den Ministerien auf fruchtbaren Boden. Erst als im Verlauf des Winters 1957/58 ein französisches Sanierungsprogramm vorgelegt wurde, erklärten sich die Bundesregierung und die Bundesbank im Rahmen einer EZU-Aktion zu einem Sonderkredit bereit ${ }^{136}$. Ende Januar 1958 wurde Frankreich ein EZU-Kredit in Höhe von 250 Mio. RE (100 Mio. RE als Rallonge; 150 Mio. RE als Sonderkredit) gewährt. Um eine Kontrolle des Sanierungsprogramms zu gewährleisten, wurde dieser Kredit in zwei Tranchen unterteilt, wobei die Zuteilung der zweiten Tranche von dem Erfolg des Sanierungsprogramms abhängen sollte.

Die französische Wirtschaftskrise zeigt, daß die deutsche Zentralbank im Rahmen der Auseinandersetzung um die geldpolitischen Standards in Europa eine wichtige Instanz war. Durch ihr Insistieren, das sich auf ihre Devisenreserven stützen konnte, kam es zu einem französischen Sanierungsprogramm. Nicht ohne Stolz vermerkte Emminger Anfang 1958: „Unser Standpunkt - der inzwischen weitgehend von der ganzen EZU und ebenso vom IWF geteilt wird - war von Anfang an, daß ein größerer Hilfskredit an Frankreich nur gerechtfertigt werden kann, wenn er nicht nur zur Finanzierung einer weiter anhaltenden Inflation verwendet wird, sondern in Zusammenhang mit einem erfolgversprechenden Sanierungsprogramm und nur zur zeitlichen Überbrückung bis zur Erreichung des Gleichgewichts aus eigener Kraft gegeben wird." ${ }^{137}$ Allerdings ist auch festzuhalten, daß der Einfluß der Zentralbank an Grenzen stieß. Zum einen befriedigte das französische Sanierungsprogramm die Bundesbank nur teilweise. Emminger stellte heraus, das Programm sei ergänzungsbedürftig und lieBe noch Wünsche offen ${ }^{138}$. Zum zweiten waren im Sommer 1958 politische Konstellationen wichtig. Als dann die Freigabe der bisher zurückgehaltenen und vom Erfolg des Sanierungsprogramms abhängigen zweiten Tranche des Sonderkredits diskutiert wurde, opponierte die Bundesbank nicht. Zwar konnte sie keinen Sa-

133 Vgl. BBK, B 330/1283, IV an Fögen, 11.12.1956.

${ }^{134}$ Vgl. BBK, B 330/103, ZBR, Protokoll, 12.6.1957; BdL an BMF, 13.6.1957.

${ }^{135}$ BAK, B 136/2595, von Süßkind, Ergebnisprotokoll über die Chefbesprechung am 24.6.1957, 25.6.1957.

136 Vgl. BBK, B 330/1282, Emminger, EZU-Kredit an Frankreich, 2.1.1958; BBK, B 330/136, ZBR, Protokoll, 8.1.1958; BBK, B 330/1290, V A 2a, Ergebnisprotokoll der Ressortbesprechung vom 6.1.1958, 7.1.1958.

137 BBK, B 330/1282, Emminger, EZU-Kredit an Frankreich, 2.1.1958.

138 Vgl. ebenda. 
nierungserfolg feststellen. Sie akzeptierte aber, daß sich die Bundesrepublik aus politischen Gründen einer Freigabe des Kredites nicht versagen konnte ${ }^{139}$.

Trotz dieser Grenzen konnte die deutsche Zentralbank aber in der zweiten Hälfte der fünfziger Jahre ihren geldpolitischen Maßstäben weitgehend Geltung verschaffen, dem de-facto-konvertiblen-EZU-System ihren Stempel aufdrücken und so in Europa eine Führungsrolle einnehmen. Warum es dazu kommen konnte, liegt in den folgenden vier Umständen begründet.

Zum ersten war die deutsche Zentralbank nur bedingt handlungsfähig. $\mathrm{Da}$ zeitweise heftig auf Wechselkursanpassungen spekuliert wurde und somit eine Zinsreagibilität nicht vorlag, konnten die Regeln eines de-facto-konvertiblen Währungssystems nicht oder nur bedingt angewandt werden. Diese Situation wenngleich keineswegs erfreulich - verstärkte die Verhandlungsposition der Bank. Ihre aus dieser begrenzten Handlungsfähigkeit resultierende geldpolitische Passivität wurde, wenn auch manchmal heftige Kritik geübt wurde, von den anderen EZU-Teilnehmern weitgehend akzeptiert.

Zum zweiten waren die Möglichkeiten, gegen die Bundesrepublik vorzugehen, eng umgrenzt. Eine Diskriminierung der deutschen Exporte war im Rahmen der OEEC schwer durchzusetzen, denn sie setzte mindestens eine Einigung innerhalb der OEEC voraus. Einer solchen Einigung stand aber nicht nur die Möglichkeit eines deutschen Vetos entgegen. Auch lag sie nicht im Interesse anderer Gläubigerländer. Hinzu kam, daß aber nicht nur die Gläubigerländer gegen solche diskriminatorischen Maßnahmen waren. Selbst von den Schuldnerländern wurden sie abgelehnt, denn sie fürchteten, die Bundesrepublik würde in einem solchen Fall die EZU verlassen und zur Konvertibilität übergehen. Selbst wenn die Bundesrepublik mit einer Konvertibilitätserklärung nicht drohte und zu keinem Zeitpunkt ein Verlassen der EZU ernsthaft in Erwägung zog, verfügte sie damit über ein wirksames Druckmittel. Eine Diskriminierung der deutschen Exporte wurde aber nicht nur durch die Möglichkeit eines deutschen Vetos, durch das Eigeninteresse der Gläubiger und durch die Angst der Schuldner behindert. Auch wurde eine Diskriminierung natürlich durch Kooperationsbereitschaft unwahrscheinlicher gemacht, oder sie konnte zumindest hinausgezögert werden. Tatsächlich ließ es die deutsche Zentralbank an dieser Kooperationsbereitschaft nicht fehlen. Für Linderungsmaßnahmen machte sie sich immer stark, und sie konnte sie auch letztlich befördern.

Zum dritten traf die Politik der deutschen Zentralbank oftmals auf Wohlwollen, Sympathie und Einverständnis in Europa. Zwar kann und soll die zeitweise heftige Kritik der europäischen Partner nicht geleugnet oder geschmälert werden. Bei mehreren Gelegenheiten war die deutsche Zentralbank mit ihrer Forderung nach restriktiven Maßnahmen der Schuldnerländer isoliert. Trotzdem war die Kritik der EZU-Länder weder einhellig noch durchgängig. Wenn auch Frankreich im Herbst 1957 im EZU-Direktorium die deutsche Geldpolitik und vor al-

139 Vgl. BAK, B 102/55340, Turowsky, Vermerk Verlängerung des EZU-Sonderkredits, 21.7.1958. 
lem die dadurch erzwungenen britischen Maßnahmen heftig kritisierte, so wollte es das Vereinigte Königreich doch nicht gegen die Bundesrepublik unterstützen $^{140}$. Wenn auch das Vereinigte Königreich im Frühjahr 1957 heftige Kritik an der deutschen Währungspolitik übte, so besannen sich die Briten schon im Sommer wieder anders und nahmen die Kritik zurück. Sich von den anderen Schuldnerländern distanzierend, faßte die Bank von England das britische Meinungsbild zur deutschen Geldpolitik zu diesem Zeitpunkt folgendermaßen zusammen: "It is quite clear, however, that neither in his (Bill Martin, M.D.) thinking nor in that of other informed people here is there any disposition to criticise the way the Germans have behaved. There is some tendency to think that we have behaved unwisely in the summer when we appeared to take the lead in Paris of the indigent countries in criticising the Germans. The feeling here is that we do not belong in that category and it would have been better tactics on our part not to have identified ourselves with it. " ${ }^{141}$ Auf der gleichen Linie liegt, daß das EZUDirektorium schon im Frühjahr 1957 zur französischen Wirtschaftskrise feststellte, die Schuld für diese Krise läge in erster Linie bei Frankreich selbst ${ }^{142}$.

Zum vierten muß betont werden, daß sich weder die Bundesregierung noch die deutsche Zentralbank in einer Zwangslage befanden. Zwar mußte die Bank einen "verzweifelten Kampf" gegen die Liquidisierungstendenzen führen. Sie war aber für diesen Kampf recht gut gewappnet. Anfänglich nicht ausreichend mit offenmarktfähigen Wertpapieren ausgestattet, vereinbarte sie mit dem Finanzminister die Mobilisierung der Ausgleichsforderungen. So konnte sie nicht nur über die Zinspolitik, sondern auch über die Liquiditätspolitik eingreifen und restriktiv wirken. Erst im Oktober 1957 zeichnete sich ein Mangel an Mobilisierungspapieren ab, doch zu diesem Zeitpunkt war auch deutlich, daß die Devisenankäufe nicht mehr in diesem Maße anhalten würden wie bisher ${ }^{143}$. Wichtiger aber war, daß die Zentralbank zu jedem Zeitpunkt die Option besaß, von ihrer Restriktion abzugehen. Darüber hinaus muß gesagt werden, daß sie in dem inzwischen gläubiger-freundlichen, de-facto-konvertiblen EZU-System letztendlich am längeren Hebel saß. Das ließen BdL-Vertreter auch manchmal, mit der notwendigen Zurückhaltung, im Gespräch mit Zentralbankkollegen durchblicken: „Dr. Guth of the BdL said [. . .] that at bottom, having a big foreign surplus was not nearly so worrying as having a large deficit. ${ }^{144}$ An-

${ }^{140}$ Pierre Calvet, französisches Mitglied im EZU-Direktorium, bemerkte zur britischen Diskonterhöhung, daß sich die Defizitländer mit solchen Maßnahmen nur den "Schwarzen Peter" zuspielen würden. Vgl. BBK, B 330/1306, Emminger, Bericht von Mangoldts über die EZU-OktoberSitzung, 18.10.1957. Als aber das Vereinigte Königreich sein Vorgehen mit Frankreich abstimmen wollte, war Frankreich nicht interessiert. Vgl. BoE, OV 46/77, Raw, Visit to Paris, 8.10.1957.

141 BoE, OV 46/76, Parsons an Cobbold, 20.9.1957.

${ }^{142}$ Vgl. HAEC, OEEC 365, OEEC Council, Report by the Managing Board of the EPU on the Position of France, $C(57) 65,5.4 .1957$.

${ }^{143}$ Vgl. BBK, B 330/135/I, Könneker, Vermerk, 8.10.1957.

144 BoE, OV 34/41, Tomkins, Report on a visit to Germany, 19.10.1956. Vgl. auch die heftige Reaktion Emmingers auf einen Vorschlag Tüngelers, den spekulativen Devisenzuflüssen zu begegnen, in: 
statt sich in einer Zwangslage zu befinden, mußte die deutsche Zentralbank nur den Preis weiterer EZU-Kredite bezahlen. Dafür erhielt sie ein Währungssystem, in dem sie ihren währungspolitischen Standards weitgehende Geltung verschaffen konnte.

\section{Die deutsche Zentralbank und die Verhandlungen über eine Europäische Wirtschaftsgemeinschaft}

Schon in der ersten Hälfte der fünfziger Jahre war deutlich geworden, daß die europäische Kooperation im Rahmen der OEEC nicht alle Teilnehmerländer zufriedenstellte. Das Liberalisierungsprogramm der OEEC sah Ausweichklauseln vor, Zölle blieben unberücksichtigt, der Staatshandel und der Handel mit landwirtschaftlichen Erzeugnissen waren ausgeklammert. Zahlreiche Initiativen versuchten dem abzuhelfen. Bis zum Frühjahr 1955 war jedoch keinem dieser Vorstöße Erfolg beschieden. Weder im Rahmen der OEEC noch im Rahmen der 6 EGKS-Staaten war ein Einvernehmen über die Lösung dieser Probleme erzielt worden ${ }^{145}$

Im Frühjahr 1955, während die OEEC-Länder die Bedingungen einer EZUAuflösung verhandelten, ergriffen die Benelux-Staaten eine erneute Initiative. Sie schlugen ihren EGKS-Partnern vor, die allgemeine wirtschaftliche Integration zu verfolgen und einen gemeinsamen Markt zu errichten. Auf der Konferenz von Messina, auf der diese Anregung diskutiert wurde, einigten sich die Außenminister der Sechs darauf, ein Komitee von Regierungsdelegierten und Sachverständigen einzuberufen. Dieses sollte die schrittweise Beseitigung der Handelsschranken, die Vereinheitlichung der Zollsysteme gegenüber Drittstaaten, Maßnahmen zur Koordinierung der Wirtschafts- wie Währungspolitik, die Errichtung eines Anpassungsfonds und eines europäischen Investitionsfonds untersuchen $^{146}$. Unter der Leitung des belgischen Außenministers Paul Henri Spaak wurden diese Fragen in den folgenden Monaten diskutiert; im Frühjahr 1956 wurde den Außenministern der Sechs der sogenannte Spaak-Bericht vorgelegt. Auf der Konferenz von Venedig wurde dieser Bericht als Verhandlungsgrundlage angenommen. Die nun folgenden Regierungsverhandlungen konnten nach großen Anstrengungen im Frühjahr 1957 erfolgreich abgeschlossen werden. Im März 1957 wurden die Römischen Verträge unterzeichnet, die nach ihrer Ratifizierung am 1.Januar 1958 in Kraft traten. Während zur gleichen Zeit das von britischer Seite in die OEEC eingebrachte Projekt einer Freihandelszone auf immer

BBK, B 330/133, ZBR, Stenogramm, 8./9.8.1957. Während Rekordüberschüsse verzeichnet wurden, stellte Emminger heraus: „Ich kann mir keine Situation außer einer völlig verzweifelten Lage vorstellen, in der eine respektable Notenbank auf so etwas zurückgreifen würde."

145 Vgl. Asbeek Brusse, Tariff Plans, S. $129 \mathrm{ff}$.

${ }^{146}$ Vgl. Resolution der Konferenz von Messina, 2.6.1955, abgedruckt in: Aufbau Europas, S. 275 f. 
größere Schwierigkeiten traf und die entsprechenden Verhandlungen im November 1958 abgebrochen wurden, trat am 1.Januar 1959 die erste Binnenzollsenkung im Rahmen der EWG in Kraft. Wenngleich die EWG beschloß, daß von dieser ersten Zollsenkung alle GATT-Mitglieder profitieren sollten, war trotzdem damit Westeuropa fortan und für lange Zeit in zwei Handelsblöcke gespalten.

Die historische Forschung hat der Europäischen Integration beträchtliche Aufmerksamkeit geschenkt. Die Verhandlungen, ihre Hintergründe, die unzähligen Probleme und die damit verbundenen Auseinandersetzungen sind ausgiebig beschrieben und analysiert worden ${ }^{147}$. Das Erkenntnisinteresse dieser Forschungen war dabei, festzustellen, worauf der erfolgreiche Abschluß der Römischen Verträge zurückgeführt werden kann, und im Verlauf der Jahre sind eine Reihe von Gründen benannt worden. Zum einen wurde auf die außenpolitischen Entwicklungen wie z.B. auf den im Sommer 1956 von den USA vorgelegten RadfordPlan, die Passivität der USA während des ungarischen Aufstandes, die Suez-Krise und die Notwendigkeit, das Deutschlandproblem dauerhaft zu lösen, verwiesen. Auch wurden das Wohlwollen und die tatkräftige Unterstützung der USA, die destruktiv anmutende Haltung des Vereinigten Königreiches und das Junktim EWG - Euratom als wichtig angesehen ${ }^{148}$. Desgleichen wurde wirtschaftlichen Aspekten wie einem zuverlässigen Zugang zum deutschen Markt, der Lösung der Agrarproblematik, den Bestrebungen zur Schaffung größerer Wirtschaftsräume Bedeutung beigemessen. Vorgeblich spielte auch der Idealismus einzelner Politiker und Entscheidungsträger sowie die noch immer virulente, wenn auch abklingende Europabegeisterung eine wichtige Rolle ${ }^{149}$. Darüber hinaus habe es, so wurde angeführt, nach dem Scheitern der EVG einen gewissen Zwang zum Erfolg gegeben ${ }^{150}$. Auch wurde die Existenz der EGKS-Institutionen und die Art der Verhandlungsführung als wichtig angesehen. Die anfängliche Unverbindlichkeit der Expertengespräche sowie die geringen Erfolgsaussichten hätten Kompromisse ermöglicht, zugleich aber hätten sie auch ein Präjudiz geschaffen ${ }^{151}$. Ferner hätte die Tatsache, daß erst spät deutlich wurde, wie protektionistisch der Gemeinsame Markt werden würde, eine Opposition erschwert, während das unbarmherzige Tempo, das Spaak in den Regierungsverhandlungen an den Tag legte, die Eingriffsmöglichkeiten reduziert hätte ${ }^{152}$. Schließlich wur-

${ }^{147}$ Als historische Arbeiten zur Gründung der EWG und Euratom vgl. Küsters, Gründung; Weilemann, Atomgemeinschaft; Guillen, L'Europe; Asbeek Brusse, Tariff Plans; Loth, Weg; Milward, Rescue, sowie die in Milward u. a., Frontier; Serra (Hrsg.), Rilancio versammelten Arbeiten. Für die deutsche Haltung vgl. die in Bührer/Herbst/Sowade (Hrsg.), Marshallplan enthaltenen Studien.

${ }^{148}$ Für die britische Haltung zur EWG vgl. Camps, Britain; Watt, Großbritannien, S. 389 ff.; Griffiths, British Policy. Für die amerikanische Haltung vgl. Winand, Eisenhower, S. $109 \mathrm{ff}$.

149 Vgl. hierzu kritisch Milward, Rescue, S.318ff.; Loth, Vertragsverhandlungen.

150 Vgl. Harbrecht, Europäische Gemeinschaft, S. $34 \mathrm{ff}$.

151 Vgl. Küsters, Gründung, S. 268.

152 Vgl. Griffiths, Common Market, S. 200. 
den die Kräftekonstellationen innerhalb einzelner Staaten und die jeweiligen Politikstile als wichtig eingeschätzt. Für die Bundesrepublik wurde auf die Entschlossenheit Adenauers verwiesen. Dadurch, daß er gegen die Opponenten des Europa-Projektes und vor allem gegen seinen lauthals protestierenden Wirtschaftsminister seine Richtlinienkompetenz ins Feld geführt habe, konnte er Kritik im Keim ersticken ${ }^{153}$. Weil er auf dem Primat der Politik bestanden habe, wären wirtschaftliche Interessen und Einwände während des Verhandlungsprozesses nicht zum Tragen gekommen ${ }^{154}$.

Eine Verifizierung, Falsifizierung oder eine Gewichtung der einzelnen Erklärungsansätze wird im folgenden nicht angestrebt. Da das Erkenntnisinteresse auf die deutsche Zentralbank gerichtet ist, wird hier nur dem Prozeß der Europäischen Integration ein weiterer Mosaikstein - die Rolle und Politik der BdL - hinzugefügt werden.

\section{Die Bank deutscher Länder und die Verhandlungen über den Gemeinsamen Markt}

Im Zusammenhang mit den EWG-Verhandlungen wird die deutsche Zentralbank meist nicht erwähnt. Weder die auf den Privatpapieren eines deutschen Delegationsmitgliedes beruhende Darstellung der EWG-Verhandlungen noch die Studien, die die Auseinandersetzungen zwischen Erhard und Adenauer in den Mittelpunkt stellen, gehen auf die Bank ein ${ }^{155}$. Diese Vernachlässigung der Zentralbank rührt daher, daß ihr bei den EWG-Verhandlungen vermutlich nur eine eng umschriebene Bedeutung zukommen konnte. Schließlich mußte die Bundesrepublik in Europafragen vor allem politische Aspekte bedenken. Um die deutschfranzösische Verständigung zu festigen und um Deutschland als vollwertiges Mitglied im westlichen und westeuropäischen Lager zu verankern, mußte sie sich an den europäischen Integrationsbemühungen beteiligen. Wirtschaftspolitische Überlegungen konnten somit nur wenig zum Tragen kommen und wirtschaftspolitische Institutionen mußten vor diesen außenpolitischen $Z$ wängen verblassen, zumal Adenauer auf seiner Richtlinienkompetenz und dem Primat der Politik bestand.

Doch wenn auch neuere Forschungen bestätigen, daß in Europafragen Adenauer und den politischen Aspekten die entscheidende Rolle zukam und sogar Milward hervorhebt, daß für Deutschland politische Motive fundamental waren ${ }^{156}$, sollte untersucht werden, inwieweit die Bank an dem Prozeß der Europäischen Integration beteiligt war, welche Haltung sie zur EWG einnahm, und wor-

\footnotetext{
${ }^{153}$ Vgl. Küsters, Streit, S.358ff.

154 Vgl. ders., Gründung, S. 276.

155 Vgl. ders., Gründung; Koerfer, Kampf; ders., Kontroversen; Küsters, Europapolitik; ders., Zollunion; ders., Streit; Lappenküper, Europapolitik.

156 Vgl. Milward, Rescue, S.208.
} 
in diese Haltung begründet war. Da die EWG in der Bundesrepublik auf viele Vorbehalte, einige Skepsis und auch auf erhebliche Kritik stieß, ist von Interesse herauszuarbeiten, wie sich die deutsche Zentralbank hier einordnete. Dadurch kann ermittelt werden, wie sie sich zum Primat der Politik, zu Adenauers Ansprüchen und zu Erhards Opposition stellte. Darüber hinaus können weitere Aufschlüsse über den Verhandlungsprozeß, über die deutsche Motivationslage und über die Machtkonstellationen innerhalb der Bundesrepublik gewonnen werden.

\section{Grundpositionen}

Die Resolution der Konferenz von Messina war in ihren Formulierungen ausgesprochen vage. Dennoch war abzusehen, daß die Realisierung eines Gemeinsamen Marktes - in welcher Form auch immer - das deutsche, europäische und globale Wirtschaftssystem nachhaltig verändern würde. Ein Zusammenschluß der Sechs würde ein gewisses Abrücken gegenüber anderen Ländern bedeuten. Neue Kooperationsforen und -mechanismen würden notwendig werden. Bisherige Handelsströme würden umgelenkt, neue Handelsströme geschaffen werden. Selbst wenn Zollunionen mit dem GATT kompatibel waren, waren sie ein Abstrich an der angestrebten liberalen Weltwirtschaftsordnung, und das hätte auch auf dem Gebiet der Währung Folgen gezeitigt. Als währungspolitische Instanz der Bundesrepublik und als eine wirtschaftspolitische Beraterin der deutschen Regierung mußte sich die BdL also mit diesem Integrationsprojekt auseinandersetzen.

Wenngleich die BdL weder an den anfänglichen Grundsatzdiskussionen noch an der späteren deutschen Delegation nach Brüssel beteiligt war, ja anfangs sogar nur zögernd von den Bonner Ressorts über die Gespräche auf dem laufenden gehalten wurde, war sie im weitesten Sinne über die integrationspolitischen Projekte informiert. Im weiteren Verlauf nahmen ihre Vertreter sogar an den Ressortbesprechungen in Bonn, in denen die deutsche Position formuliert wurde, teil ${ }^{157}$. Trotzdem widmete sich die Bank diesem wichtigen Thema nur sporadisch, und ihre Intervention gegen die Bonner Informationspolitik war gemäßigt. Vorerst fühlte sich die BdL nämlich von diesen Verhandlungen nicht berührt. Im Sommer 1955 hob das Direktoriumsmitglied Eduard Wolf hervor, „daß besondere währungs- und kreditpolitische Maßnahmen bei den jetzt in Gang gekommenen Integrationsgesprächen kaum ins Auge zu fassen sein würden, da wir auf währungspolitischem Gebiet bereits auf viel weiter gesteckte Ziele zusteuern und kreditpolitisch vorläufig über den bereits bestehenden Kontakt zwischen den Notenbankleitern hinaus praktisch fürs erste nichts getan werden kann ${ }^{\alpha 158}$.

$157 \mathrm{Vgl}$. BAK, B 102/22 160, Adenauer an AA, BMWi, BMF, BMA, 14.7.1955. Die geheimen Berichte von der Groebens über die Expertengespräche gingen bis zum Herbst 1955 nicht an die BdL. Das BMW1 hatte Bedenken, die BdL zu informieren. Vgl. BAK, B 102/22161, Müller-Roschach, Aufzeichnung, 8.8.1955.

${ }^{158}$ BBK, B 330/3380, Wolf an Vocke, 15.7.1955. 
Grundsätzliche Bedenken hegte die Bank somit vorerst nicht. Die Aussicht auf die Beseitigung der Handelsschranken zwischen den Sechs und auf eine Vereinheitlichung ihrer Zollsysteme gegenüber Drittstaaten rief zunächst keinen prinzipiellen Einspruch hervor. Über die Konsequenzen wie zum Beispiel die weitgehende Aufgabe der Zollautonomie sorgte sich die Bank zunächst nicht. Nur im Verlauf der Verhandlungen stellte Emminger heraus, daß die Einigung auf einen gemeinsamen Außenzoll für Deutschland eine Zollerhöhung bedeute, und monierte, das wäre für ein extremes Gläubigerland „ungünstig “159. Auch gegen die im Gemeinsamen Markt vorgesehene Liberalisierung der Kapitalbewegungen hatte die BdL anfangs nichts einzuwenden ${ }^{160}$. Erst Ende 1956 sorgte sie sich darum, daß der deutschen Wirtschaftspolitik mit einer definitiven Festschreibung der Kapitalverkehrsliberalisierung "für alle Zukunft" die Möglichkeit genommen würde, Regeln für den Zugang zum deutschen Kapitalmarkt zu formulieren $^{161}$.

Bis Mitte 1956 sah sich das Zentralbanksystem zu einer fundierteren und prinzipiellen Auseinandersetzung mit dem Projekt eines Gemeinsamen Marktes nicht veranlaßt. Dabei spielten neben den inhaltlichen Aspekten auch die anfängliche Unverbindlichkeit der Expertenverhandlungen und die geringen Erfolgsaussichten dieses Projektes eine wichtige Rolle. Als in der Sitzung des Zentralbankrates am 22. Februar 1956 das Projekt des Gemeinsamen Marktes detaillierter diskutiert wurde, hob Emminger den unverbindlichen Charakter der Besprechungen hervor. Auch verwies er auf den erheblichen Widerstand Frankreichs gegen den Gemeinsamen Markt. Dieser würde die Realisierung des Projektes unwahrscheinlich machen. Sie könne sich "ohne weiteres eine unabsehbare Zeit" hinziehen ${ }^{162}$. Erst im Herbst des Jahres 1956 veränderte sich die Haltung der Bank. Nunmehr fand Emminger es notwendig, die „Expertenberatungen“" „sicherheitshalber“ ernst zu nehmen ${ }^{163}$. Mitte November 1956 - nachdem Adenauer und der französische Ministerpräsident Guy Mollet in den Verhandlungen einen Durchbruch erzielt hatten - nahm die Bank kritisch zu einigen Punkten des Vertragswerkes Stellung ${ }^{164}$. Die grundsätzliche und zum Teil harsche Kritik, die sich während der letzten Monate innerhalb der BdL formiert hatte, wurde dabei jedoch nicht vorgebracht ${ }^{165}$. Die „Hochzüchtung“ einer internationalen Bürokratie, die „gemeinsa-

159 BBK, B 330/6463, Emminger, Kritische Gedanken zum Gemeinsamen Markt, 23.2.1957.

160 Vgl. BBK, B 330/3326, Emminger, Kurzbericht, 24.10.1955; BBK, B 330/1876, J2, Werner, Brüsseler Integrationsverhandlungen, 29.10.1956.

161 BBK, B 330/1876, Emminger, Liberalisierung des Kapitalverkehrs im Gemeinsamen Markt, 22.12.1956.

162 BBK, B 330/92, ZBR, Stenogramm, 22.2.1956. Vgl. auch BBK, B 330/1876, von Schelling, 10.10.1956. Von Schelling verwies auf die EVG und meinte, es sei denkbar, daß die EWG, ähnlich wie die EVG, scheitern würde.

${ }^{163}$ BBK, B 330/1876, IV an Vocke, 12.10.1956. Die "Expertenberatungen“" waren zu diesem Zeitpunkt schon ausgewachsene Regierungsverhandlungen.

164 Vgl. BBK, B 330/1876, IV, Vermerk, 12.11.1956.

165 Vgl. BBK, B 330/1876, BdL an BMWi, 15.11.1956. 
me Planwirtschaft" ${ }^{\text {" }}$ die Einfuhrbehinderung, die Gefahren für die deutsche Wettbewerbsfähigkeit, die „organisatorische Schwerfälligkeit" der EWG und der protektionistische Charakter des Gemeinsamen Marktes sowie seine Begrenzung auf Länder, auf die nur 25 Prozent des deutschen Außenhandels entfiel, wurden nun nicht vorgetragen ${ }^{166}$. Im November 1956 übte die deutsche Zentralbank gegenüber der Regierung keine prinzipielle Kritik, sondern nur „Zurückhaltung “167.

Für diese Zurückhaltung der Bank waren mehrere Gesichtspunkte verantwortlich. Aus politisch-taktischen Erwägungen heraus empfand sie bei nunmehr fortgeschrittenen und inzwischen ausgesprochen symbolträchtigen Verhandlungen eine prinzipielle Ablehnung als unangebracht. Emminger betonte in einer Ausarbeitung zum Gemeinsamen Markt, daß er „trotz aller Bedenken und Zweifel [...] in der gegenwärtigen Lage niemals für eine radikale Ablehnung des Brüsseler Vertragswerks plädieren [würde]. Das wäre politischer Donquichotismus. Nachdem das Brüsseler Vertragswerk, ob zu Recht oder zu Unrecht, nun einmal in der ganzen Welt zum Symbol für die nächste Etappe der europäischen Einigung geworden ist (oder gemacht worden ist) gibt es jetzt ja wohl nur noch den Weg vorwärts ${ }^{\alpha 168}$. Hinzu kam, daß die Bank immer wieder einräumte, der Vertrag habe in erster Linie einen politischen Charakter. Demnach kämen ihr "nur geringe Einflußmöglichkeiten“ zu. Diese Verminderung ihres Gewichtes bedauerte die Bank nicht. Vielmehr sah sie dies als gerechtfertigt an ${ }^{169}$. Darüber hinaus war die Bank trotz einiger Kritik prinzipiell positiv zu einem solchen Integrationsprojekt eingestellt. Sie wollte die "Zusammenschließung Europas" auch aus wirtschaftlichen Gründen "so rasch als irgend möglich" durchsetzen, und sie stellte in dem Brüsseler Vertragswerk „zweifellos auch vorhandene positive Keime" fest ${ }^{170}$. Bestrebt, die Verhandlungen über den Gemeinsamen Markt zu einem guten Ende zu führen, griffen ihre Vertreter nur zu speziellen Punkten wie zum Beispiel zu den Zahlungsbilanzartikeln des EWG-Vertrages, zu den Kapitalfragen und den Kredithilfen ein.

Konvertibilität - Zahlungsbilanzpolitik - Kreditbeihilfen

In den fünfziger Jahren war heftig umstritten, wie man die wirtschaftliche Integration von Nationalstaaten erreichen kann. Hier standen sich Institutionalisten

166 Vgl. BBK, B 330/92, ZBR, Stenogramm, 22.2.1956; BBK, B 330/97, ZBR, Stenogramm, 31.10.1956; BBK, B 330/1876, von Schelling, Vermerk, 10.10.1956; Emminger, Diskussionsbeitrag, 30.11.1956; BBK, B 330/6463, Emminger, Kritische Gedanken zum Gemeinsamen Markt, 25.2.1957.

167 BBK, B 330/97, ZBR, Stenogramm, 31.10.1956. Selbst wenn die Bank stets darauf hinwies, daß auf die 5 EGKS-Partner nur $25 \%$ des deutschen Außenhandels entfielen, spricht aus den Veröffentlichungen der Bank eher Zurückhaltung als prinzipielle Kritik. Vgl. Deutsche Bundesbank, Geschäftsbericht 1957, S. 58 und Bank deutscher Länder, Geschäftsbericht 1956, S. 1 ff.

${ }^{168}$ BBK, B 330/6463, Emminger, Kritische Gedanken zum Gemeinsamen Markt, 25.2.1957.

169 BBK, B 330/1876, von Schelling, Vermerk, 10.10.1956.

170 BBK, B 330/6463, Emminger, Kritische Gedanken zum Gemeinsamen Markt, 25.2.1957. Vg1. auch BBK, B 330/1876, von Schelling, Vermerk, 10.10.1956. 
und Funktionalisten gegenüber. Während sich die ersteren für die Schaffung von Institutionen und für die Übertragung der Kompetenzen von nationalen auf supranationale Einrichtungen stark machten, verfolgten die letzteren "die Setzung einer internationalen Ordnung [...] bei der nicht institutionelle oder personelle Befehlsgewalten in Erscheinung treten müssen, um ein bestimmtes Verhalten der einzelnen Nationalstaaten oder ihrer Regierungen zu erreichen ${ }^{\text {“171. Inner- }}$ halb der deutschen Regierung strebte vor allem der Funktionalist Erhard die Konvertibilität an, denn die Errichtung dieser Ordnung würde weitere Institutionen unnötig machen. Demgegenüber sahen das Auswärtige Amt und die Schumanplan-Abteilung des Wirtschaftsministeriums die Konvertibilität zwar als wichtig an. Sie betonten aber, daß die Errichtung neuer Institutionen für den Gemeinsamen Markt unerläßlich sei. Bei der Vorbereitung der deutschen Stellungnahme zur Konferenz von Messina mußten die deutschen Ressorts eine gemeinsame Position in dieser Frage finden. Schließlich einigten sie sich darauf, daß die funktionelle Integration mittels Konvertibilität anzustreben sei, und daß dieser Funktionalismus durch ein institutionelles Gefüge ergänzt werden müßte ${ }^{172}$. Diesen neuen Institutionen sollte es obliegen, den Zollabbau zu überwachen, aber auch eine gewisse Koordinierung der allgemeinen Wirtschafts- und Währungspolitik herbeizuführen.

Sobald die Expertengespräche begannen, bezog die BdL zu diesen Fragen Stellung, da die Währungs- und Zahlungsbilanzpolitik davon direkt betroffen war. Die wichtigste Frage war hier, wie die Sechs ihre Währungspolitik koordinieren und Zahlungsbilanzschwierigkeiten vermeiden konnten. Auch war zu entscheiden, wie die Sechs bei Zahlungsbilanzkrisen reagieren, und ob in einem solchen Falle spezielle Regelungen greifen und besondere Hilfen gegeben werden sollten. Gleichzeitig mußte möglicherweise die Form der Institution, die die Währungspolitik der Sechs koordinieren, harmonisieren, begutachten oder gar beaufsichtigen würde, diskutiert werden.

Die Stellungnahme der BdL zu diesen Fragen war denkbar einfach. Sie plädierte dafür, im Vertrag die Verpflichtung zu einer zahlungsbilanzkonformen Politik für die Mitglieder eines Gemeinsamen Marktes festzuschreiben ${ }^{173}$. Durch eine solche Verpflichtung würden Zahlungsbilanzprobleme weitgehend vereitelt. Neue währungspolitische Institutionen, die die Bank in funktionalistischer Haltung ablehnte, wären damit überflüssig. Solche Institutionen waren nämlich ihrer Meinung nach nicht nur eine "Hypertrophie“, die mit Doppelarbeit verbunden war. Sie waren vielmehr geradezu "gefährlich“ und "unerträglich“. Eine neue Institution würde nämlich möglicherweise mit sich bringen, daß die Bank ihre Politik dann noch zusätzlich vor dieser regionalen Institution rechtfertigen

${ }^{171}$ Erhard in einer Rede vor dem Club Les Echos am 7.12.1954, abgedruckt in: Hohmann (Hrsg.), Erhard, S. 421.

172 Zur Vorbereitung der Konferenz von Messina vgl. Küsters, Gründung, S. $112 \mathrm{ff}$.

${ }^{173}$ Der Begriff „zahlungsbilanzkonform“ wurde dabei nicht näher problematisiert. Vgl. BBK, B 330/ 3326, Emminger, Kurzbericht, 14.10.1955. 
müßte. Das behagte ihr verständlicherweise nur wenig, zumal eine regionale Institution möglicherweise nur die Teilzahlungsbilanz, nicht aber die Gesamtzahlungsbilanz im Auge behielt. Das war ihres Erachtens problematisch, denn diese Vernachlässigung würde zwangsläufig zu unpassenden Empfehlungen führen ${ }^{174}$.

Die Verpflichtung zu einer zahlungsbilanzkonformen Politik barg aber noch einen weiteren Vorteil für die BdL. Da mit dieser Verpflichtung Zahlungsbilanzprobleme schon im Vorfeld verhindert würden, machte sie die Vereinbarung weiterer Kredithilfen unnötig. Daran war der BdL, die als Zentralbank eines Gläubigerlandes voraussichtlich Kreditgeberin sein würde, sehr gelegen. Stets betonte sie, Kredite wären in keinem Fall in der Lage, Zahlungsbilanzstörungen nachhaltig zu beseitigen ${ }^{175}$. Anstatt Kredite zu vergeben, sollten die Überschußländer unilateral im Abbau der Einfuhrbeschränkungen vorangehen und auf diese Art helfen, eine sich anbahnende Krise zu entschärfen ${ }^{176}$. Für den Fall, daß sich dennoch Schwierigkeiten ergeben würden, wollte die Bank die Teilnehmer des Gemeinsamen Marktes auf die Kreditmöglichkeiten der EZU, des Europäischen Fonds oder des IWF verweisen ${ }^{177}$.

Die Forderung der BdL, lediglich eine Verpflichtung zur zahlungsbilanzkonformen Politik festzuschreiben, traf auf viel Sympathie bei den deutschen Ressorts. Die Meinung, daß weitere Institutionen unnötig seien und daß die Konvertibilität als Ordnung greifen sollte, war weit verbreitet. Auch herrschte weitgehende Übereinstimmung, daß die Verantwortung für die allgemeine Wirtschaftspolitik bei den Mitgliedsstaaten verbleiben müsse. Wenn auch einige Vertreter des Wirtschaftsministeriums manchmal hervorhoben, daß die Zahlungsbilanzkonformität der Währungspolitik zu wichtig sei, um von den Organen einer Sechser-Gemeinschaft auBer acht gelassen zu werden ${ }^{178}$, setzte sich die funktionalistische Linie in bezug auf die Währungspolitik innerhalb der Bundesrepublik vorerst durch ${ }^{179}$. Da in anderen Ländern und Zentralbanken ähnliche Ansichten vorherrschten, wurde im SpaakBericht das Schwergewicht auf die Forderung nach einer zahlungsbilanzkonformen Politik und nach richtigen Wechselkursen gelegt. Wenn der Spaak-Bericht auch von einer gemeinsamen Währungspolitik sprach, wurde die Errichtung von entsprechenden Institutionen hier nicht anvisiert ${ }^{180}$. Mit diesen Empfehlungen war die BdL zufriedengestellt und sah von einer weiteren Intervention $a b^{181}$.

${ }_{174}$ BBK, B 330/3326, Emminger, Kurzbericht, 14.10.1955; Emminger, Kurzbericht 28.10.1955.

$175 \mathrm{Vgl}$. BBK, B 330/1876, von Schelling, 10.10.1956.

176 Vgl. BBK, B 330/1876, Emminger, Kurzbericht, 14.10.1955. Die Problematik einer solchen Politik - namentlich die Schwierigkeit, bei weitgehend liberalisiertem Außenhandel die Importe durch weiteren Abbau von Beschränkungen zu steigern - wurde dabei wohlweislich verschwiegen.

177 Vgl. BBK, B 330/1876, Emminger, Kurzbericht, 14.10.1955.

${ }^{178}$ Vgl. BBK, B 330/3326, Emminger, Bericht über eine Ressortbesprechung, 14.10.1955.

${ }^{179}$ Vgl. BBK, B 330/3326, Emminger, Bericht über eine Ressortbesprechung, 28.10.1955. Allerdings konnte die von der Bank geforderte ausdrückliche Negativklausel nicht durchgesetzt werden.

${ }^{180} \mathrm{Vgl}$. Spaak-Bericht, abgedruckt in: Aufbau Europas, S. $277 \mathrm{ff}$.

181 Vgl. BBK, B 330/1876, Emminger, Staatssekretärbesprechung über Bericht der Brüsseler Experten zur Europäischen Integration, 17.4.1956. 
Im Verlauf der Regierungsverhandlungen wurde jedoch das unverbindliche Übereinkommen des Spaak-Berichtes in Frage gestellt. Wenn auch die Notwendigkeit einer zahlungsbilanzkonformen Politik nicht expressis verbis angezweifelt wurde, wurden dennoch im weiteren Verlauf die Möglichkeit von Zahlungsbilanzkrisen, die Gewährung besonderer Hilfen und die Formulierung gewisser Ausnahmeregelungen rege diskutiert. Im Herbst 1956 schlug Frankreich sogar die Einrichtung eines Währungsausschusses vor. Dieser sollte im Fall von Zahlungsbilanzkrisen Beistand gewähren ${ }^{182}$. Der französische Vorschlag traf in der BdL auf strikte Ablehnung. Sie sah ein solches Gremium als eine Gefahr für die Unabhängigkeit der deutschen Zentralbank an: „Die Errichtung eines solchen Währungsausschusses kann die Unabhängigkeit der Bank deutscher Länder sehr gefährden. Es steht zu befürchten, daß dieser Währungsausschuß [.. . ] die übernational bedeutsamen währungspolitischen Entscheidungen in die Hand bekommt. “183 Darüber hinaus sorgte sie sich um die Stabilität der Währung, da sie befürchtete, daß die Gewährung von Beistandskrediten im Gläubigerland zu inflationären Tendenzen führen würde ${ }^{184}$.

Das aus diesen Bedenken sowohl gegen einen Währungsausschuß als auch gegen Zahlungsbilanzkredite resultierende Petitum der Bank war jedoch in den weiteren Verhandlungen nicht durchzusetzen. Wenngleich deutsche Regierungsvertreter dem französischen Vorschlag keineswegs zustimmten, akzeptierten sie, $\mathrm{da} ß$ die Schaffung eines besonderen Gremiums notwendig sei ${ }^{185}$. Da somit abzusehen war, daß ein aus Regierungsmitgliedern bestehender Ausschuß eingerichtet würde und dieser das Recht besitzen würde, Anträge auf Zahlungbilanzkredite zu prüfen, sie abzulehnen oder zu befürworten, verlegte sich die BdL im Verlauf der Gespräche darauf, Einstimmigkeit für die Entscheidungen dieses Ausschusses zu fordern ${ }^{186}$. Zusätzlich dazu befürwortete sie die Errichtung eines Beratungsgremiums, das aus Zentralbankvertretern bestehen sollte. Dieses Gremium sollte ein Gegengewicht zu den im Währungsausschuß versammelten Politikern sein: „Für uns und die Staatsangehörigen sämtlicher Mitgliedsstaaten wäre eine solche Regelung wahrscheinlich wesentlich besser als ein Zustand, unter dem die einzelnen Notenbanken - mehr oder weniger unter den Druck ihrer Regierungen gesetzt - die Empfehlungen eines mindestens teilweise aus Politikern bestehenden Währungsausschusses ausführen müßten, von denen angenommen werden kann, daß sie häufig nur Behelfslösungen darstellen, um eine auftau-

${ }_{182}$ Vgl. BBK, B 330/3327, Regierungskonferenz für den Gemeinsamen Markt und Euratom, Französisches Memorandum betreffs Einsetzung eines Währungsausschusses, 15.10.1956.

183 BBK, B 330/1876, von Schelling, Vermerk, 10.10.1956.

184 Vgl. BBK, B 330/6463, Emminger, Kritische Gedanken zum gemeinsamen Markt, 25. 2. 1957.

185 Vgl. BBK, B 330/3328, Ergebnisprotokoll über die Ressortbesprechung im Auswärtigen Amt, 13.10.1956.

${ }^{186}$ Schon im Februar 1956 hatte Emminger in der Sitzung des Zentralbankrates die Gefahr einer "Vergewaltigung" der deutschen Zentralbank beim Mehrheitsprinzip beschworen. Vgl. BBK, B 330/92, ZBR, Stenogramm, 22.2.1956. 
chende Zahlungsbilanzschwierigkeit in politisch möglichst einfacher Weise vorübergehend zu beseitigen. "187 Aber auch dieses Plädoyer der Bank konnte nur teilweise durchgesetzt werden. Zwar bestimmt der EWG-Vertrag, daß neben der Verpflichtung zu einer zahlungsbilanzkonformen Politik ein beratender Währungsausschuß, der sich aus Vertretern der Zentralbanken zusammensetzte, eingerichtet werden sollte. Die Kompetenzen dieses Ausschusses blieben aber eng umgrenzt. Nicht er, sondern der EWG-Ministerrat konnte auf Empfehlung der Kommission über Kreditbeihilfen entscheiden. Für die Gewährung eines Kredites war dabei nicht Einstimmigkeit, sondern nur eine qualifizierte Mehrheit notwendig ${ }^{188}$.

Bei der Zahlungsbilanzproblematik und den Kreditbeihilfen konnte die BdL also nur bewirken, daß die Verpflichtung zur zahlungsbilanzkonformen Politik im EWG-Vertrag festgeschrieben und dabei die Gesamtzahlungsbilanz zugrunde gelegt wurde. Hingegen mußte sie einen gegenseitigen Beistand in Form von Zahlungsbilanzkrediten und damit den ihrer Meinung nach „inflationistischen Charakter" des Gemeinsamen Marktes akzeptieren ${ }^{189}$. Entsprechend kritisch stellte Bernard in der Sitzung des Zentralbankrates am 19.Dezember 1956 zum EWG-Vertrag fest: „Ich glaube, die Währungsbestimmungen sind dem Wortlaut nach noch gerade so geregelt, daß wir keinen unmittelbaren Einbruch in die Kompetenzen der einzelnen Notenbanken zu befürchten brauchen." 190

Kapitalfragen - Europäischer Investitionsfonds

In der Resolution der Konferenz von Messina hatten die Außenminister festgehalten, daß die Verwirklichung eines Gemeinsamen Marktes gewisse Kapitalhilfen notwendig macht. Deshalb sollten die Experten auch die Schaffung eines europäischen Investitionsfonds diskutieren. Dabei kamen sie zu der Überzeugung, daß nicht nur ein Investitionsfonds, sondern auch der Abbau aller Kapitalverkehrsbeschränkungen das Funktionieren eines Gemeinsamen Marktes erleichtern würde ${ }^{191}$.

Der Liberalisierung des Kapitalverkehrs stand die BdL positiv gegenüber. Selbst wenn die Bank kritisch vermerkte, daß die deutsche Wirtschaftspolitik mit einer Festschreibung der Kapitalverkehrsliberalisierung ihre Gestaltungsmöglichkeiten in Kapitalmarktfragen verringerte, hatte sie keine prinzipiellen Bedenken gegen eine solche Bestimmung. Weder den daraus möglicherweise resultierenden Kapitalexport noch die aufgrund der Liberalisierung schwerer zu bän-

${ }^{187}$ BBK, B 330/1876, von Schelling, Vermerk, 10.10.1956. Vgl. BBK, B 330/1876, IV, Fühlungsnahme mit den Notenbank-Gouverneuren in der BIZ, 12.10.1956.

${ }^{188}$ Vgl. EWG-Vertrag Art. 104 ff., abgedruckt in: BGBL 1957 II, S. $766 \mathrm{ff}$.

${ }_{189}$ BBK, B 330/6463, Emminger, Kritische Gedanken zum Gemeinsamen Markt, 25.2.1957.

190 BBK, B 330/98, ZBR, Protokoll, 19.12.1956.

191 Vgl. Konferenz von Messina, Schlußresolution, 3.6.1955; Spaak-Bericht, 21.4.1956; beide abgedruckt in: Aufbau Europas, S.275f. und S.310ff. 
digenden Kapitalzuflüsse betrachtete sie mit Sorge. Die entsprechenden Paragraphen des EWG-Vertrages akzeptierte sie, ohne Einspruch zu erheben ${ }^{192}$.

Weitaus reservierter war die Bank bei der Frage eines europäischen Investitionsfonds. Hier schlug sie Einschränkungen vor. Die wichtigste war, daß ein solcher Fonds nach kommerziellen Prinzipien arbeiten sollte. Die Mittel sollten ähnlich wie bei der Weltbank - nicht von den Regierungen, sondern von den Kapitalmärkten aufgebracht werden, wobei für Anleiheemissionen auf dem Kapitalmarkt eines Mitgliedstaates eine Genehmigung des betreffendes Landes notwendig sein sollte ${ }^{193}$. Diese von der Bank vorgebrachten Einschränkungen wurden von den deutschen Ressorts gutgeheißen ${ }^{194}$. Sie konnten in den Verhandlungen zumindest teilweise durchgesetzt werden. Schon der Spaak-Bericht betonte, der Investitionsfonds solle als eine unabhängige Körperschaft eingerichtet werden und nach „bankmäßigen Grundsätzen“ arbeiten. Seine Mittel solle er vor allem auf den internationalen Kapitalmärkten aufnehmen ${ }^{195}$. Diese Empfehlungen des Spaak-Berichtes wurden in den Römischen Vertrag übernommen. Im Protokoll über die Satzung der Europäischen Investitionsbank hieß es, daß sie auf die internationalen Kapitalmärkte zurückgreifen und diese Gelder ,wirtschaftlich zweckmäßigst" verwenden soll. Zusätzlich dazu bestimmte die Satzung, daß den nationalen Behörden bei Anleiheemissionen in ihrem Land ein Einspruchsrecht zukam. Sofern "ernstliche Störungen“ des Kapitalmarktes drohten, konnte das betreffende Land seine Zustimmung versagen ${ }^{196}$.

\section{EWG, Freihandelszone und OEEC}

Im Jahre 1953/54 hatte sich die BdL vehement gegen eine engere Zusammenarbeit der sechs EGKS-Staaten ausgesprochen. Der Kreis der Sechs sei zu begrenzt, das Vereinigte Königreich und andere Länder würden dadurch ausgeschlossen. Vor allem aber könnte eine solche Zusammenarbeit die OEEC-Kooperation unterminieren ${ }^{197}$. Auch im Jahre 1955 war abzusehen, daß eine intensivere Kooperation der Sechs zu Lasten des OEEC-Zusammenhalts gehen würde. Um dem zu entgehen, hatten zwar die Außenminister der Sechs auf der Konferenz von Messina das Vereinigte Königreich explizit aufgefordert, sich an den Beratungen über einen Gemeinsamen Markt zu beteiligen. Doch wenn auch die Briten eine Delegation entsandten, waren die britische Skepsis und der britische Unwillen weithin bekannt. Mit dem Rückzug der britischen Delegation im November 1955 war es

\footnotetext{
192 Vgl. BBK, B 330/1876, Emminger, Liberalisierung des Kapitalverkehrs im Gemeinsamen Markt, 22.12.1956; BAK, B 201/22162, Treitschke, Kurzvermerk, 22.10.1955. Vgl. EWG-Vertrag Art. 67ff., abgedruckt in: BGBL 1957 II, S.766ff.

193 Vgl. BBK, B 330/3326, Emminger, Kurzbericht, 14.10.1955; BBK, B 330/1876, Emminger, Vermerk, 17.4.1956.

194 Für die Haltung der Ressorts vgl. Küsters, Gründung, S. $182 \mathrm{ff}$.

${ }^{195}$ Spaak-Bericht, abgedruckt in: Aufbau Europas, S. 287.

196 Vgl. Protokoll über die Satzung der Europäischen Investitionsbank, abgedruckt in: BGBL 1957 II, S. $964 \mathrm{ff}$.

197 Vgl. S. $168 \mathrm{f}$.
} 
dann sehr wahrscheinlich, daß sich ein Gemeinsamer Markt, sofern er denn stattfinden würde, vorerst auf die sechs EGKS-Länder beschränken würde.

In der Bundesrepublik wiesen vor allem Erhard, aber auch Wirtschafts- und Bankenvertreter unentwegt darauf hin, daß eine auf die sechs EGKS-Staaten beschränkte Wirtschaftskooperation für die deutsche Volkswirtschaft unsinnig sei $^{198}$. Das war auch ganz die Meinung der Zentralbank. Bei verschiedenen Gelegenheiten hob sie hervor, auf die sechs EGKS-Staaten würden nur 25 Prozent des deutschen Außenhandels entfallen ${ }^{199}$. Konsequenterweise bedauerte sie den Rückzug des Vereinigten Königreiches von den Verhandlungen, und in Ressortbesprechungen wandte sich Emminger gegen eine „Exklusivität“ der Sechs ${ }^{200}$. Andererseits aber war in der Sitzung des Zentralbankrates vom 22. Februar 1956, in der das Projekt eines Gemeinsamen Marktes detaillierter diskutiert wurde, die britische Nicht-Beteiligung kein Anlaß, sich den Bemühungen um einen Gemeinsamen Markt nunmehr offensiv entgegenzustellen. Ein Grund hierfür war, daß die Realisierung des Gemeinsamen Marktes als unwahrscheinlich eingeschätzt wurde ${ }^{201}$. Hinzu kam, daß sich die Bank nicht mehr so intensiv über die Auswirkungen eines Gemeinsamen Marktes auf den gesamteuropäischen Zusammenhalt wie in den Jahren zuvor sorgte. Die OEEC war ihr 1955/56 nicht mehr so wichtig wie noch 1953/54. Selbst wenn die BdL in der zweiten Hälfte der fünfziger Jahre in keiner Form auf die Auflösung der EZU drängte, sie sogar beibehalten wollte und auch gewisse Vorteile dieses Systems noch immer schätzte ${ }^{202}$, fehlen nunmehr die starken Plädoyers für die OEEC bzw. EZU, die 1953/54 stets an der Tagesordnung gewesen waren.

Auch im weiteren Verlauf zeichnete sich die Bank nicht durch striktes Eintreten für die OEEC aus. Als im Sommer 1956 das OEEC-Sekretariat auf eine britische Anregung hin den Plan einer Freihandelszone, die alle OEEC-Mitglieder umfassen würde, vorlegte, und der OEEC-Ministerrat beschloß, eine Studiengruppe einzurichten, fand dies innerhalb der BdL nur geringe Aufmerksamkeit. Während Erhard im Herbst 1956 angesichts neuer französischer Forderungen für den Gemeinsamen Markt nochmals versuchte, das Kabinett gegen dieses Projekt zu mobilisieren, und gleichzeitig den Plan einer OEEC-weiten Freihandelszone propagierte ${ }^{203}$, bemerkte der BdL-Sachverständige in Europafragen und Abgesandte zu den Verhandlungen Reinhold Werner nur, daß die Arbeiten der OEEC-Studiengruppe einer Zentralbank „etwas ferner" lägen $^{204}$. Zwar stand die Bank positiv zu einer OEEC-weiten Freihandelszone, und sie versäumte auch

${ }^{198}$ Für die Wirtschafts- und Bankenvertreter vgl. Rhenisch, Industrie, S. $186 \mathrm{ff}$.

199 Vgl. BBK, B 330/1876, Emminger, Diskussionsbeitrag, 30.11.1956.

200 Vgl. BAK, B 102/22 161, Müller-Roschach, Staatssekretärbesprechung, 3.1.1956.

201 Vgl. BBK, B 330/92, ZBR, Stenogramm, 22.2.1956; BBK, B 330/1876, Emminger, Vermerk, 17.4.1956.

${ }^{202}$ Vgl. S. $208 \mathrm{ff}$.

${ }^{203}$ Vgl. Koerfer, Kampf, S. $141 \mathrm{ff}$.

${ }^{204}$ BBK, B 330/1876, J 2, Werner, Vermerk, 29.10.1956. 
nie, darauf hinzuweisen, daß die Errichtung einer solchen Freihandelszone, selbst wenn sie ihre eigene Problematik habe, $\mathrm{zu}$ wünschen und $\mathrm{zu}$ fördern $\mathrm{sei}^{205}$. Gleichwohl unterstützte sie Erhard in seiner letzten großen Kampagne gegen die EWG nicht. Wenn ihr auch bewußt war, daß die von französischer Seite vorgebrachte Forderung nach Assoziation der Überseegebiete der EWG-Länder ein nahezu unüberwindliches Hindernis für eine spätere Freihandelszone mit den Briten sein würde, sprach sie sich im Herbst 1956 nicht offensiv gegen das Brüsseler Vertragswerk aus. So stimmte sie in gewisser Weise der Möglichkeit einer Spaltung Westeuropas in zwei Handelsböcke $\mathrm{zu}^{206}$. Nachdem sich nämlich Adenauer und der französische Ministerpräsident Guy Mollet im November 1956 auch über die Assoziation der Überseegebiete geeinigt hatten, konnte Emminger im Februar 1957 zwar betonen, daß man „unter allen Umständen“ den Gemeinsamen Markt in eine ganz Westeuropa umfassende Freihandelszone mit möglichst freiheitlicher Verfassung einbetten muß. Gleichzeitig aber mußte er feststellen, daß die rechtzeitige Verwirklichung einer europaweiten Freihandelszone angesichts der mit dem EWG-Vertrag geschaffenen Probleme - wie zum Beispiel der Assoziation der Überseegebiete - und aufgrund des Zeitdrucks „fast ausgeschlossen“" war $^{207}$.

\section{Rolle und Einfluß der Bank deutscher Länder auf dem Weg nach Rom}

Am 25. März 1957 wurde der Vertrag zur Errichtung einer Europäischen Wirtschaftsgemeinschaft in Rom unterzeichnet. Dieses Vertragswerk fand keineswegs das uneingeschränkte Wohlwollen der deutschen Zentralbank. Ende Februar 1957 hatte Emminger in einer grundsätzlichen Kritik festgestellt, es bestünde die Gefahr, daß sich aus der „kleinräumigen Gemeinschaft der Sechs ein nach außen protektionistischer, im Innern von Inflationskrisen heimgesuchter und von inneren Spannungen durchzogener Wirtschaftskörper" entwickeln wird. Auch befürchtete er eine Aufspaltung Westeuropas und vermutete, daß das in den nächsten vier bis sechs Jahren tatsächlich Erreichte wahrscheinlich „enttäuschend gering" sein werde ${ }^{208}$. Doch wenn auch seines Erachtens das Vertragswerk weder wirtschaftlich noch politisch positiv zu beurteilen war, so hatte es die deutsche Zentralbank während der Verhandlungen nicht vehement attackiert. Zu Beginn hatte sie sich zurückgehalten und auf ihre Einbindung in die Verhandlungen nicht insistiert, da sie sich nicht betroffen fühlte. Erst im Verlauf der Expertengespräche und später der Regierungsverhandlungen hatte sie sich dann zu einigen Punkten geäußert und konnte dabei auch ihren Ansichten z. B. bei der Festschreibung der Verpflichtung zu einer zahlungsbilanzkonformen Politik Geltung verschaffen.

\footnotetext{
${ }^{205}$ Vgl. Deutsche Bundesbank, Geschäftsbericht 1957, S.58f.; BBK, B 330/101, ZBR, Protokoll, 6.3.1957.

206 Vgl. BBK, B 330/1876, IV, Vermerk, 12.11.1956.

${ }^{207}$ BBK, B 330/6463, Emminger, Kritische Gedanken zum Gemeinsamen Markt, 25.2.1957.

${ }^{208}$ Ebenda.
} 
Damit war sie anscheinend vorerst zufriedengestellt, und sie intervenierte im weiteren Verlauf nicht. Selbst als im Sommer 1956 die Verhandlungen durch die Forderungen der französischen Regierung in eine Krise gerieten und Erhard nunmehr seine letzte große Kampagne gegen die EWG führte, erhob sie keinen grundsätzlichen Einspruch. Erst nachdem Adenauer und Mollet im November 1956 den entscheidenden Durchbruch bei den Verhandlungen erzielt hatten, meldete sie sich wieder zu Wort. Da aber inzwischen eine prinzipielle Opposition gegen den Gemeinsamen Markt ihres Erachtens „politischer Donquichotismus“ war, konnte sie nur noch zurückhaltende Kritik üben.

Insgesamt kann deshalb festgehalten werden, daß die deutsche Zentralbank bei den europäischen Integrationsprojekten nur eine eng umgrenzte Rolle spielte. Gleichwohl hat sie mit ihrem Verzicht auf Interventionen und grundsätzliche Kritik das Ihre zum Gelingen der EWG beigetragen. Wie gezeigt werden konnte, waren für diesen Verzicht verschiedene Gründe verantwortlich. Zum einen waren die Art und der Verlauf der Verhandlungen von Bedeutung. Aufgrund der anfänglichen Unverbindlichkeit und aufgrund der Unwahrscheinlichkeit, daß das Projekt eines Gemeinsamen Marktes realisiert werden würde, sah sich die Bank erst relativ spät veranlaßt, konkret zu intervenieren. Da aber zu diesem späten Zeitpunkt das Integrationsprojekt eine gewisse Eigendynamik entwickelt hatte, konnte sie dann nur noch bedingt eingreifen. Zum zweiten erkannte die Bank bei diesen Verhandlungen das Primat der Politik durchgängig an, und sie mischte sich in die Auseinandersetzung zwischen Adenauer und Erhard nicht ein. Zum dritten war sie der Idee eine Sechser-Gemeinschaft nicht von Anfang an und prinzipiell abgeneigt. Vielmehr nahm sie zu Beginn eine wohlwollende Haltung ein, und die Schaffung einer engeren europäischen Kooperation in Zoll- und Handelsfragen, die Gründung eines Gemeinsamen Marktes bzw. einer Zollunion und eine damit zwangsläufig verbundene gewisse Aufspaltung des OEEC-Europas wie die Bildung einer Präferenzzone innerhalb einer liberalen Weltwirtschaftsordnung trafen auf keine grundsätzliche Opposition der Bank. Erst als sich zeigte, daß der Gemeinsame Markt vermutlich protektionistischer sein würde, als sie anfänglich angenommen hatte, wandelte sich ihr Wohlwollen in Zurückhaltung.

\section{Der Übergang zum Konvertibilitäts- und EWG-Regime}

Die OEEC-Länder hatten im Jahre 1955 mit dem EWA Vorbereitungen für die Konvertibilität getroffen. Auch hatten sie sich mit der EZU-Härtung einem Konvertibilitätssystem angenähert. Gleichwohl hatten sie sich noch nicht verbindlich und unwiderruflich auf die Auflösung der EZU und die Konvertibilität als zukünftiges internationales Währungssystem geeinigt. Deshalb sind die Jahre 1955 bis 1958 als Probezeit des de-facto-konvertiblen EZU-Systems zu verstehen, in der Standards gesetzt wurden und wesentliche Entscheidungen getroffen werden mußten. Aber auch in einer zweiten Hinsicht standen in der zweiten Hälfte der 
fünfziger Jahre Weichenstellungen auf der Tagesordnung, denn seit 1955 diskutierten die sechs EGKS-Staaten neue Formen der europäischen Zusammenarbeit. Wenngleich handelspolitische Probleme den Anstoß für dieses Projekt gegeben hatten und auch in den Verhandlungen im Vordergrund standen, war offensichtlich, daß sich mit der Errichtung eines Gemeinsamen Marktes die Formen der europäischen Zusammenarbeit, die europäische Kooperation in der OEEC und die Weltwirtschaftsordnung nachhaltig verändern würden. Zwischen der Europäischen Integration zu Sechst, der Konvertibilität und der OEEC-EZU-Kooperation bestanden zahlreiche Beziehungen, Zusammenhänge und Wechselwirkungen.

In der Probezeit des de-facto-konvertiblen EZU-Systems offenbarten sich die Vor- und Nachteile der de-facto-Konvertibilität und der gehärteten EZU. Vor allem zeigte sich, daß in einem solchen Währungssystem die außen- und die binnenwirtschaftliche Stabilität schwer zu vereinbaren waren. Wenn diese Schwierigkeit auch dazu angetan war, die Konzepte sowohl der de-facto-Konvertibilität als auch der EZU in Frage zu stellen, zog die deutsche Zentralbank diese Konsequenz nicht. Vielmehr beschränkte sie sich auf ad-hoc-Maßnahmen und versuchte damit die Spannungen zu lindern. Durchgreifende Veränderungen des Währungssystems wies sie zurück. Trotz der existierenden Friktionen und Schwierigkeiten nahm sie weder von der Konvertibilität Abstand, noch drängte sie zur EZU-Auflösung. Bei verschiedenen Gelegenheiten setzte sie sich sogar explizit für die Fortführung der europäischen Zusammenarbeit im Rahmen der EZU ein. Wenn sie auch häufig öffentlich für die Konvertibilität plädierte, so lehnte sie doch in den entscheidenden Situationen ein Währungsregime, das auf Konvertibilität und dem EWA beruhte, ab.

Doch wenn die deutsche Zentralbank sich auch nicht gegen die Fortführung der OEEC-EZU-Kooperation aussprach, so zeigte sich, daß sie der OEEC bzw. EZU nicht mehr die Bedeutung beimaß wie in der ersten Hälfte der fünfziger Jahre. Nicht nur, daß sie eine Politik betrieb, die mit erheblichen Belastungen für die EZU verbunden war. Auch nahm sie, wie sich bei den Verhandlungen der sechs EGKS-Staaten über einen Gemeinsamen Markt zeigte, nur wenig Anstoß daran, daß die europäische Kooperation im Rahmen der OEEC durch die Errichtung eines Gemeinsamen Marktes wahrscheinlich unterminiert werden würde. Während Erhard nunmehr, nach jahrelanger, heftiger Kritik an der OEEC, die Vorzüge dieser europaweiten Zusammenarbeit schätzte, und obgleich es eine formidable Opposition zur EWG gab, hielt sich die deutsche Zentralbank mit Kritik zurück. Zwar betrachtete sie, vor allem bei fortgeschrittenen Verhandlungen, einige Aspekte des Gemeinsamen Marktes mit großer Skepsis. Dennoch beschränkte sie sich bei den Verhandlungen darauf, nur für eine zahlungsbilanzkonforme Politik, geringe Kredithilfen und die Unabhängigkeit der Währungspolitik einzutreten. Eine prinzipielle Kritik äußerte sie in den Verhandlungen nicht. Für diese Haltung gaben taktische Überlegungen, politische Rücksichten, das Primat der Politik und auch die Tatsache, daß ein engerer wirtschaftlicher Zusammenschluß ihres Erachtens sinnvoll war, den Ausschlag. 
Insgesamt ist also festzuhalten, daß sich die deutsche Zentralbank zwar einerseits in den Jahren 1955 bis 1957 zu Fragen der europäischen und internationalen Wirtschafts- und Währungskooperation geäußert hatte. Andererseits aber war sie weitgehend passiv geblieben und hatte noch nicht abschließend und endgültig zur Frage des zukünftigen internationalen Währungssystems Stellung bezogen. Das war möglich, da in dieser Zeit keine Initiativen unternommen wurden, das existierende Währungssystem auf neue Grundlagen zu stellen. Das änderte sich aber im Jahre 1958. Mit der Verbesserung seiner Zahlungsbilanzposition wandte sich das Vereinigte Königreich wieder dem Projekt der Konvertibilitätserklärung zu. Nun mußte die deutsche Zentralbank Farbe bekennen. Dabei ging es keineswegs nur um die Existenz der EZU. Das Problem war komplizierter und vielschichtiger. Eine Auflösung der EZU bedeutete nicht nur die Konvertibilität, die Beendigung der währungspolitischen Diskriminierung zum Dollarraum und den Übergang zum Bretton-Woods-System. Sie implizierte auch einen weiteren Bedeutungsschwund der OEEC. Darüber hinaus war abzusehen, daß sie die Verhandlungen über eine OEEC-weite Freihandelszone beeinflussen würde. Schließlich würde sie unter Umständen den Zusammenhalt der sechs EWG-Länder in Frage stellen, denn Frankreich hatte mit wirtschaftlichen Schwierigkeiten zu kämpfen, und es war nicht ausgemacht, daß es die Konvertibilität für den französischen Franken erklären würde. Möglicherweise würde deshalb nach der EZUAuflösung ein gemeinsames Währungssystem für die sechs EWG-Länder nicht mehr existieren. Zusätzlich dazu würde sich eine Konvertibilitätsinitiative auf die für den 1.Januar 1959 vorgesehene erste EWG-Binnenzollsenkung auswirken. Frankreich hatte schon angedeutet, daß es unter Umständen am 1.Januar 1959 die Ausnahmeregelungen des EWG-Vertrages in Anspruch nehmen werde. Vor dem Hintergrund einer Konvertibilitätserklärung war eine solche Politik noch wahrscheinlicher, sei es, daß die Konvertibilität Frankreich zu sehr belasten würde, sei es, daß ein Zusammenhalt der sechs EWG-Länder durch die Konvertibilität erschüttert würde. Aus diesen Gründen kam im Jahre 1958 die Haltung zu der britischen Konvertibilitätsinitiative einer Stellungnahme zur Ordnung und Organisation Europas gleich. Wie verhielt sich die Bundesbank Ende 1958 in den entsprechenden Verhandlungen zu diesem Fragenkomplex?

Da die britischen Währungsreserven seit Ende 1957 kontinuierlich angestiegen waren, wandte sich das Vereinigte Königreich Anfang 1958 wieder der Frage der Konvertibilität $\mathrm{zu}^{209}$. Vor allem die Bank von England setzte sich für eine baldige Konvertibilitätserklärung ein. Wenn auch das britische Schatzamt den Zeitpunkt vorerst noch nicht für gekommen hielt, wurden nun entsprechende Vorbereitungen eingeleitet ${ }^{210}$. Im Forum des IWF sprach der britische Vertreter das Problem

${ }^{209}$ Die britischen Währungsreserven (Gold und konvertible Währungen) waren von 2273 Mio \$ (Dezember 1957) auf 3076 Mio. \$ (Juni 1958) angewachsen. Vgl. International Financial Statistics XIII, Mai 1960, S.254.

210 Vgl. BoE, OV 44/21, Cobbold an Makins, 4.2.1958; Parsons, Note on a meeting with Rowan, 7.2.1958. Vgl. hierzu auch die Schilderung von Fforde, Bank of England, S. $585 \mathrm{ff}$. 
der internationalen Liquidität an und plädierte für eine Erhöhung der IWF-Quoten. In der Bundesbank traf das auf offene Ohren ${ }^{211}$. Auch die USA unterstützten eine Ausweitung der internationalen Liquidität, ja sie übernahmen es sogar, eine Erhöhung der IWF-Quoten vorzuschlagen ${ }^{212}$. Im August 1958, nach einem erneuten Plädoyer der Bank von England für die Konvertibilität, konnte auch der bisher zurückhaltende britische Schatzkanzler Derick Heathcoat Amory gewonnen werden. Er bat den Premierminister um eine Grundsatzentscheidung ${ }^{213}$, und nachdem dieser einer Konvertibilitätsinitiative zugestimmt hatte, forcierte das Vereinigte Königreich die internen Vorbereitungen für die Operation "Unicorn“. Gleichzeitig sprach es das Thema der Konvertibilität vorsichtig auf der IWF-Jahrestagung in Neu-Delhi an. Soweit die deutsche Seite, vertreten durch Erhard und Blessing, betroffen war, erhielten die Briten eine positive Antwort. Es wurde bestätigt, daß die Bundesrepublik beabsichtige, einer britischen Initiative ohne Zögern zu folgen: „He (Blessing, M.D.) confirmed, in reply to my enquiry, that inspite of the setting up of the EEC, Germany still had every intention of following suit immediately, if we took the plunge. "214

Ob sich die Briten jedoch auf diese deutsche Zusage verlassen konnten, war eine andere Frage. Es war zu bedenken, daß sich Frankreich im Übergang zwischen der IV. und V. Republik befand. Wenngleich der französische Ministerpräsident Charles de Gaulle im September 1958 ein Komitee unter der Leitung Jacques Rueffs mit der Ausarbeitung eines wirtschaftspolitischen Reformprogramms betraut hatte, so waren die wirtschaftlichen Probleme Frankreichs noch keineswegs gelöst ${ }^{215}$. Obendrein gab es einige Stimmen, die in einer britischen Konvertibilitätsinitiative zu diesem Zeitpunkt ein Druckmittel oder gar eine Vergeltungsmaßnahme für die intransigente französische Haltung bei den Verhandlungen über eine Freihandelszone sahen. Deshalb war es fraglich, ob sich Frankreich an einer britischen Konvertibilitätsinitiative beteiligen würde, bzw. ob die anderen EWG-Länder einer Konvertibilität ohne Frankreich und damit der Aufgabe eines gemeinsamen Währungssystems zustimmen würden. Entsprechend hatten die Briten einige Zweifel: „They (the Six, M.D.) are all determined to maintain the monolithic structure of the Six. French domination is such that, however anxious other governments might be to make a move to convertibility and EMA, they would not move without the French. " ${ }^{216}$

Tatsächlich hatte sich in Deutschland noch keine abschließende Meinung zu der bisher noch vagen und nur in Umrissen bekannten britischen Initiative gebildet.

${ }^{211}$ Vgl. PRO, T 236/4579, Thorold an Rowan, Talk with Emminger, 2.7.1958.

212 Vgl. Horsefield u. a., International Monetary Fund, Bd. I, S.446ff. Vgl. Fforde, Bank of England, S. $573 \mathrm{ff}$.

213 Vgl. PRO, PREM 11/2671, o.V., Note on a discussion at Chequers, 30.8.1958.

${ }^{214}$ BoE, OV 44/21, Parsons an Cobbold, 6.10.1958. Für Erhard vgl. PRO, T 236/4818, HMT, Note of talk between Chancellor of the Exchequer and Dr. Erhardt (sic!), 7.10.1958.

215 Zur französischen Wirtschaftsentwicklung vgl. Pitman, Crisis; Bonin, IVième république, S. $341 \mathrm{ff}$.

${ }^{216}$ BoE, OV 46/68, Payton, Note, 30.10.1958. 
Zwar sah man die Konvertibilität weiterhin als erstrebenswert $\mathrm{an}^{217}$. Gleichzeitig aber strebte man die Einrichtung der Freihandelszone sowie die planmäßige Durchführung der ersten EWG-Binnenzollsenkung an. Deshalb gab es einige Stimmen, die angesichts der Krise bei den Freihandelszonenverhandlungen ${ }^{218}$ offen dafür plädierten, Europa solle jetzt nicht zur Konvertibilität übergehen. So stellte beispielsweise die deutsche OEEC-Delegation heraus, daß die Bundesrepublik an einer Konvertibilitätsinitiative nur teilnehmen solle, sofern auch Frankreich ihr zustimmen würde. Im Falle des Falles müßte die Bundesrepublik zu Frankreich stehen $^{219}$. Eine ähnlich zurückhaltende Meinung vertrat auch Adenauer. Anfänglich skeptisch in bezug auf de Gaulle, nach einem ersten und zweiten persönlichen Treffen mit dem französischen Ministerpräsidenten jedoch in gutem Einvernehmen, meinte er noch Anfang Dezember 1958 verständnisvoll, daß de Gaulle „ja jetzt den Kopf voll hat in den nächsten Wochen mit anderen Dingen". Deshalb solle man Frankreich in dieser schwierigen Situation nicht zur Konvertibilität drängen $^{220}$. Auch innerhalb der Bundesbank war eine endgültige Meinung zu den Fragen Konvertibilität und Freihandelszone noch nicht formuliert, zumal die britischen Pläne vorerst nur in Umrissen bekannt waren. Zwar sah die Bundesbank die Konvertibilität auch weiterhin als positiv an, führte nun wieder Untersuchungen über die Liquidation der EZU durch und stellte bei Treffen mit Zentralbankkollegen heraus, Deutschland würde einer britischen Initiative ohne Zögern folgen ${ }^{221}$. Gleichzeitig aber hielten ihre Vertreter in Ressortbesprechungen über die Freihandelszone fest, daß die EZU das geeignete Zahlungssystem für Europa wäre ${ }^{222}$.

Doch wenn die deutsche Meinung auch noch nicht endgültig formuliert war, so wuchs im Herbst 1958 in den anderen Ländern die Erwartung, daß Deutschland seinen Einfluß auf Frankreich zur Geltung bringen müßte, sei es um Frankreich für die Freihandelszone zu gewinnen, sei es um Frankreich zur Übernahme seiner EWG- und OEEC-Verpflichtungen zu drängen, oder sei es um einen gemeinsamen Konvertibilitätsschritt zu ermöglichen. Auch in Deutschland selbst fand die Idee einer besonderen deutschen Initiative großen Anklang. Schon im August hatte Adenauer in einem Gespräch mit dem französischen Finanzminister Antoine Pinay die problematische wirtschaftliche Situation Frankreichs angesprochen. Angeblich schlug Adenauer in diesem Zusammenhang deutsche

${ }^{217}$ Nur ein Beispiel: BAK, B 126/7744, Sprechzettel für Gespräch mit Herrn Dr. Birrenbach (MdB), 16.10.1958.

${ }^{218}$ Im Herbst 1958 spitzte sich die Krise bei den unter erheblichem Zeitdruck geführten Verhandlungen über eine OEEC-weite Freihandelszone zu, da sich Frankreich nunmehr gegen die Zollautonomie der Länder außerhalb der Sechs aussprach. Vgl. hierzu Dokumentation der Europäischen Integration, S. 162 ff.; Groeben, Aufbaujahre, S. 61 ff.; Camps, Britain, S.130ff.; Griffiths, British Policy.

219 Vgl. BoE, OV 44/22, Watson, Note, 3.11.1958; Payton, Unicorn, 13.11.1958.

220 Adenauer, Teegespräche, 1.12.1958. Zum Verhältnis Adenauer - de Gaulle vgl. Schwarz, Adenauer, S. $439 \mathrm{ff}$.; Köhler, Adenauer, S. $999 \mathrm{ff}$.

${ }^{221}$ Vgl. BBK, B 330/1626, J2, Prozedur für die Liquidation der EZU, 6.11.1958; PRO, T 236/4820, Cobbold, Note, 11.11.1958.

${ }^{222}$ Vgl. BBK, B 330/1828, J21, Vermerk, 18.10.1958. 
Kredithilfe im Austausch gegen eine gemeinsame Konvertibilitätserklärung und einen geordneten Übergang zur EWG vor ${ }^{223}$. Auch der Bundeswirtschaftsminister, im allgemeinen stets skeptisch gegenüber Frankreich, befürwortete im Herbst eine besondere deutsche Initiative, und er stellte richtig, daß er Kredite an die Regierung de Gaulle keineswegs grundsätzlich ablehne ${ }^{224}$. Selbst die Bundesbank, die sich noch im Sommer 1958 im Währungsausschuß der EWG gegen weitere Kredite an Frankreich ausgesprochen hatte, wurde im Herbst entgegenkommender ${ }^{225}$. Zwar wies Blessing den Vorschlag des Präsidenten der EWGKommission Walter Hallstein, einen EWG-Hilfsfonds einzurichten, zurück und wies zum wiederholten Male darauf hin, daß ein gemeinsames Währungssystem der Sechs am besten und einfachsten durch die Konvertibilität gewährleistet werden würde. Gleichzeitig aber verschloß er sich „keineswegs der Einsicht [...], daß in außergewöhnlichen Situationen unseren EWG-Partnern vielleicht einmal kurzfristige Hilfskredite zur Überbrückung temporärer Anspannungen gewährt werden müssen, ebenso wie ich mich keineswegs der besonderen Verantwortung der Bundesrepublik bei derartigen Hilfsoperationen verschließe"226.

Doch wenn auch eine besondere Initiative in Deutschland weite Zustimmung fand, hatte das Vereinigte Königreich vor allem in der zweiten Novemberhälfte Bedenken, ob es sich auf den seines Erachtens notwendigen deutschen Druck auf Frankreich verlassen könne. Vor dem Hintergrund der Berlin-Krise hatte nämlich Adenauer am 26. November 1958 beim Gespräch mit de Gaulle dem kurz zuvor erfolgten französischen Einspruch gegen die Fortführung der Freihandelszonenverhandlungen de facto zugestimmt ${ }^{227}$. Auch bei anderen Gelegenheiten zeigte sich immer wieder, daß Frankreich letztendlich auf die deutsche Unterstützung rechnen konnte ${ }^{228}$. Demnach befürchtete das Vereinigte Königreich, auch in der Konvertibilitätsfrage nicht auf die deutsche Hilfe zählen zu können ${ }^{229}$. Ende November überwog deshalb in London das Zögern, und die

${ }^{223}$ Das berichten britische Quellen unter Bezugnahme auf französische Presseberichte. Vgl. BoE, OV 46/48, Payton, Unicorn, 30.10.1958. Vgl. auch BoE, OV 44/22, Payton, Unicorn, 13.11.1958. In seinen Erinnerungen erwähnt Adenauer diesen Aspekt nicht. Vgl. Adenauer, Erinnerungen, S. $421 \mathrm{ff}$.

${ }^{224}$ Vgl. LESt, I 1)6, Erhard an Adenauer, 11.9.1958; Erhard an Adenauer, 26.9.1958.

${ }^{225}$ Vgl. BBK, B 330/1285, Emminger, Behandlung Frankreichs in der EWG, 2. 6.1958.

${ }^{226}$ BBK, B 330/6463, Blessing an Hallstein, 11.11.1958; Hallstein an Blessing, 28.10.1958; Hallstein an Blessing 28.11.1958.

${ }^{227}$ Am 14.11.1958 hatte der französische Informationsminister Jacques Soustelle in einem Interview betont, daß es Frankreich unmöglich sei, den britischen Wünschen in bezug auf die Freihandelszone nachzukommen. Vgl. Dokumentation der Europäischen Integration, S. 215. Zu dem Gespräch in Bad Kreuznach und zur Berlin-Krise vgl. Schwarz, Adenauer, S. $464 \mathrm{ff}$.

${ }^{228}$ Um die von den EWG-Maßnahmen ausgehende Diskriminierung zu verringern, boten die sechs EWG-Staaten allen GATT-Mitgliedern eine 10\%ige Zollsenkung an. Allerdings lehnte Frankreich die Ausdehnung der ebenfalls vorgesehenen Erhöhung der Liberalisierungskontingente auf andere Länder ab. Darin wurde es von Deutschland unterstützt. Vgl. Pitman, Programme, S.463.

229 In seinen Zweifeln wurde das Vereinigte Königreich beispielsweise durch die deutsche Botschaft in London bestärkt. Sie hob hervor, daß die Bundesregierung noch nicht entschieden sei. Vgl. PRO, T 236/4820, Rickett, Convertibility and the Free Trade Area, 20.11.1958. 
für den 8. Dezember schon fest geplante Konvertibilitätserklärung wurde aufgeschoben. Dieses Zaudern blieb aber nur eine Episode. Zum einen vermutete das Vereinigte Königreich, daß die Schweiz zum Jahresende aus der EZU ausscheiden würde. Die EZU würde also auf jeden Fall in Frage gestellt werden ${ }^{230}$. Zum zweiten war zu befürchten, daß angesichts der Gerüchte über eine Konvertibilitätserklärung die Marktkräfte den britischen Handlungsspielraum einengen würden $^{231}$. Noch wichtiger aber war, daß der Bundesbankvertreter bei dem Dezember-Treffen der Zentralbankpräsidenten in Basel erneut versicherte, Deutschland wäre selbstverständlich an der Konvertibilität interessiert und es würde ohne Zögern einer britischen Konvertibilitätserklärung folgen ${ }^{232}$. Hinzu kam, daß man im Vereinigten Königreich damit rechnete, Frankreich könnte die Initiative an sich reißen und die Konvertibilität von sich aus erklären ${ }^{233}$.

So blieb also die Konvertibilitätserklärung auf der Tagesordnung, und nachdem am 10. Dezember der Gouverneur der Banque de France Wilfried Baumgartner ein grundsätzliches Einverständnis Frankreichs mit einer britischen Initiative zum Jahresende signalisiert hatte ${ }^{234}$, wurde dieses Thema anläßlich der OEECMinisterratstagung, der Ministertagung der NATO und der WEU-Versammlung in Paris weiter besprochen. Dabei wurden nun auch die schon vorher ventilierten deutschen Hilfestellungen konkretisiert. Seitens der deutschen Regierung bot Erhard de Gaulle einen Kredit von 300 Mio. Dollar für den Fall einer Konvertibilitätserklärung an ${ }^{235}$. Dies traf auf ein reges Interesse seitens Frankreichs. Die Banque de France hatte sogar schon eine diesbezügliche Initiative ergriffen und informell bei der Bundesbank wegen eines langfristigen Kredites vorgefühlt. Dabei hatte die Bundesbank durchblicken lassen, daß sie zu einer solchen Hilfestellung durchaus bereit war, und sie erwartete nun einen offiziellen Antrag auf einen langfristigen, vermutlich zweijährigen Kredit in Höhe von 150 Mio. Dollar ${ }^{236}$. Vor dem Hintergrund dieser Kreditmöglichkeiten erklärte Pinay am 17. Dezember das endgültige Einverständnis Frankreichs mit einer Konvertibilitätserklärung, und die Zentralbanken wurden beauftragt, die technischen Details auszuarbeiten ${ }^{237}$. Als Ergebnis wurde am 27. Dezember 1958 nach der Abwertung des französischen Franken um 14,93 Prozent die EZU aufgelöst, das EWA in Kraft gesetzt und die Konvertibilität für acht europäische Währungen erklärt.

${ }^{230}$ Die Schweiz hatte sich bei der EZU-Verlängerung im Sommer 1958 die Möglichkeit eines Ausscheidens zum Jahresende vorbehalten. Vgl. PRO, T 236/4819, France, Unicorn: Free Trade Area, 30.10.1958.

${ }^{231} \mathrm{Vgl}$. BoE, OV 44/23, Stevens, Basle Meeting, 6./8.12.1958.

${ }^{232}$ Vgl. ebenda.

${ }^{233}$ Nachdem am 8.12.1958 in Paris der Bericht des Rueff-Komitees, der strikte Sanierungs- und durchgreifende Reformmaßnahmen vorsah, diskutiert worden war, hatte Wilfried Baumgartner, Gouverneur der Banque de France, angedeutet, daß de Gaulle demnächst wichtige Entscheidungen fällen würde. Vgl. Pitman, Programme, S. $460 \mathrm{f}$.

${ }^{234} \mathrm{Vgl}$. Fforde, Bank of England, S. 598.

${ }^{235}$ Vgl. PRO, T 236/4821, Record of a Conversation, 14.12.1958.

${ }^{236} \mathrm{Vgl}$. BBK, B 330/1626, Tüngeler an die Mitglieder des Zentralbankrates, 27.12.1958.

${ }^{237}$ Vgl. PRO, T 236/4822, Record of Conversation, 17.12.1958. 
Dem spektakulären Kreditangebot Erhards haben vor allem die Briten eine große Bedeutung für die französische Zustimmung zur Konvertibilität beigemes$\operatorname{sen}^{238}$. Das trifft jedoch nur zum Teil den Kern, denn Frankreich hatte sich schon vor dem 15. Dezember 1958 der Option Konvertibilität angenähert und griff letztlich auch nicht auf die Offerte Erhards zurück ${ }^{239}$. Wenngleich diese Feststellung die Bedeutung dieses Kreditangebotes nicht zwingend schmälert, verdeutlicht sie, daß im Dezember 1958 noch andere Faktoren wichtig gewesen sein müssen. Neben der Gewißheit, im Falle eines Falles auf umfassende und langfristige deutsche Unterstützung zurückgreifen zu können, war vermutlich auch die Bereitstellung kurzfristiger ad-hoc-Hilfen sowie die langfristige Konsolidierung der aufgelaufenen EZU-Schulden Frankreichs wichtig. Bei den umfassenden französischen Reformmaßnahmen, der Abwertung, der Konvertibilitätserklärung und der EZU-Liquidation war es notwendig, diese Schritte durch ad-hocHilfen abzusichern und nicht auf eine schnelle Rückzahlung der EZU-Schulden verpflichtet zu werden. Hier waren die Notenbankkooperation und ein Entgegenkommen der Bundesbank entscheidend. Tatsächlich war Mitte Dezember schon abzusehen, daß die Bundesbank in Zusammenarbeit mit anderen Zentralbanken der Banque de France die notwendigen kurzfristigen Swap-Fazilitäten einräumen würde. Sie stellten problemlos, auf eine einfache telegraphische Anfrage hin, der Banque de France dreimonatige Kreditlinien in Höhe von insgesamt 250 Mio. Dollar zur Verfügung ${ }^{20}$. Ferner hatte die Bundesbank schon Ende November 1958 die Meinung vertreten, daß die Gläubigerländer den Schuldnerländern im Falle der EZU-Liquidation bei der Konsolidierung ihrer EZU-Schulden entgegenkommen sollten. Im Falle einer Konvertibilitätserklärung sollten diese schwächeren Länder nicht über Gebühr belastet werden. Deshalb wollte die Bank nicht auf einer Rückzahlung der aufgelaufenen EZU-Kredite innerhalb von drei Jahren, wie es der Normalfall vorsah, bestehen. Statt dessen erklärte sie sich im französischen Fall zu einen Rückzahlungszeitraum von acht Jahren bereit, wobei sie sogar für die Zeit vom Januar 1960 bis Juni 1961 wegen des dann $\mathrm{zu}$ tilgenden französischen Sonderkredites eine tilgungsfreie Zeit in Aussicht nehmen wollte ${ }^{241}$. Wenngleich es die Quellenlage nicht erlaubt, die Determinanten des französischen Entscheidungsprozesses eindeutig auszumachen, muß also festgehalten werden, daß die Bundesbank im Winter 1958 in einer Position war, in der sie die französische Entscheidung zur Konvertibilität maßgeblich erschweren oder erleichtern konnte. Immerhin hatte Frankreich im Verlauf der Jahre ne-

${ }^{238}$ Vgl. PRO, T 237/198, Hubback, German Support for France, 29.12.1958.

239 Auch suchte Frankreich nicht um einen langfristigen Bundesbankkredit nach. Vgl. BBK, B 330/ 1626, Tüngeler an die Mitglieder des Zentralbankrates, 27.12.1958.

240 Der Anteil der Bundesbank belief sich dabei auf $250 \mathrm{Mio}$. DM. Die von den anderen Zentralbanken eingeräumten Swap-Fazilitäten betrugen: 80 Mio. \$(BIZ), 25 Mio. $£$ (Bank of England), 100 Mio. hfl. (Nederlandsche Bank) und 20 Mio. \$ (Banque Nationale de Belgique). Vgl. BBK, B 330/1626, Tüngeler an die Mitglieder des Zentralbankrates, 27.12.1958.

${ }^{241} \mathrm{Vgl}$. BBK, B 330/1626, Emminger/Schleiminger, Auswirkungen einer EZU-Liquidation, 29.11.1958. 
ben dem Sonderkredit in Höhe von 150 Mio. Dollar eine EZU-Schuld in Höhe von 485 Mio. Dollar akkumuliert. Auf die Bundesbank entfielen von diesem Betrag 264,6 Mio. Dollar, von denen der Betrag von 144,9 Mio. DM noch nicht konsolidiert $\mathrm{war}^{242}$. So hatte neben dem spektakulären Angebot Erhards vor allem der unspektakuläre Beitrag der Bundesbank die EZU-Liquidation und die Konvertibilitätserklärung ermöglicht.

Da die Bundesbank auch im Winter 1958 keine Konvertibilitätsinitiative unter-

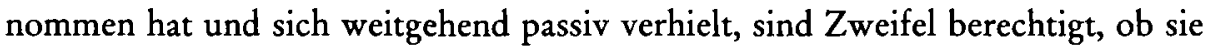
letztendlich auch einer Konvertibilität ohne Frankreich zugestimmt hätte. Andererseits aber wird deutlich, daß sie zu diesem Schritt in erheblichem Umfang beigetragen hat, denn sie hat die britische Initiative durch stetes Bekunden ihres Interesses und durch ihre Zusicherung, einer britischen Initiative unmittelbar zu folgen, gestärkt. Ferner hat sie die britisch-französische Konvertibilitätsbereitschaft durch ihren materiellen Beitrag abgesichert, und damit die Beendigung der Probezeit des de-facto-konvertiblen EZU-Systems zugunsten einer globalen Lösung befördert.

${ }^{242}$ Die französische EZU-Schuld an die Bundesbank setzte sich zusammen aus 161,6 Mio. \$ regulären EZU-Schulden, 82,3 Mio. \$aus dem deutschen Anteil am Sonderkredit und 20,7 Mio. \$aus den bei EZU-Auflösung zu verteilenden EZU-Vermögenswerten. Die Schulden aus dem Sonderkredit waren konsolidiert. Ebenfalls konsolidiert waren von den regulär aufgelaufenen Schulden 16,7 Mio. \$, so daß noch 144,9 Mio. \$ zu konsolidieren waren. Vgl. BBK, B 330/1626, Emminger/ Schleiminger, Auswirkungen einer EZU-Liquidation, 29.11.1958. 
